\title{
SEED FOR CHANGE
}

the making and implementation

of seed policies in Ethiopia 



\section{SEED FOR CHANGE}

the making and implementation of seed policies in Ethiopia

Mohammed Hassena Beko 


\section{Thesis committee}

\section{Promotor}

Prof. B.M.J. van der Meulen

Professor of Law and Governance

Wageningen University \& Research

\section{Co-promotors}

Dr B. de Jonge

Researcher, Law and Governance Group

Wageningen University \& Research

Dr O. Hospes

Associate professor, Public Administration and Policy Group

Wageningen University \& Research

Dr N.P. Louwaars

Director Plantum, Gouda / external member Law and Governance Group, Wageningen University \& Research

\section{Other members}

Prof. Dr C. Leeuwis, Wageningen University \& Research

Prof. Kssahun Berhanu, Addis Ababa University, Ethiopia

Prof. Dr G.T.P. Ruivenkamp, Wageningen University \& Research

Dr Shawn McGuire, School of International Development, UK

This research was conducted under the auspices of Wageningen School of Social Science (WASS) 


\title{
SEED FOR CHANGE
}

\section{the making and implementation of seed policies in Ethiopia}

\author{
Mohammed Hassena Beko
}

\section{Thesis}

submitted in fulfilment of the requirements for the degree of doctor at Wageningen University

by the authority of the Rector Magnificus,

Prof. Dr A.P.J. Mol,

in the presence of the

Thesis Committee appointed by the Academic Board to be defended in public

on Wednesday 13 September 2017 at 1:30 p.m. in the Aula. 
Mohammed Hassena Beko

Seed for change: the making and implementation of seed policies in Ethiopia 151 pages

PhD thesis, Wageningen University, Wageningen, the Netherlands (2017)

With references, with summary in English

ISBN ISBN: 978-94-6343-668-7

DOI: https://doi.org/10.18174/421204 
To my late father Hassena Beko (1907 - 2008) 


\section{Acknowledgements}

This $\mathrm{PhD}$ process has been possible with the support of many individuals and organizations. I would like to express my sincere thanks to all of them. In this text if by chance I fail to mention them in one way or another, it was not intentional and they always deserve my sincere appreciation. I am grateful to the Director General for International Cooperation of the Netherlands, through the Embassy of the Kingdom of the Netherlands in Addis Ababa, for funding the Integrated Seed Sector Development (ISSD) Ethiopia programme of which this $\mathrm{PhD}$ research is part.

I thank my promotor, Prof. B.M.J. van der Meulen for giving me the chance to pursue my PhD study with the Law and Governance group of Wageningen University. That opened the door for me to success. I would like to express my deepest thanks to my co-promoters, Bram De Jonge and Otto Hospes, with whom I have worked most and received guidance towards success. Without your guidance, this thesis would not have been realized. I gained a lot from your different styles of supervision and guidance. Bram, I appreciate your straight forward comments and criticism, which always helped me to be alert. Otto, unlike Bram, your style is indirect, forcing me to look at the data through different lenses. There are always other ways of looking at data. The combination of these styles helped me to shape the analysis of the data. I would like also to thank my co-promotor, Niles Louwaars for his input in the research process based on his experience in the Ethiopian seed sector.

I would like to thank the thesis examining committee members, Prof. dr.ir. C. Leeuwis, Prof. Kassahun Berhanu, Prof. dr. G.T.P Ruivenkamp and Dr. Shawn McGuire for their interest and willingness to review this thesis and contribute to the public defence. I appreciate your valuable contributions and I am honoured to have you as my thesis examiners.

In Wageningen, I was part of both the Law and Governance group and the Public Administration and Policy group. It was great to work with these groups and I greatly value the time that I spent with them. Our coffee breaks in the corridor were an important social event, where people from diverse backgrounds could exchange their experiences.

My thanks to the ISSD family, both in Wageningen and Ethiopia. I appreciate the support of all the members of the team at Centre of Development Innovation (CDI)ISSD as they were always at my disposal when I needed help. Whenever I visit the 
CDI office, I always feel as if I am in Addis Ababa the ISSD office. Marja, you deserve special thanks for your overall support, not only as project coordinator, but also as a close colleague. In Wageningen, I enjoy being part of your family, and you always made me feel at home. I thank the support of all the ISSD family in Ethiopia for their support. Amsalu, I appreciate your support in helping me to focus on my research, when I sometimes engulfed myself in ISSD work. I would also like to thank the regional partnership and innovation facilitators (Mesfin, Meseret, Mergia) for your support during data collection. The ISSD family also includes Walter de Boef, who has left a visible finger print in my ISSD career, an important contribution to my study.

I thank all those who provided me with data for this research. I interviewed 80 informants from diverse organizations and backgrounds, who allocated their time, sometimes for repeated interviews and were keen to share what they know about the Ethiopian seed sector and the policy making processes. I appreciate your time and the information that you gave me, and I hope you find your contribution in this thesis.

Finally, I thank my family for understanding and supporting me during my research. My sincere thanks to my wife Worke Ireso. You quit your job to take care of our kids, while I was busy with this study. That cost you a lot in terms of your career, and I appreciate your dedication to our family. My kids, Robdu, Biftu, Gemechu, Milky and Dureti, you deserve special thanks not only because you tolerated my absence and busyness, but also you contributed to this thesis by transcribing interview data both in Afan Oromo and Amharic. Lastly, I am grateful to my late father, Hassena Beko, who was not able to go to formal school, but constructed a school with his fellow villagers without waiting for the government. Your self-reliance and pro-active determination created a chance for me and people of my age to go to school, which formed the basis of my current success. 


\section{Table of contents}

Acknowledgements

vi

Table of contents viii

List of figures $\quad x$

List of maps $\quad x$

Acronyms $\quad$ xi

Chapter 1. General introduction 1

1.1 Introduction 2

1.2 Problem statement 4

1.3 Objectives and research questions 4

1.4 Key theoretical concepts and analytical lenses 7

1.5 The organization of the research 10

$\begin{array}{lll}1.6 & \text { Structure of the thesis } & 11\end{array}$

Chapter 2. Reconstructing policy decision-making in the

Ethiopian seed sector: actors and arenas influencing the policy making process

2.1 Introduction 16

2.2 The policy making process 18

2.3 Data generation and analysis 20

2.4 Reconstruction of the seed policy making process 21

$2.5 \quad$ Policy arenas and actors shaping seed policy making 29

2.6 Discussion 33

Chapter 3. Unpacking the paradox of governance solutions for seed quality in Ethiopia

3.1 Introduction 38

3.2 Frames and framing 39

3.3 Data generation and analysis 41

3.4 The challenges of seed quality governance in Ethiopia 42

3.5 Frames and negotiating frames 44

3.6 Analysis $\quad 52$

$\begin{array}{lll}3.7 & \text { Discussion } & 57\end{array}$ 
Chapter 4. Organizing changes in the centrally managed seed market system through collaborative governance: piloting direct seed marketing in Ethiopia

4.1 Introduction 60

4.2 Transition and transition management 61

4.3 Data generation and analysis 64

4.4 The seed market system 65

4.5 Organization of changes in the seed market system 71

4.6 Analysis 81

4.7 Conclusion 88

Chapter 5. The rise of seed marketing and its uncertain future in Ethiopia: facing ambiguous policy making and institutional lock-in

5.1 Introduction 92

5.2 Institutional lock-in 93

5.3 Data generation and analysis 95

5.4 The challenges of the centralized seed distribution system 96

5.5 DSM and its benefits 98

5.6 Dangling to institutionalize DSM 100

$5.7 \quad$ Non-decision explained 102

5.8 Conclusion 111

$\begin{array}{lll}\text { Chapter 6. Conclusion and discussion } & 113\end{array}$

6.1 Introduction 114

6.2 Conclusion 116

$\begin{array}{ll}6.3 \text { Discussion } & 122\end{array}$

$\begin{array}{ll}\text { References } & 127\end{array}$

$\begin{array}{ll}\text { Appendixes } & 143\end{array}$

Appendix-A. Date and place of interview of anonymous informants $\quad 144$

$\begin{array}{ll}\text { Summary } & 147\end{array}$ 


\section{List of figures}

Figure 1.1. Structure of the thesis $\quad 13$

Figure 4.1. Multi-level perspective on transition $\quad 62$

Figure 4.2. The seed market regime in the Ethiopian formal seed system 68

Figure 4.3. DSM - the niche in the Ethiopian seed market system $\quad 70$

Figure 4.4. Regional seed core group and its link to the regional bureau of agriculture and ISSD $\quad 72$

Figure 4.5. Increase in number of districts and amount of maize seed sold $\quad 81$

Figure 4.6. Multi-level perspective on the transition process in Ethiopian seed $\begin{array}{ll}\text { marketing } & 87\end{array}$

\section{List of maps}

Map 4.1. Expansion of DSM districts in Ethiopia (2011 - 2016) 


\section{Acronyms}

ADLI Agricultural development-led industrialization

AGP Agricultural Growth Program

APHRD Animal and Plant Health Regulatory Directorate

ASC Agricultural Standing Committee

ASE Amhara Seed Enterprise

ATA Agricultural Transformation Agency

BoA Bureau of agriculture

BPR Business process re-engineering

CDI Centre for Development Innovation

CoM Council of Ministers

COMESA Common Market for Eastern and Southern Africa

CPA Cooperative promotion agency

DSM Direct seed marketing

EHPEA Ethiopian Horticulture Producer Exporters Association

EPRDF Ethiopian People's Revolutionary Democratic Front

ESE Ethiopian Seed Enterprise

FBSPMS Farmer-Based Seed Production and Marketing Scheme

FDRE Federal Democratic Republic of Ethiopia

HoPRs House of Peoples' Representatives

IDLO International Development Law Organization

IFPRI International Food Policy Research Institute

ISSD Integrated seed sector development

MLP Multi-level perspective on transition

MoA Ministry of Agriculture

MoU Memorandum of understanding

NAIA National Agricultural Input Authority

NFIA National Fertilizer Industry Agency

NGO Non-governmental organization

NSIA National Seed Industry Agency

OSE Oromia Seed Enterprise

SNNPR Southern Nations, Nationalities and Peoples' Region

SSE South Seed Enterprise

TPLF Tigray People's Liberation Front

WUR Wageningen University and Research 



\section{Chapter 1}

General introduction 


\subsection{Introduction}

In Ethiopia, the end of the cold war brought changes in the political and economic systems of the country. Politically, the country was restructured from a unitary government to a federal state. The new constitution of Ethiopia, which legitimized the federal structure in 1995, also introduced a separation of powers into the government structure, in particular between the parliament, which is responsible for policymaking, and the executive, which is responsible for implementing policies. In Ethiopia, this has been a major shift, as policies were made or changed at the discretion of the emperor for nearly a century, and then for a short time was in the hands of military dictators.

The prevailing economic structure of the country has been under transformation from a centrally planned system of socialism towards a market economy. Since the early 1990s, the government of Ethiopia has placed emphasis on economic development, starting with agricultural development-led industrialization in 1992. For Ethiopia, agriculture accounts for about $40 \%$ of the real GDP, employs about $77 \%$ of the population, and contributes about $84 \%$ of the export earnings (ATA 2015; World Bank 2016). Given the agrarian economy of Ethiopia, agriculture has been considered to be an engine of growth in this strategy, and it will continue to be so for some decades to come.

Since 2001, the government has identified poverty as one of the major threats to the survival of Ethiopia as a sovereign country. It has become apparent that Ethiopia follows the 'developmental state' political economy (Gebresenbet 2014; Vaughan 2011; Simon 2011; Veen 2015). As a result, the government prepared different policies, including the rural and agricultural development policy document of 2002 to guide rural development. By following the developmental state approach, the government intensified its involvement in the economic sector. Massive development efforts were re-initiated across the country (Vaughan 2007). Over the last decade, reports indicate that the Ethiopian economy is one of the fastest-growing economies in the world (World Bank 2016).

Despite the development efforts since the mid-1990s and reported rapid economic growth, food production still does not satisfy demand. In particular, the agricultural sector has not been able to withstand certain natural shocks. Most recently, the drought in 2015 and 2016 resulted in food shortage for over ten million people, showing the low level of surplus food production in the country (FAO 2016). This is partly the result of the limited use of agricultural technologies in Ethiopia, as in most other sub-Saharan African countries (Sheahan and Barrett 2017). One of the most important agricultural technologies in this respect is seed. Seed is in fact a carrier of 
many technologies, and is essential to increase production. Although the formal seed system (a system that follows seed certification procedures) has been operational since the end of the 1970s, the use of quality seed from formal sources is estimated at less than 10\% (ATA 2015). The seed sector is facing different challenges: the development of the seed sector is not keeping pace with the growth in demand for seed. The demand for seed exceeds the supply. Shortage of seed in terms of amount and type is a critical issue (Bishaw, Sahlu and Simane 2008).

To explain why the seed sector has not been able to respond adequately to the growing demand for seed in the country, many studies have identified technical gaps (Alemu and Tripp 2010; Bishaw 2004; Bishaw, Sahlu and Simane 2008; Sahlu, Alemu and Atilaw 2012). While discussing the challenges of developing a healthy seed system, McGuire (2005) highlighted that studies in Ethiopia do not consider policy issues, whereas these issues are critical in guiding seed sector development. However, in recent years many studies have tried to analyse the gaps in policy implementation in Ethiopia that are seed related (Alemu and Atilaw 2012; Alemu and Tripp 2010; Atilaw 2010; Atilaw and Korbu 2012; Lakew and Alemu, 2012; Spielman, Mekonnen and Alemu 2013; Sahlu 2012; Teklewold and Mekonen 2012).

Some of the issues illustrated in these studies include the wide gap between policy on paper and in practice on the ground in terms of seed quality certification, as discussed by Alemu and Tripp (2010), indicating the malfunctioning of the seed certification system. Sahlu, Alemu and Atilaw (2012) elaborate that the problem of seed quality is related to the poor capacity of the laboratories to inspect seed production. They further state that the restructuring has affected the overall management of the seed sector. Other studies also show the limited participation of the private sector in the Ethiopian seed sector, although policies encourage private sector development (Alemu and Tripp 2010; Spielman, Mekonnen and Alemu 2013). Similarly, the plant variety protection law, which was enacted in 2006, was not implemented; and the Ministry of Agriculture $(\mathrm{MoA})^{1}$ has not been able to adequately facilitate the process of variety release (Teklewold. and Mekonen, 2012). Atilaw and Korbu (2012) indicate that seed marketing is the weakest link in the seed value chain. Spielman, Mekonnen and Alemu (2013) note that while the policy on paper indicates market liberalization, this is hardly implemented in Ethiopia. Others

\footnotetext{
${ }^{1}$ The name of this ministry has changed several times. Initially, it was referred to as the Ministry of Agriculture; in 2004, it became the Ministry of Agriculture and Rural Development; in 2010, it was changed back to the Ministry of Agriculture; and recently it was renamed the Ministry of Agriculture and Natural Resources. In this document, for consistency we refer to it as the Ministry of Agriculture.
} 
also emphasize the importance of tackling the seed marketing problem in Ethiopia (Alemu and Tripp 2010).

\subsection{Problem statement}

As discussed above, various studies have identified problems in the seed sector, including policy implementation gaps. However, these studies have not taken further steps to understand why there are all these gaps, or why certain policies have not been implemented. None of the studies in Ethiopia appear to have looked into the ways in which seed policies are made and implemented, or how actors and institutions have influenced the process and outcome. Most studies have rather focused on technical problems or policy implementation gaps, and at best some have tried to show the government's interest in seed sector policy implementation (Alemu 2011). Such studies have little to say about the reasons behind the gaps in policy making and implementation. This calls for an analysis of how the content of a policy document is shaped and determined, and how a policy is implemented.

Given the dominant role of agriculture in the Ethiopian economy, the seed sector has always been a priority for many actors, for different motivations and interests. Some actors are eager to ensure that seed is made available to farmers, other actors want to make a business in the seed sector, while others may want to have better access to high-quality seed, others want to effectively engage in seed sector administration. These are important reasons for different actors to take part in the policy making and implementation process. Given these interests and motivations, actors try to influence the outcome of policy making and implementation. The extent to which different actors can influence the outcome is guided by formal and informal institutions (Ostrom 2007). As these institutions are both diverse and not equally visible, it is likewise unclear as to why actors choose a certain policy option, or avoid the implementation of another. Thus, although different challenges in the seed sector have been identified in many of the previous studies, knowledge is still lacking regarding the institutional dimensions or roots of these problems, limiting room for innovation and improvement of the seed sector.

\subsection{Objectives and research questions}

The objective of this research is twofold: to narrow the knowledge gap about policy making and implementation in the Ethiopian seed sector, and to contribute to the debate as to how to make the seed sector function better. To attain the objective, this study aims to unravel the institutions behind the challenges faced by the Ethiopian seed sector, covering the policy making and implementation continuum from 2008 to 2016, and looking at how actors, and the environment in which they interact, influence the outcome. The overall research question is: how did actors and institutions 
influence the formulation and implementation of seed policy in Ethiopia from 2008 to 2016 ? This question comprises two processes: policy making and policy implementation. For each of these processes, two further questions were devised, resulting in four specific research questions, which are introduced below.

By the end of 2008, the process of revising the 2000 seed law had begun, with the aim of mitigating problems in the seed sector. The revision was finalized at the beginning of 2013. Over the four years of the revision process, actors had to negotiate on different policy options. There were different rounds of revision and discussion. In addition to the actors, the arenas in which the negotiations and decisions took place were important in influencing the contents of the drafts. This is partly because not all the actors had access to all the arenas. Against this background, the first specific research question is: how did the seed policy actors and associated arenas influence the outcome of Ethiopian seed sector policy making during the period 2008-2013? While the actors had to negotiate on various issues, this study concentrates on two major themes: seed sector governance, and variety registration.

Different actors have different perceptions of the problems and possible solutions that are the basis for these actors to negotiate on the content of the policy document. Actors frame each problem and solution differently based on their perceptions, experience, vision, and inevitably interests and values. In order to understand how actors frame seed sector problems, this study focuses on the governance of seed quality, which leads to the second specific research question: how have different actors framed the seed quality problem and its governance solutions, and how can these different frames and the decision making on the governance of seed quality be explained? These first two specific research questions help to understand how actors and institutions influence policymaking processes and outcomes in the formal policymaking process. It also helps to understand the institutions and interests behind an actor's preference for a particular policy option.

The influence of actors and institutions is not only limited to the policy making process, but it also extends to the policy implementation stage. This study considers the process of introducing and expanding a practice of seed marketing to overcome the problem of seed distribution inefficiency from 2010 to 2016. In Ethiopia, seed of major food crops is not exchanged formally in a free market, but is instead centrally allocated and distributed through a government controlled system to ensure that farmers across the country get equitable access to seed. Seed distribution includes the process of estimating demand and production, and allocating and supporting the entire disbursement process. As the volume of seed and geographical area to which the seed is distributed increases, the process becomes more cumbersome. As 
a result, the system became increasingly inefficient and the quality of the seed supplied to the farmers become increasingly poor, which is also related to change of ownership of the seed in the process (Sahlu, Alemu and Atilaw 2012).

The process of introducing and expanding the practice of seed marketing was facilitated by regional seed core groups, a collaborative governance structure established in mid-2010 in four regional states- Amhara; Oromia; Southern Nations, Nationalities and Peoples' Region (SNNPR); and Tigray2. The major seed sector stakeholders in the regions are members of the regional seed core groups. They were tasked with identifying critical challenges in the seed sector, and finding options to implement or recommend policy solutions for change if necessary. The collaborative governance structures in the different regional states have identified different challenges and implemented different activities. For this research, the issue of seed marketing was selected to study the process and outcome more closely.

The regional seed core groups are operational under two constraining environments. The first is the top-down governance culture of Ethiopia, which focuses on a centralized planning approach where suggestion from below is generally only considered when it fits in with the interest of decision makers. The second constraining environment is related to the competing discourses about seed marketing: liberalization of seed marketing and centralized distribution. While seed distribution is promoted for equity, those who advocate seed marketing focus on the efficiency of seed supply and seed sector development. Under such conditions, the core groups introduced direct seed marketing (DSM) in 2011, and they have been implementing and expanding it over the years. By 2016, more than one-third of the hybrid maize seed in three regional states (Amhara, Oromia and SNNPR) was sold through DSM. This leads us to the third specific research question: how have the regional seed core groups introduced DSM from below in the top-down governance culture of Ethiopia; and how have they been able to expand DSM given the competing discourses?

The potential of DSM to overcome seed supply inefficiency, coupled with the support of actors including government, helped to expand DSM in Ethiopia (Benson, Spielman and Kasa 2014). Despite the alleged benefit to and support of the government for its expansion, DSM has not been officially embraced by the government. However, actors in the seed distribution system expect the official decision of the government to fully switch to the new system, including investment

\footnotetext{
${ }^{2}$ Ethiopia is a federal state with nine regional states and two city administrations. Amhara, Oromia, SNNPR and Tigray are considered as agriculturally important regional states of Ethiopia.
} 
in marketing infrastructure. The fourth specific research question is therefore why has the Ethiopian government still not formally endorsed the use of DSM despite the positive results of this pilot and the fact that the initiative falls squarely within Ethiopian seed policy? Specific research questions three and four help to understand how actors and institutions affect the implementation of policies on paper. In summary, the twofold objective of this study is to widen our understanding of the causes of the Ethiopian seed sector problems, looking into the policy making and implementation continuum, and to contribute to the debate on how to make the Ethiopian seed sector function better.

\subsection{Key theoretical concepts and analytical lenses}

Public policy is not something that experts alone can formulate to recommend to those in power the 'best' policy option to solve a societal problem. Public policy making and implementation is rather something that is constructed in a process (Ingram, Schneider and Deleon 2007). This is partly because, regardless of the rationality assumption of both the experts and those wielding power, the proposals of experts are not always accepted by those in power (Mead 2013). This reflects the fact that social problems are not always objectively verifiable, which forces those in power to accept the proposal of the expert. Rather, the 'problem' is subjectively defined by different actors based on an interpretation of a phenomenon (Ingram, Schneider and Deleon 2007). This subjective interpretation of a phenomenon as a 'problem' raises questions regarding the extent to which the 'problem' and thus the policy thereof, reflects the problems of a society. This necessitates clarification of who defines societal problems, and whose interests and values a public policy reflects.

Though government makes public policies, it is important to distinguish between society and government interests and values (Akindele and Olaopa 2004). Society's interests may not necessarily all be the same as government's interests and vice versa; however, regardless of the difference, a policy developed by a government is public policy. In formulating public policies, the government has different interests ranging from those that are self-serving to those that genuinely try to solve societal problems (ibid.). The vested interest in public policy making is not only limited to the government, but extends to all actors that take part in the process of public policy making and implementation. An actor wants to be included in the process to make sure that the policy includes his/her preferred option (Ostrom 2007; Sutton 1999). Thus, public policy is the result of interactions between actors, including government, to attain their interests (van der Zee 1997). Like the other actors, the government as a political group has its own interests, which include at least the 
interest to remain in power by satisfying the interests of its constituency, which otherwise will result in power loss (Rausser and Goodhue 2002). As such, actors taking part in policy making and implementation use all possible means and opportunities to influence the outcome to the best of their interests. Thus, public policy is not the business of policy makers alone, it is the outcome of interactions between different actors (Adam and Kriesi 2007; Ostrom 2007).

Akindele and Olaopa (2004) illustrated the hierarchy of public policy, which includes technical, administrative, executive, and political policy. While technical policy concerns the details of how policy is translated into practice, the political policy is the overarching objective of the political group. The political policy provides underlying guidance to other policies. The government, as a political group holding power, puts its objectives at the political policy level so as to be used as a base for designing and implementing policies. The extent to which such objectives are included in the technical and administrative policies depends on the strength of the government relative to the other actors. It is thus the composition of actors, networks and rules, as well as policy-specific issues, that influence the outcome of the policy making process (Walt 1994).

Similarly, influencing policy formulation does not mean that the policy will be implemented, or will be implemented as stipulated in the policy document. Policy implementation also depends on how the implementer of the final policy reconstructs and translates the policy into practice (Vaughan and Rafanell 2012). Policy reconstructions are related to the interests and values of the implementers: policies that negatively affect the interests and values of implementers are less likely to be implemented as stipulated in the policy document. Lipsky (1980) introduced the concept of 'street-level bureaucrats' and noted that what frontline staff implemented becomes policy, regardless of the initial intention put on paper. However, May and Winter (2009) elaborate how the political attention of the government and managerial guidance influence the actions of the 'street-level bureaucrats', showing the impact of different actors, in addition to the implementers, during the implementation of policies as well. As also discussed by Kjaer and Joughin (2012), a series of political decisions are required during the implementation of policies. This means that 'street-level bureaucrats' may not always have the leverage to change policy. Rather, the high-level political interests influence policies at the implementation stage, and the influence does not end at policy formulation level. Actors influence policy as far as its implementation through the institutions that facilitate the influence. 
To understand policy processes and implementation, this study focuses on institutions, especially informal ones, and how these institutions shape the way in which actors make and implement policies. According to Ostrom (2007), 'institutions are the shared concepts used by humans in repetitive situations organized by rules, norms and strategies' (p. 23). Institutions organize the structured interaction of members, and thus determine what is perceived as right and wrong, and accordingly influence an actor to think in a certain way (Duffield 2007; Khan 2013; Klein 1998). These institutions are both formal (constitutions, laws, regulations, official procedures) and informal (norms, values, taboos, beliefs, and conventions) (Duffield 2007; Geels 2004; Khan 2013; Mulé 1999; Strambach, 2010). It is important to note that these institutions are 'humanly devised constraints that shape human interaction' (North 1990: p. 3), but also provide opportunities for societal change. Thus, institutions and actors presuppose each other. While institutions are shared concepts among members, some of them are tacitly shared, and are not clear from the outset, yet influencing human interaction and their outcome. The complex interactions of actors influenced by institutions determine the process as well as the outcome of policy making and implementation.

To study policy processes and their outcomes, different theoretical concepts have been used in this research. Societal phenomena are complex and thus the analysis of these phenomena require the use of different theories that each help to conceptualize and explain them. There are a variety of theories that can be used to explain the complex process of policy making and implementation, but a theory may not necessarily explain the whole process, given the diversity of how, and the circumstances under which, public policy is developed and implemented. Different theories have to be used to complement each other and to better explain the complexity of public policy making and implementation. This is what scholars have coined as theoretical multiplicity (Dewulf et al. 2009; Karpouzoglou, Dewulf and Clark 2016). It is important to note that theoretical multiplicity is not just about putting different theoretical concepts together, but it is primarily about how the different theories complement each other and can create synergy to help conceptualize the process in its complete structure while maintaining their distinctiveness (Karpouzoglou, Dewulf and Clark 2016). In this thesis, the complex policy making and implementation process, influenced by the strategic nature of the seed sector in Ethiopia, is analysed. The use of different theoretical concepts under such circumstances becomes a necessity to explain the policy process. For these reasons, several theoretical concepts have been used and combined in this research: the theoretical concept of discourse analysis focusing on frame, the round model, policy arena, multi-level perspective on transition, transition management, non- 
decision making, and institutional lock-in. While using these analytical lenses to explain seed policy making and implementation, the concept of institutions, as discussed above, has remained a central concept.

\subsection{The organization of the research}

This research approaches policy making and implementation as something that is not a given, but as something that actors decide on during the process. It focuses on how actors select and/or implement a given policy, also looking into the underlying reasons behind the decisions. As such, it uses qualitative data to explain why actors favour certain policy options, while choosing not to implement others. Major data used in the study include descriptions of the processes of negotiation as well as the outcome of revising the 2000 Ethiopian seed law (2008 - 2013), and the process of implementing DSM (2011 - 2016). The fieldwork for this research was carried out from the end of 2013 to mid-2016, in two phases. During the first phase up until 2014, key data were collected to answer the first two specific research questions, basically focusing on the process of revising the 2000 Ethiopian seed law. In addition, major data were generated through interviews with 40 informants $^{3}$, many of whom had participated in the revision process. Most of the informants were identified purposely because they were part of the process and therefore had better knowledge of the process and the outcomes. Moreover, different drafts, reports produced during the revision process (November 2008 to January 2013), and the final seed law, were used as data to answer specific research questions one and two.

During the second phase, from 2015 to 2016, data were generated to answer research questions three and four. The data for these research questions focused on the activities of the regional seed core groups that were established in mid-2010 by the Integrated Seed Sector Development (ISSD) Ethiopia project. Different reports were reviewed and used as a starting point. Interviews were conducted with 47 informants ${ }^{4}$, both at national and regional state levels, who had been involved in DSM piloting. Similar to phase one, these informants were also identified purposely because they had better knowledge of the process of initiating and implementing DSM. In addition, I was part of the design and implementation of the pilot, serving as a coach to the process facilitators at regional state level between 2010 and 2012 . My affiliation to ISSD, and good working relationship with major actors in the seed

${ }^{3}$ In this thesis, I refer to the interviewees as informants, because they were selected purposely, not randomly, because of their better knowledge of the subject under investigation.

${ }^{4}$ Some of the informants, particularly those from seed companies and actors at national level, are the same for the two data sets. Since the data sets are different and were not combined during data analysis, the number of informants remained at 40 and 47 for the two phases, and the total number (87) does not indicate the number of informants (80) interviewed. 
sector, created easy access to information, despite being based at a distance from the DSM activity owing to my PhD studies. Furthermore, knowledge of the process helped me to reflect on observations as an action researcher during data collection.

Being part of the process also has some drawbacks. The first is the researcher's possible bias towards achieving a particular outcome, and thus focusing on some parts but not others; the second is how the researcher is viewed by the respondents, which may affect their responses. Although total objectivity is unachievable, in most research, particularly in social sciences, knowing the problem and making the researcher's perspective clear adds to transparency and accountability (Silverman 2011). My preference for bottom-up processes and deliberation about change might have caused me to overlook some of the positive benefits of top-down decision making. Moreover, being part of the process may have also predisposed me to expect a positive outcome from the interventions. However, being aware of such challenges, I aimed to 1) work as an outsider trying to generate more information from the respondent; 2) focus on the processes and reasons behind them rather than the outcome; 3) stick to a checklist during the interviews, being careful not to skip any of the points with the assumption of prior knowledge; and 4) ensure that twothirds of the members of the regional core group were included in the interviews, to obtain a range of views from the actors in the process.

Before starting to collect the data, I was concerned that respondents would only tell the positive parts of the story, or that they might withhold information they assumed that I already knew, owing to the fact that they knew that I was part of the team supporting the introduction of DSM. I used key terms, in addition to open-ended questions in the checklist, to elicit the information the interviewees might withhold. During the interviews, the interviewees were open to mentioning both the positive and negative aspects of the pilot. This may have been because they knew that I was familiar with all the processes and that I was now collecting data as a researcher. All the interviews were tape-recorded, transcribed and coded using Atlas.ti ${ }^{5}$.

\subsection{Structure of the thesis}

This thesis answers the abovementioned four specific research questions in the chapters that follow. Chapter 2 addresses research question number one. This chapter is aimed at understanding the process of revising the 2000 Ethiopian seed law, specifically looking into how different actors influenced the outcome in different arenas. A public policy decision is not a one-off event, rather it is an iterative process of negotiations among actors and decision making. The concept of

\footnotetext{
${ }^{5}$ Atlas.ti is a computer programme that is used in qualitative research data analysis.
} 
the rounds model proposed by Teisman (2000) and the concept of a policy arena (Hermans and Cunningham 2013; Ostrom, Gardner and Walker 1994; Sabatier 1988) were combined to reconstruct the process and understand the influence of actors and arenas. This chapter elaborates how the disconnected arenas and the power of actors influenced the content of the seed policy document.

Chapter 3 answers research question number two. The chapter starts with the concept that policy problems and solutions are not something that exist objectively, but rather are 'constructed' by actors. How actors define a problem tends to imply a preferred solution (Peters 2005; Coburn 2006). Discourse theory focusing on frame analysis is used to understand how and why actors frame seed quality problems and governance solutions in different ways. This chapter analyses how actors use a frame to structure the content of seed policy. Chapter 4 answers research question number three, and this is about how DSM is introduced and widely used in Ethiopia. The purpose of this chapter is two-fold: 1) to show that the existence of a policy on paper does not mean that the policy has been implemented; and 2) to highlight the influence of actors in translating the existing policy into practice. The concept of transition management and multi-level perspective (MLP) (de Haan and Rotmans 2011; Geels and Schot 2007; Rotmans, Kemp and van Asselt. 2001) are used to understand how the process of implementing policies that are not in line with the interests of influential actors is managed. This chapter discusses how the collaborative governance structure facilitated the process of introducing DSM, and examines the role of different actors in the process. It also elaborates how the strategic management of collaboration, including networking, helped to introduce and expand DSM. Chapter 5 answers research question number four, and is a continuation of Chapter 4. This chapter analyses why the widely used DSM is not officially endorsed by the government, using the concept of non-decision making and institutional lock-in (Bonal 2012; Cantarelli et al. 2010; Geels 2011). This chapter presents the different institutional lock-ins that hindered decision making on the future use of DSM. It discusses how actors used various institutions to create the lock-ins and influence decision making.

Chapter 6 concludes the research by summarizing the answers to the specific research questions, providing an overall answer to the main research question. On the basis of the answers, the chapter discusses the major outcomes of the research and lessons learned. By focusing on the Ethiopian seed sector problems, and based on the experiences in this research, the chapter also suggests alternative ways of dealing with the seed sector challenges, and future research that is needed to 
strengthen the Ethiopian seed sector. Figure 1-1 provides a schematic overview of the structure of the thesis.

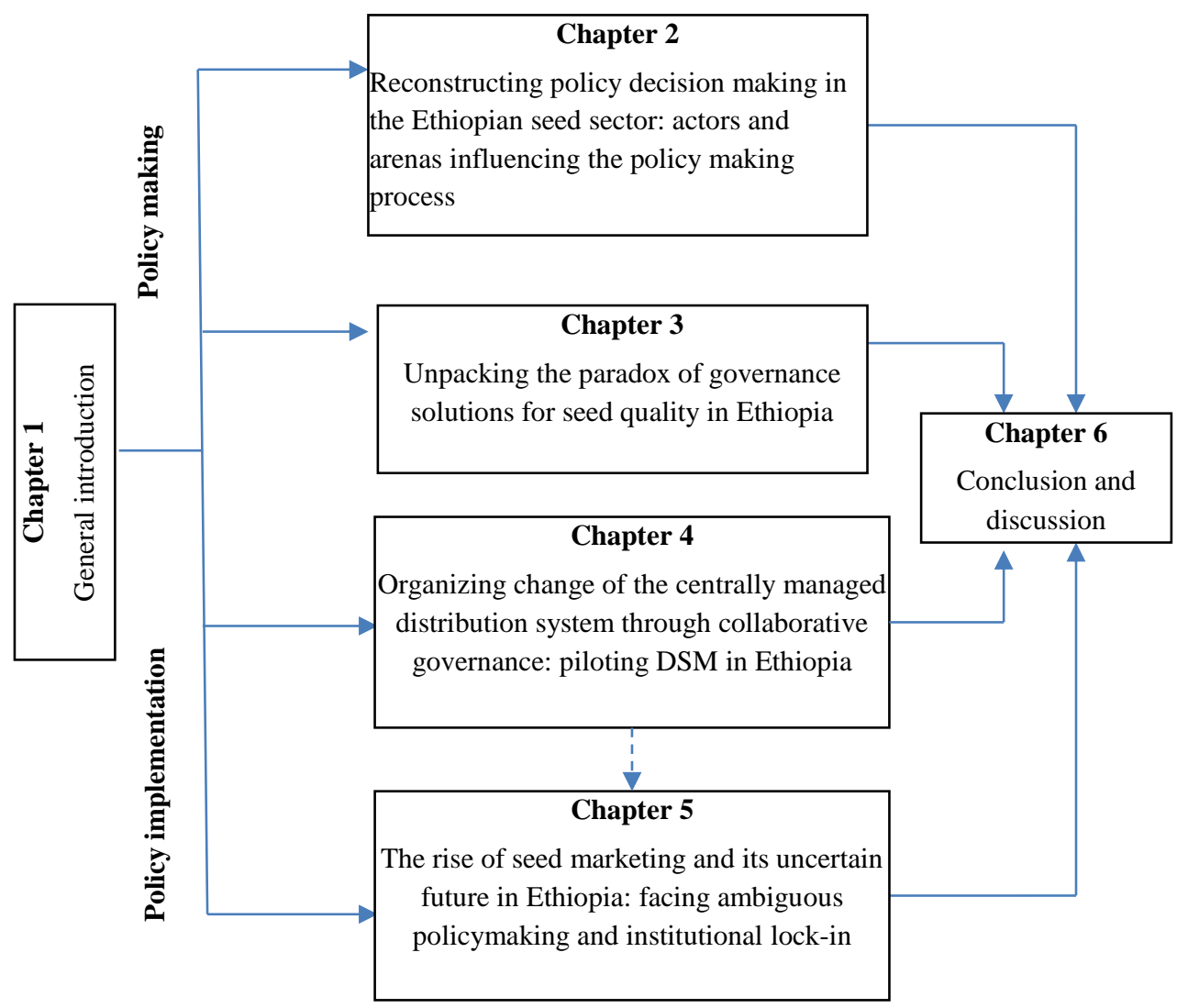

Figure 1-1. Structure of the thesis 



\title{
Chapter 2.
}

\section{Reconstructing policy decision-making in the Ethiopian seed sector: actors and arenas influencing the policy making process $^{6}$}

\begin{abstract}
In Ethiopia, new policy actors and arenas have emerged as a result of major changes that took place in the political and economic system in the early 1990s: the separation of state powers between the legislature and the executive, and the decision to move towards a market-oriented economic system. These are important bases that define the policy making processes. However, the mere separation of power and emergence of new actors do not necessarily guarantee effectiveness of the established system, and thus need analysis. Focusing on the four years of discussions on developing seed law, this chapter analyse show the emergence of new actors and new policy arenas has influenced the process and outcome of policy making in the Ethiopian seed sector. Furthermore, it sheds a new light on policy making processes in Ethiopia, considering policy making as a process involving multiple actors, arenas and interactions between policy actors. The analysis reveals that the new policy arenas provided opportunities for actors to place their preferred policy options on the agenda, and get them incorporated into the draft seed law. However, mainly because of a blurred separation of power between the executive and the legislature, decision making ultimately remained firmly in the hands of the executive.
\end{abstract}

\footnotetext{
${ }^{6}$ This chapter is based on an article published in Public Policy and Administration Research, 6(2), as: Mohammed Hassena, Otto Hospes and Bram De Jonge (2016), 'Reconstructing policy decision-making in the Ethiopian seed sector: actors and arenas influencing policy making process'.
} 


\subsection{Introduction}

Since the creation of modern Ethiopia in the second half of the 19th century, public policy making has been the domain of emperors, kings and palace courts, the nobility, military dictators, and civilian and bureaucratic elites (Abebe 2005). The historically authoritarian system of the country provides little room if any, for society to influence policy making. Rather, as in many other developing countries, society is ill informed about the policy making process, yet nevertheless affected by the resulting policies (Saasa 1985). Since 1974, the political regime of Ethiopia has dramatically changed twice. In 1974, the socialist regime replaced the age-old monarchical system, and in 1991, 'revolutionary democracy' replaced the socialist regime (Abebe 2005). Under the monarchy and socialist regime, the power of policy making was vested in the monarchy and the executive, respectively (ibid).

The political shift of 1991 brought about two major changes in the policy making process in the country. The first is the separation of state power between the executive and the legislature, demarcating their respective roles in the policy making process (Dercon 2006; HoPRs 1995). After a four-year transitional period, the constitution that separates their powers was ratified in 1995. Accordingly, the House of Peoples' Representatives (HoPRs) is the highest authority of federal government, retaining the legislative power over all matters of federal jurisdiction, while the executive, which is composed of the Prime Minister and Council of Ministers (CoM), implements policies. Both the legislative and executive can draft policies. The drafting of policies by the executive is mainly conducted by sectoral agencies.

The second change was the transformation of Ethiopia's economic system from a command economy to a more market-oriented economy (Abebe 2005; Dercon 2006), which consequently led to changes in the landscape of policy actors in the agricultural sector. The change brought private sector and donor agencies into the policy making process. The involvement of new actors, including the HoPRs and the private sector, and increased participation of others, have introduced new arenas, such as public hearings, and have changed the dynamics in existing arenas. As a result, sectoral agencies often organize stakeholder workshops to improve the content of the draft policy document. The sectoral standing committee of the HoPRs may also organize public hearings to get the views of the public about a draft policy document.

Until very recently, with a few exceptions of government companies, agriculture in Ethiopia was the domain of smallholder subsistence farmers. The government agencies were the only policy actors involved in developing policies that target these smallholder subsistence farmers. In recent years, although smallholders still 
dominate, commercial farming has become part of the Ethiopian agricultural system, supported by different development programmes of the government. The first five-year development plan, the Sustainable Development and Poverty Reduction Program, which began in 2002, prioritized the private sector in its agenda, as did the second five-year development plan, the Plan for Accelerated and Sustainable Development to End Poverty, which was initiated in 2006 (FDRE 2002; FDRE 2005). As a result, seed companies and other commercial companies operating in the agricultural sector, including export-oriented horticultural companies that have stakes in the seed sector, are taking part in agricultural policy making processes (Melese and Helmsing 2010). Moreover, the Development Assistance Group ${ }^{7}$ has been taking part in different development and policy making activities in Ethiopia, since 2001 (Young 2005).

Actors in the seed sector have diverse interests, and in the context of the policy making process they may frame problems and solutions concerning the seed sector in different ways (Chapter 3 ). Seed ${ }^{8}$ is a strategic input for agricultural productivity, and the government has an interest in designing policies that ensure the equitable availability of seed to all farmers. Seed is also a commercial commodity, and it is in the interests of seed companies that policies be conducive to their business. Similarly, as seed users, the emerging horticultural companies want policies to ensure easy access to high quality seed. The experts in the ministry and research system who usually take part in policy making are concerned about the governance of the seed sector, and risks to the seed sector and agriculture in general. These underlying drivers are key to actors' engagement in the policy making process of the seed sector. Actors use different venues or arenas to take part in the policy making process. The arenas create an opportunity for actors to table their preferred policy option and negotiate to include the option in the draft policy documents. Similarly, some arenas are used to enact policies according to the authority vested in the actors.

Ethiopia revised the 2000 seed law after a policy making process that spanned four years, from late 2008 until early 2013. On close examination of the various drafts produced over those four years, it become clear that the policy options for variety

\footnotetext{
7 The Development Assistance Group was established in 2001 to foster information sharing and policy dialogue, and harmonize donor support to Ethiopia in order to support the country in its effort to meet the targets set in the United Nations Millennium Development Goals. The group comprises 28 bilateral and multilateral development agencies. See http://dagethiopia.org/new/, accessed 30 May 2017.

${ }^{8}$ In this study, the term 'seed' refers to true botanical seed, bulbs, tubers, cuttings, rhizomes, roots, seedlings or any other plant propagating material intended for planting.
} 
registration and seed sector governance are the elements that change most often, showing that these were some of the most contentious issues in the process. The revised law was the result of interactions among actors, both new and existing, in the various arenas that were created in the process. As indicated above, a landscape of new seed sector policy actors has been emerging in Ethiopia over the last two decades. The appearance of these new actors has led not only to the emergence of new arenas (e.g. public hearings ${ }^{9}$ ) but has also changed the dynamics in existing arenas, affecting the policy making process and its outcome. The central research question is how did this new landscape of seed policy actors and associated arenas influence the process and outcome of Ethiopian seed sector policy making during the period 2008$2013 ?$

To address this question, the chapter has been organized as follows: the next section provides a brief description of key concepts (rounds model and the policy arena) used to analyse decision-making processes (2.2). This is followed by reconstructing the process involved in developing the seed law, focusing on the different rounds of revision, the arenas used, the interaction between actors, and the main outcomes of the process (2.3). These is analysed in terms of how the different policy arenas and policy actors have influenced policy making in the context of seed (2.4). Based on the results of the study, the final section reflects on the extent to which the arenas and actors influence Ethiopian seed policy making (2.5).

\subsection{The policy making process}

Developing public policies is complex: they are often the result of complex interactions between various actors with different perceptions, values and resources, and varying levels of participation and influence, in a challenging administrative and legislative setting (Hermans and Cunningham 2013; Howlett 2007; Mintrom, 2011). Moreover, policy making is never determined by one-off decisions, rather it is a technical and political process, extending over a period of time and involving many decisions, in which there is conflict, bargaining and negotiation among actors (Teisman 2000). Recognizing how policy actors navigate through this complex process helps to foster an understanding of how policies are made, and how challenges are identified in the process of policy making. Different models can support an understanding of the policy making process. This study considered the rounds model proposed by Teisman (2000) and the concept of the policy arena

\footnotetext{
9 The legislative is a new actor as a result of the separation of power, which uses public hearings (a new arena) as an important venue to get the views of the public about draft policies.
} 
(Hermans and Cunningham 2013; Ostrom, Gardner and Walker 1994; Sabatier 1988) for reconstructing and understanding the complex process of seed policy making.

The rounds model emphasizes that decisions are made through interactions among purposeful actors in which they negotiate on acceptable combinations of problems and solutions (Teisman 2000). According to Teisman (2000), the decision-making process can be regarded as an indefinite number of decision-making rounds. Important decisions demarcate different rounds in the decision-making process in which there is a dynamic combination of problems and solutions, and a process of mutual adjustment. In the adjustment process, there could be cooperation whereby actors agree on certain issues, or there could be conflict, which may force one actor to adjust. Alternatively, there could be domination by one actor, leading to the adoption of a policy option presented by that actor without agreement. As pointed out by Carrozza (2011), the rounds model helps to deal with unpredictable chains of events, where identifying the round at which a central decision is made is difficult due to the incremental nature of the process itself. Hence, there are unpredictable numbers of rounds of discussions in which some decisions are made in each round, which may or may not affect the next round. In an ongoing policy making process, each decision can be considered a 'temporarily-stable state of equilibrium in which streams of negotiation, deliberation and fact-finding are connected' (Van Burren and Gerrits 2008: p. 382).

The participation of policy actors with different interests, resources and values makes public policy making processes dynamic and complex (Young 2005). In the policy making process, the decision of an actor is related to the value that an actor places on the usefulness of the decision, also showing the internal motivation of the actor. As there are multiple actors, such motivations make the process more chaotic, but there are rules, at least informal ones, that guide the policy making process. The rounds model does not identify the setting in which decision making takes place. This setting is named differently by different scholars: policy subsystems (Sabatier 1988), action arenas (Ostrom, Gardner and Walker 1994), constellations (Scharpf 1997), and policy arenas (Hermans and Cunningham 2013). Arenas are venues in which actors negotiate or bargain with the purpose of influencing decision making; they determine how actors interact with formal and informal rules, and demarcate the boundaries in which actors operate (Ostrom, Gardner and Walker 1994; Sabatier 1988). In these venues, different discussions can result in different intermediate decisions, contributing towards a formal policy decision. The arenas determine the extent to which actors have access to and influence over the policy making process (Mayer, van Daalen and Bots 2013). Depending on the rules of the game, as well as 
the participating actors, the game itself changes, and consequently changes the outcome (Van Buuren and Klijn 2006).

\subsection{Data generation and analysis}

Empirical data were generated from documents, and from semi-structured interviews conducted with informants comprising seed sector actors involved in the policy making process. The data generation focused mainly on the policy actors and policy arenas that guided the process of policy making. Different drafts, in addition to reports produced in the course of the revision process and minutes of a public hearing, were used as starting points to identify changes in the content of policy options over the full period of the process. The drafts and reports were obtained from experts and consultants involved in the drafting process. The minutes of the public hearing were obtained from the Agricultural Standing Committee (ASC) of the HoPRs. After scrutinizing drafts and reports, interviews were held with selected actors involved in the policy making process. The interviews were conducted to understand the process, the rules of the game, the level of interaction among different actors, and the extent to which the actors influenced changes in the content of the drafts and the final policy document. For the interviews, major emphasis was placed on experts, including external consultants that were involved in the drafting process; staff members of Plant Health Regulatory Directorate, the then Animal and Plant Health Regulatory Directorate (APHRD) of the Ministry of Agriculture (MoA), which was leading the process; policy actors who took part in the drafting and negotiation workshops; experts in the Prime Minister's office; and members of the ASC of the HoPRs. A total 40 informants were interviewed for the study, and all the interviews were transcribed and uploaded in Atlas.ti for analysis.

In this study, policy making is considered not only as a process that involves multiple actors and different rounds of discussions, but also as a process that is shaped by policy arenas, operating according to different rules. The rounds model can be combined with the concept of policy arena to better understand the Ethiopian seed policy making process. The process of revising the 2000 seed law began at the end of 2008, and went through three rounds of drafting separated by interruptions until it was completed in 2013. Each round comprised arenas with specific settings in terms of actors, rules and boundaries. The arenas included drafting processes involving experts; different workshops and consultative meetings where drafts were discussed and options were negotiated among actors; and decision-making for a in the ministry, the CoM, and the HoPRs.

The six drafts, including the final seed law, were compared to identify policy options that were frequently changing across the drafts. After uploading the transcribed 
interview data into Atlas.ti software, the data were coded with two major objectives: the first was to reconstruct the drafting process to give a background to the changes in the content of policy options; the second objective was to understand why policy options regarding variety registration and seed sector governance changed throughout the revision process. After a thorough reading of the transcriptions, fragments of texts related to the objectives were coded. Since this was an inductive analysis of data, new codes were included as they emerged. These primary codes with all the quotations were reorganized into families to facilitate the description of the revision process as well as identify the reasons behind the changes of policy options.

\subsection{Reconstruction of the seed policy making process}

Sectoral agencies usually draft policy documents to be enacted by the HoPRs. The way in which a responsible sectoral agency drafts a policy document depends on the nature of the policy document and the capacity of the agency. In addition to experts within the agency, donors are increasingly involved in drafting policies. Regardless of who and how a draft policy is prepared, the respective sectoral agency is responsible for its content. The agency approves the draft and passes it to the Prime Minister's office, to be endorsed by the CoM, and experts in the Prime Minister's office review the document prior to its endorsement. Because of separation of power, the endorsed draft is sent to the HoPRs. To evaluate a draft document and come up with a recommendation, the HoPRs commonly directs a draft document to a parliamentary standing committee of a specific sector. Finally, the HoPRs enacts the policy document based on the recommendation of the standing committee. Throughout the entire approval process, the state agency, the CoM, and the HoPRs have to make sure that the draft does not conflict with the constitution, or with other policies that the country has ratified, including international laws (Alemu 2015).

To understand the specific case of seed policy making, this study reconstructs the process from the beginning until the enactment of the policy that took place over the four-year period (2008-2013). As a sectoral agency, the MoA initiated and coordinated the process from its inception in the latter part of 2008 until the draft policy was submitted to the Prime Minister's office towards the end of 2012. The whole process involved three rounds of drafting, with two drafts produced in each round. This section narrates the process of seed policy making in terms of the rounds and the arenas, focusing on variety registration and seed sector governance. The ministry initiated the first round by organizing a team of experts from the MoA, the Ethiopian Institute of Agricultural Research, the Ethiopian Seed Enterprise (ESE), the Institute of Biodiversity Conservation, and the Ethiopian Standards Authority. 
These are public organizations that have a stake in the seed sector at the federal level. Being in charge of the seed sector regulation, the APHRD represented the ministry and guided the drafting process throughout.

The expert team formed by the ministry produced the first draft (draft-1), mainly based on their experience in the seed sector and through reviewing the existing documents. The APHRD did not organize a stakeholders' consultation in this round (informant 4, 5, 76). With regards to variety registration, the drafting team and the APHRD did not agree. During the drafting process, major emphasis was placed on food crops, whilst the issue of export crops (horticulture in particular) was not considered. As indicated by the former manager of the Ethiopian Horticulture Producer Exporters Association (EHPEA), for many experts, seed policy only concerns itself with smallholder agriculture. As a result, the issue of the export market is generally not considered (informant 34). The team strongly felt that in order to 'protect smallholder agriculture' from any risk related to the introduction of new varieties, all varieties need to be evaluated before registration ${ }^{10}$. Major risks expected were the introduction of new pests to the country and a risk of low yield (informant 4). The APHRD touched upon the issue by suggesting that the drafting team give the ministry an opportunity to allow the importation of some varieties without registration to encourage private sector investment in Ethiopia. Although the expert team did not fully agree with the idea of the APHRD, the team created an apparent 'loophole' in the draft by indicating that the exemption of any variety would be decided through ministerial directives in the future. The idea of the expert team was to minimize requirements for registration, rather than exempting from registration as suggested by the APHRD (informant 4).

In the case of seed sector governance, the team suggested establishing two offices: one for variety registration and the other for seed quality control at national level. The proposal to establish a variety registration office was actually already under discussion in the ministry (informant 39; MoA/FAO 2008). In 2009, when the Agricultural Growth Program (AGP) commissioned a study on the formal seed system, there was a general understanding that the variety registration office would be established (AGP 2009). The team submitted draft-1 in February 2009 to the APHRD indicating that the draft was mainly technical and needed to be reviewed by legal experts in the ministry or Prime Minister's office (informant 4, 5, 7). Before officially sending the draft to the Prime Minister's office, the ministry sent the

\footnotetext{
${ }^{10}$ Registration of new varieties is beyond inclusion in the national list. The varieties have to be evaluated through field trials before being registered.
} 
document informally to experts in the Prime Minister's office to obtain their comments (informant 39).

Before obtaining comments from the experts, the ministry began a second round of drafting, as they wanted to ensure the law would allow Ethiopia to trade internationally (informant 14). An event that triggered this idea was the confiscation of Ethiopian flowers at Schiphol airport, in the Netherlands, at the end of $2008^{11}$. The confiscation resulted from the failure of the Ethiopian exporter to complete the payment of royalties for intellectual property rights, and this was partly because Ethiopia had not implemented plant variety protection. This led to a discussion between the Embassy of the Kingdom of the Netherlands in Addis Ababa and the MoA on the subject of seed policy and intellectual property rights. The embassy presented different options to overcome problems related to the international trade of agricultural commodities (informant 3, 39) ${ }^{12}$. Furthermore, there was an ongoing request from the Common Market for Eastern and Southern Africa (COMESA) to harmonize seed policy across eastern and southern African countries to facilitate easier regional trade. The Association for Strengthening Agricultural Research in Eastern and Central Africa (ASARECA), together with COMESA, aims to foster the harmonization of seed policies in the region. Ethiopia is also interested in working towards this direction (Alemu 2011). Thus, the ministry realized that it was necessary to accommodate the issue of international markets in the process of revising the 2000 seed law. The ministry approached the Dutch Embassy in Addis Ababa and requested their support in drafting the new seed law (informant 3, 39). Moreover, the ministry also requested support from the International Development Law Organization (IDLO), which had been supporting the ministry in the livestock sector. Both IDLO and the embassy accepted the invitation and hired consultants to draft the seed law.

Just before the start of the second round, the ministry received a revised draft (draft2) from the experts in the Prime Minister's office; the comments made by the experts were important for the subsequent drafting. In the revised draft, the proposal to establish new offices for variety registration and quality control, and the loophole exempting varieties from registration were excluded. Although the comments were informal, their input was substantial and the APHRD advised the team of

\footnotetext{
${ }^{11}$ See, for example, http://ip4all.com/increasing-number-of-illegal-flowers-are-expected-toenter-the-eu/ (accessed 30 May 2017).

12 Since 2006, the Dutch Embassy has been supporting the seed sector in Ethiopia; Dutch companies are also involved in the horticultural sector.
} 
consultants to follow the revised version, reflecting the power of the experts in the Prime Minister's office (IDLO 2010).

The second round of drafting took place during January and February 2010. In this round, the external consultants held discussions with a wide range of stakeholders in the seed sector. In the case of variety registration, the horticultural companies and their supporters (the Ethiopian Horticulture Development Agency and the EHPEA) were major actors. The challenges raised by companies and their supporters included the lack of appropriate varieties in the country for the export market and the lengthy process involved in registering imported varieties, which is not in keeping with the fast-changing demand for horticultural products (informant 34). Their interest in participating in the seed policy making process is to make sure that the new policy enables them to import seed easily. International companies in particular have little patience for lengthy procedures, and they often choose to work with other countries where they can more easily register and use their varieties. However, the government does not want to lose this investment opportunity (informant 33). Accordingly, the consultants proposed to exempt 'export-only varieties $^{\prime 13}$ from registration, in opposition to draft- 2 .

In the case of seed sector governance, the main issue is concerned with the deterioration of seed quality and poor coordination of activities in the seed sector. Similar to draft-1, but at odds with draft-2, the consultants recommended the establishment of a national office for seed sector governance, based on their discussions with different stakeholders. Parallel to the discussions with stakeholders, there were continuous consultations back and forth between the ministry and the consultants to make sure that the draft included the concerns of the ministry (informant 2,14). The consultancy team produced the next draft (draft-3), and when submitting this draft to the ministry, the team requested the ministry to organize a stakeholders' workshop to obtain more inputs (informant 1). Although the ministry did not support some of the issues, like establishing a national office for better coordinating activities in the seed sector, these unresolved issues remained on the table for discussion during the workshop.

The workshop was organized in March 2010, and over the course of a long debate the issues of variety registration and seed sector governance became even more contentious (informant 2, 4, 33; IDLO 2010). With regards to the issue of governance, two camps of negotiators could be distinguished: the APHRD as the ministry

\footnotetext{
${ }^{13}$ Export-only varieties are those varieties that are imported to be used as seed or planting material for which the product is fully exported.
} 
representatives on the one side, and the experts from different offices and seed companies on the other. In the ministry, the idea of establishing an office for seed sector governance has been a discussion point for a long time. The APHRD was in favour of establishing a coordinating office and stimulated this idea in discussions within the ministry (informant 36). However, since the ministry officials were not in favour of establishing an office, the APHRD carefully positioned itself during the workshop, stating that the issue of establishing a new office should be left to the ministry (informant 14,31). Experts and seed companies suggested that the main legislative document should at least indicate the general structure of seed sector governance. However, there was no room for the APHRD to negotiate, and thus an agreement could not be reached (informant 2,14; IDLO 2010). Due to the firm stance of the ministry officials, the issue of establishing a national office remained an omission in the finalization of the draft following the workshop (informant 4,11).

In the case of exempting specific varieties from registration, the discussion was mainly between the EHPEA on the one side, and researchers and ministry experts on the other. Representatives from the EHPEA argued strongly that exemption would facilitate international trade and help to generate foreign currency. This is in line with the government policy of export promotion to generate foreign currency. An additional argument was that these varieties would only be used on company farmland, and would therefore not affect smallholder agriculture (informant 4, 14, 34). Given the general policy that favours the export sector, the experts' group could not strongly oppose the idea of exemption during the workshop. The consultants incorporated feedback from the workshop and, in consultation with the ministry, produced the next draft (draft-4) and submitted it to the ministry in April 2010. In this draft, the issue of establishing a national office was omitted, whilst the exemption of export-only varieties was included. Draft- 4 was expected to be endorsed by the ministry and submitted to the Prime Minister's office, but the draft was not submitted for more than a year. This is partly because 2010 was an election year and the seed law was not an urgent matter for the ministry officials (informant 7). Moreover, following the election in May 2010, there were changes in the officials of the ministry, which also slowed down the policy making process.

In December 2010, the Agricultural Transformation Agency (ATA) ${ }^{14}$ was established, and the seed sector was on its list of priorities. However, the MoA did not finalize the revision of the seed law, which could have been used to support the

\footnotetext{
${ }^{14}$ The ATA is a federal government agency that was established at the end of 2010 with the support of the Bill and Melinda Gates Foundation to promote the development of agriculture in Ethiopia.
} 
sector. Instead, the ATA was tasked with drafting the seed law. Therefore, the ATA initiated a third round of drafting in mid-2011. Initially, the ATA started from scratch, because it thought that not much progress had been made. However, the agency was informed that there had been progress and finally they decided to build upon draft-4 as the base of the final draft (informant 4). Only experts from the ministry, the ATA and researchers were involved in revising draft-4; ministry officials were consulted during the process, but there was no consultation with other stakeholders. Draft-4 was revised (draft 5) and presented at a workshop in October 2011 (informant 5). The participants from the horticultural sector, who had earlier proposed the inclusion of an exemption clause, did not attend the workshop. Similarly, the Dutch Embassy, which works with the horticultural sector and was involved in the development of draft-3 and draft-4, learned at a very late stage that draft- 4 had been withdrawn from the approval process, and they were not consulted during the revision of draft-4 (informant 33). The major participants in this workshop were experts from different government offices, and public and private seed companies, all of whom consider seed law mainly from the perspectives of smallholder farmers.

In the absence of actors from the horticultural sector in particular, the participants of the October 2011 workshop who had been against the exemption of varieties from the very beginning of the drafting process, excluded that option from the draft. One major reason was a perceived risk of unregistered varieties ending up in the hands of farmers. Presentations by experts, which dominated different discussions, cited incidences of farmers obtaining unregistered varieties (informant 33, 34). Although there was suggestions to find other means of controlling unregistered varieties from ending up in the hands of farmers, the ministry officials preferred to exclude automatic exemption for export-only varieties from the draft (informant 14, 33, 34). As a result, exempting varieties from registration was excluded from subsequent drafts, including the draft submitted to the Prime Minister's office.

During the third round, efforts were made by the ATA and experts to convince the ministry to accept the establishment of a national office to coordinate activities in the seed sector. For example, presentations were made to the ministry officials to illustrate the practices of other countries (informant 29). Similarly, the same experience was presented during a national workshop of seed sector development in 2011 organized by the Ethiopian Institute of Agricultural Research (EIAR) (Dessalegne, Sahalu and Mekbib 2012). Moreover, during the seed law revision workshop in 2011, one of the arguments made by participants was that if a national office is established, it could be easily aligned with the regional seed regulatory 
offices that were in the process of being established ${ }^{15}$. There was not much resistance from the APHRD during the workshop, but the idea was simply ignored during the editing of the document. As indicated by one of the informants, the ministry officials only indicated that this was something that the ministry could do if necessary, which did not convince other actors in the process. Instead, the ministry rejected the proposal, because they ultimately had the power to decide (informant 31). Draft-6 was finalized with the consent of the ministry officials. In this final draft, the issue of exempting varieties from registration was not included; neither was the provision to establish an office. The draft law was submitted to the Prime Minister's office during the second half of 2012, accompanied by a letter summarizing the objectives of the draft and how the draft was developed, and highlighting major changes compared to the 2000 seed law. However, this letter did not include the perspectives of different stakeholders concerning the different policy options discussed during the preparation of the draft (informant 40). In the CoM, no major changes were proposed, as the draft also complied with the initial comments made by experts from the Prime Minister's office.

The draft was presented to the HoPRs in November 2012, and was passed to the ASC who evaluated the draft for its relevance. The ASC then organized a separate discussion with the ministry in December 2012 to have a better understanding of the objectives and the content of the draft. The purpose was to understand the objectives of the draft and to build consensus between the ministry and the committee. As indicated by one ASC member, the common ground for both the executive and the legislature is the policy and strategy set by the ruling party (informant 38). The discussion between the committee and the ministry was thus to make sure that the draft reflected this common policy. As noted by a parliamentary member, such discussions between the ASC and the ministry are usually in line with the discussions conducted between the ministry and the CoM (informant 35). The ASC also decided to conduct a public hearing session, to check if any issue had been left out, before passing the draft to the HoPRs for final endorsement (ASC 2012). The public hearing was open to the public, but participation was limited mainly to a representation of different governmental offices as well as the private sector, including the EHPEA. In the public hearing, the ministry was expected to clarify questions raised by the participants, and the issue of variety registration and seed sector governance were again the major focus of the discussion.

\footnotetext{
15 By this time, regional states were discussing the establishment of seed regulatory bodies, and discussions in Oromia regional state were at an advanced stage.
} 
In the case of variety registration, EHPEA questioned why the issue of exemption had been excluded, also indicating that it had been discussed in different fora, and had been agreed upon in earlier drafts (ASC 2012). For EHPEA, which had not been involved in the previous negotiations in the third round, the omission of the exemption of 'export-only varieties' was unexpected. From the ministry's side, the overall direction was registering all varieties, but it recognized the fact that capacity to provide the service was limited. As such, one informant acknowledged that the ministry had decided beforehand that if participants raised strong objections to the idea of registering all varieties during the public hearing, they would accept the exemption (informant 14). As soon as the EHPEA raised an objection, the ministry indicated that the case of export-only varieties would be dealt with separately. It was also pointed out that it would not be mandatory to register export-only varieties, referring to the existing directive, which the ministry released to allow the companies to import unregistered varieties before the revision of the seed law had begun (informant 7; ASC 2012). This was eventually indicated in the endorsed seed law under Article 17(2), which indicates that the ministry will issue a separate directive regarding the importation of unregistered varieties for exceptional cases (HoPRs 2013).

Similarly, the issue of seed sector governance was raised by those participants who had previously proposed the establishment of a national office. However, it was concluded by the state minister that this issue should not be part of the seed law and presented to the HoPRs. If necessary, the ministry can establish the office despite its exclusion from the seed law (ASC 2012). As indicated by one of the ASC members, the issue of the national office was not included in the justification that the ministry presented along with the draft law. The ministry limited the purpose of the law to creating a clear demarcation of responsibilities between regional and federal governments; specifying the quality control systems for different seed types; establishing standards for emergency seed; and establishing integrated seed production planning (informant 35, 36; ASC 2012). When the draft law was submitted to the Prime Minister's office, these objectives were listed in the official letter accompanying the draft. Since the ministry did not include the issue of establishing a national office in the objectives, the standing committee considered the issue to be outside the scope of the draft. As indicated by one of the senior experts in the ministry, even if the ASC accepted the idea of including a national office, in practice they cannot include it in the draft without the consent of the ministry. This is because, the ASC assumes that the ministry prepared the policy document based on the existing problem (informant 38). Thus, although theoretically the ASC has the right to make changes, they did not attempt to include the issue of establishing a 
national office, as the ministry had not accepted the suggestion of the participants during the public hearing (informant 7). Taking into consideration all the reviews and suggestions, the ASC updated the document and requested the ministry to provide its final comments on the edited version, which the ministry then endorsed without contest. The standing committee presented the revised draft and their positive recommendation to the HoPRs, and in January 2013 it was endorsed as proclamation No. 782/2013, and officially gazetted in February 2013 (HoPRs 2013).

\subsection{Policy arenas and actors shaping seed policy making}

In this section, the process of seed policy making in Ethiopia is analysed according to how policy actors and associated arenas influenced the process of developing seed law and its outcome based on the results presented in section three. Different policy arenas are analysed to understand how they provide opportunities to generate alternative policy options, and the power of individual actors in influencing the ultimate policy decision-making is then discussed.

\subsubsection{Policy arenas and policy output}

As indicated by Mayer, van Daalen and Bots (2013), arenas determine the extent to which actors have access to and influence over the policy making process. The main focus of the arena in the first round was on the experts developing the document, regardless of the opinions of other actors in the seed sector. In addition to the experts who drafted the policy, the ministry consulted experts from the Prime Minister's office to obtain comments before formally submitting the draft. There was no attempt to consult stakeholders about their perceived problems and solutions. As a result, the experts produced a draft document based only upon their knowledge and perspectives.

The needs to accommodate international markets dominated the second round of drafting the seed law, which made it important to adjust the arenas accordingly. Although the setup of the arenas was still with the experts developing the document, international consultants led the process instead of national experts. However, the consultants, who did not have in-depth knowledge about the Ethiopian seed sector, wanted to consult different actors in the seed sector, thereby altering the setup of the arenas. This gave stakeholders the chance to express their ideas and perspectives in the drafting process. Although it was not the original intention, by holding a workshop to stimulate more stakeholder discussions, the arenas expanded not only in terms of number and types of actors involved, but also the dynamics of their interaction. The workshop created an opportunity for discussions and negotiations among actors with different perspectives. 
The aim of the third round was to finalize and approve the draft. In order to prepare the final draft for submission to the ministry and the CoM, the arenas for finalizing the draft policy - i.e. revising the document and holding the workshop - were dominated by the MoA, regional bureaus of agriculture (BoAs), research institutes, the ATA, and seed companies. The domination of these actors in these arenas meant that the issue of exempting export-only varieties could be ignored, while the issue of seed sector governance could be brought back to the table. The CoM decisionmaking arena was an internal discussion among experts in the Prime Minister's office, members of the council and the ministry following the development of the draft policy. The final draft of the new seed law easily obtained the approval of the CoM: the experts in Prime Minister's office had commented on draft-1, and the final draft (draft-6) was largely in accordance with their comments four years back.

Before the HoPRs approves a draft policy, it has to pass through another important arena - evaluation by the standing committee. This arena comprises two rooms: the first is for the introduction of the draft document to the standing committee, and the second is for the public hearing. In the first room, the standing committee identifies any unclear issues, and requests the ministry to clarify. The purpose is to make sure that the committee understands why the ministry has proposed the policy, and to clarify any doubts that the committee may have. In fact, this room is where agreement between the standing committee and sectoral agency (in this case, the MoA) should be reached, and only if necessary is a public hearing called for. Public hearings organized by standing committees are open to anyone who wants to participate, and provide the last opportunity for different actors to express their views. In the case of seed law, the participants were limited to representatives of government offices, seed companies and the EHPEA. This arena provided the chance for actors to raise the issues of exempting 'export-only varieties' and establishing a national office, which were omitted in the preparation of the final draft by the ministry. However, the public hearing arena helped to get the exemption clause back into the new Ethiopian seed law.

Informally, the scope of the standing committee's evaluation of the draft is limited to maintaining the objectives set in the draft document, and identifying contradictions with any other policy or legal document. This is because the standing committee assumes that the executive has set the objectives based on the problems faced, and follows the policy direction of the ruling party. Comments are only considered if they help attain the objectives indicated in the draft, or if they concern potential contradictions with existing policy documents. However, the objectives in the draft are what the ministry intends to target, which may not necessarily address 
all the challenges in the sector. This then limits the potential of the public hearing to a discussion of issues within the objectives of the draft, and contradictions with other policy documents. The two issues focused upon in this chapter - variety registration and seed sector governance - are good examples of this challenge. Although both issues were contentious throughout the whole discussion leading up to the public hearing, the state minister accepted the argument of exempting 'export-only varieties', because rejecting it would contradict the existing policy of supporting agricultural exports. Conversely, the ministry rejected the idea of establishing a national office, as it did not contradict any existing policy and the ministry did not consider it to be a problem that limited the seed sector. Whilst the existence of different arenas has created an opportunity for actors to put their policy options on the table, the informal institutions that give the power to the ministry in the critical arenas has limited the potential contribution of the arenas to policy making.

\subsubsection{The policy actors and their influence}

Different policy actors, with different interests, aims and perspectives, took part in the policy making process. These actors included executive officials and experts inside and outside the ministry, the EHPEA, seed companies, the APHRD and the HoPRs. The different policy options and configuration of actors reflected the role of actors in the process. During this policy process, it was observed that some issues attracted the interest of some actors but not others. While the issue of seed sector governance was the concern of seed companies, it was not the case for the EHPEA. The opposite was true concerning the exemption of 'export-only varieties' from registration. This is because the seed companies and the EHPEA have different objectives to attain. The EHPEA is not in seed business, but they are users of seed of imported varieties, and they want to import seed easily. In the case of seed sector governance, the debate took place between the executive, on the one side, and the experts and seed companies on the other. This debate was a domestic governance issue, concerned with how to make sure that the seed sector operates more efficiently. The malfunctioning of the seed sector after 2004 was partly the reason behind the initial push towards revising the 2000 seed law. As a result, the experts and seed companies strongly argued for the establishment of a national office, but both had little power to influence decisively the final policy decision. Despite some decision-making power, the APHRD did not strongly support the idea, as they knew the ministry officials were not in favour of it. In the end, the ministry officials did not agree with the establishment of a national office, showing the exclusive power of the ministry in making decisions. 
Regarding the issue of variety registration, the experts inside and outside the ministry, and the EHPEA were the only two groups of actors that were negotiating on this topic, each with an opposing perspective on the policy, thereby making variety registration a contentious issue. Experts mainly see the issue of seed in relation to the smallholder farmers that dominate Ethiopian agriculture. For this group, the export sector is of minor importance and does not merit special privilege. However, the import of varieties without registration may pose 'risks' to smallholder agriculture, and the experts could also lose the possibility to oversee the import process in general. The experts dominated the process of drafting the new seed law, and therefore most drafts excluded the issue of exemption, except the first draft in which the APHRD asked the experts to include the issue, and the third draft, which involved external consultants. For actors from the horticultural sector, the export of horticultural products is in line with the government policy of export promotion, and they strongly pushed for the idea of exempting 'export-only varieties' from registration. Given the general policy privilege granted to the export sector, the ministry officials could not but accept the idea of exempting 'export-only varieties' from registration, as raised by the EHPEA during the public hearing.

Regardless of the technical and administrative reasons behind the actors' arguments, the configuration of policy actors differed for the two issues concerned. In the case of variety exemption, the major points of conflict were between the experts who wanted to control the system and the companies who did not want to be controlled. The horticultural companies had to play their political card - export promotion - to win the political interest of the officials that hold the actual decision-making power. In the case of seed sector governance, although the experts and the seed companies were aligned, their power of influence was not strong enough to convince the officials. As a bureaucratic department within the ministry, the APHRD, has a vested interest in the management of the seed sector at national level. This is also because experts in the APHRD are loosely connected to the activities in the regions, and they are interested in controlling the sector. However, this is not the direction of the ministry officials, and the APHRD had at times to play an internal mediatory role between the experts and the ministry officials. Yet, in the discussions outside the ministry, the APHRD only presented the position of the ministry officials, in order to be politically correct.

The standing committee plays critical role in getting the HoPRs to reach a decision. The role of the standing committee is to provide recommendation to the HoPRs by carefully analysing the draft, inviting independent experts for consultation when necessary. Unfortunately, the standing committee assessed the draft policy based 
on the information from the MoA and the legal experts who support the HoPRs. Consequently, the standing committee only saw the perspectives of the ministry and did not consider the views of other stakeholders or any other independent body. This prevented the standing committee from evaluating the draft from different perspectives. The standing committee relied heavily on the ministry partly because of the shared policy direction of the ruling party.

\subsection{Discussion}

As indicated above, the new actors and associated arenas have contributed to the emergence of policy options from the perspectives of actors that took part in the process. While this is a positive step forward, the opportunity was not fully utilized in the Ethiopian policy making process mainly for two reasons. In the first place, the different arenas are not systematically linked to one another, and secondly, the separation of power between the executive and the legislature is blurred, with the executive dominating the policy making process. In the following sub-sections, the argument is elaborated in more detail.

\subsubsection{The loosely connected arenas}

Different arenas were used in developing and enacting the seed law. Some of the arenas focused on drafting, which also involved negotiations between actors with differing perspectives. During the second round for instance, there were clear differences among participants as to how the policy options for both variety registration and seed sector governance should be formulated. While participants from research institutions, experts in the ministry and seed company representatives argued for the establishment of a national office, the ministry, represented by the APHRD, argued that such a decision should be left to the ministry. The second round was concluded without coming to an agreement as to how to structure the governance of the seed sector. Similarly, in the case of variety registration, there was a difference of opinion between experts from the ministry and researchers on one side, and the EHPEA on the other side. This difference could be observed vividly in the third round, when the decision made in the second round was changed in the absence of the EHPEA. The differences in opinion were not resolved in either case.

The CoM is where the policy document is practically approved: none of the documents submitted to the HoPRs have been rejected since the establishment of the parliament (Alemu 2015). Formally, the draft is sent from the ministry to the Prime Minister's office, accompanied by a letter. However, the letter from the MoA does not explain the debates and the perspectives of different stakeholders, in terms of policy options and why the option in the draft has been chosen. Rather it presents the perspective of the ministry, and the ministry frames the problem and the 
solutions included in the draft document based on its own perspective. For the CoM, what the ministry presents is sufficient, and the perspectives of other actors are not considered. Similarly, when the approved document was passed to the HoPRs, only a summary letter was written, which did not indicate any debate among actors. Thus, the critical decision-making arenas, the processes in the CoM and the HoPRs, were detached from the arenas where reflection and discussion on policy options among actors took place. In Article 50(8) of HoPRs regulation 3/2006, requirements for submitting draft laws are listed, but this list does not include information about prior negotiations (HoPRs 2006). This suggests that the HoPRs believe that there is no need to share discussions held in the earlier consultations. As will be discussed later, the policy formulation is based on the policy and strategy of the ruling party, which are shared equally by the legislature and the executive. Thus, the CoM and HoPRs accept the preceding decision neglecting any other idea that might have emerged in the process.

\subsubsection{The blurred separation of power}

The above analysis shows that although the actors and arenas influenced the process of policy making, the final policy decision remained firmly in the hands of the executive, which strongly resembles former regimes in Ethiopia. Two decades have passed since the constitution separated the powers of the executive and the legislature, and yet it is not clear from the outset why policy decision-making ultimately remains in the hands of the executive. This requires a close look at how the two are structured, and the extent of separation of power in policy making. One party dominates the Ethiopian HoPRs, and during the period of 2010-2015, 99.6\% of members of the HoPRs were from the incumbent political party or its allies. Likewise, the executive is composed of ruling party members selected by the ruling party from among the HoPRs members. This is important for the ruling party to control both the executive and the legislative wings of government (Lefort 2013). Moreover, the party reserves executive positions for more capable and experienced members of the HoPRs, and thus they develop policies. The less experienced members remain in the HoPRs to evaluate and enact the draft policies (Abebe 2005). Such disparity in capacity between the ordinary members of the HoPRs who enact policies, and members of the executive who draft policies, increases the dependency of the legislature on the executive. Furthermore, compared to the ordinary members of the HoPRs, members of the executive are at a higher political position in the party, which is important for controlling junior members in the HoPRs. Abebe (2005) in his earlier research on policy making processes in Ethiopia also noted a heavy dependence of members of the legislature on the executive: 
Having seen no difference between party and the executive leadership, some ruling party members of the HoPR have bestowed enormous trust on the executive, in terms of the capability to articulate policies and the competence to implement them. They are very strongly and candidly of the view that not only they have no objections to the executive presiding over or prevailing on the entire policy making process, but there is also nothing wrong for the executive to command an overwhelming influence, for many of the persons in the executive are members of the HoPR representing their positions. They further contended that officials in the executive are also in the political leadership (or are party leaders); thus, they are in a better position than the legislature to be able to articulate and forge policies along party lines (Abebe 2005: p. 218).

Such dependency limits the role of the HoPRs in legitimizing the policy developed by the executive. Alemu (2015) noted that the executive proposed 100\% of the bills during the government's fourth term (2010-2013), and the HoPRs endorsed them all. The fact that all the policies were proposed by the executive, and that all were endorsed, shows the undisputed power of the executive in the policy making process. A decade after Abebe's observations about the domination of the executive, and almost two decades after the instalment of parliament as the legislative body, the power of the executive in policy making remains the same. Alemu (2015) also confirms this in his recent research about policy making practices and challenges of the HoPRs:

All of the responses of the MPs explicate that the reason they hold up to initiate law is, for one thing, they understand that the task of the legislature is to promulgate the policies proposed by the executive and to oversee their implementation; they rather mull over themselves only to approve detailed legislation/law than as formulators. Secondly, they believe the ability of the MPs' is not as such competent compared with the executive to propose well-informed policy ideas (Alemu 2015: p. 148).

Our findings suggest that the separation of power between the executive and the legislature in Ethiopia is orchestrated by the ruling party under which this separation has evolved as a mere division of activities within the government. The ruling party has assigned more power to the executive, making it difficult for the legislature to play a pro-active and meaningful role in the process. More importantly, the ordinary members of the legislature have accepted the supremacy of the party and the executive in terms of policy making, limiting their roles to just approving the policies designed by the executive (Alemu 2015). Such obedience is very much linked to the democratic centralism of the party system and the blurred boundaries between the executive and the ruling party. This centralism promotes 
accountability to the party instead of to the legislative that is supposed to play a direct role in policy making (Aalen 2006; Lefort 2013). As such, the introduction of a formal government structure that separates power between the executive and the legislature does not define the policy making process in Ethiopia. In the Ethiopian context, the party system provides the underlying rules and values of formal structures in the policy making process. In principle, the executive has only the leverage to propose a policy option. In reality, the executive has much more power, and can enact policy options regardless of their acceptance by other actors. 


\title{
Chapter 3.
}

\section{Unpacking the paradox of governance solutions for seed quality in Ethiopia}

\begin{abstract}
This chapter addresses one of the most controversial issues that arose during the revision of the 2000 Ethiopian seed law: the governance of the seed sector to improve seed quality. Whereas all actors agreed that seed quality is one of the major problems, divergent views existed on the main causes of the problem and its solution. The central question addressed in this chapter is how different actors framed the causes for, and solutions to, the problem, and how differences between the opposing frames might be explained. In this study, two opposing frames have been identified: the decentralization frame and the centralization frame. The chapter provides a two-layered explanation of the outcome of the policy making process: lack of reflexivity and deliberation in policy making, and structural features of the political regime. By doing so this chapter unpacks the paradox of governance solutions for seed quality.
\end{abstract}




\subsection{Introduction}

Following the overthrow of the socialist regime in 1991, the Ethiopian government adopted a multitude of policies to guide the change from a centralized government to a federal state, and from a planned economy to a market economy. In 1991, the government created regional states that were constitutionally established in 1995. As indicated in Article 52(2b) of the constitution, the regional states are accorded the power to formulate and execute social and economic development policies, strategies and plans of the state (HoPRs 1995). In 1992, the government developed the agricultural development-led industrialization (ADLI) strategy. Several fiveyear economic development and poverty reduction plans followed. Given its key role in economic growth, agriculture remains high on the priority list of economic policies and strategies (Teshome 2006).

Ethiopia experienced high economic growth, albeit from a low base, averaging $10.9 \%$ per year from 2004/05 to 2012/13, and this is high compared to the $5.3 \%$ average of sub-Saharan Africa (World Bank 2014). However, the government feels that there are still steps to be taken to improve agriculture, as development goals have not yet been reached (Spielman, Mekonnen and Alemu 2013). The government considers the development of the seed sector as a critical step to increasing agricultural productivity and food security. This has resulted in a series of programmes, laws and regulations directed at improving different dimensions of the seed sector.

In 1992, the general seed policy was drafted; in 1997, the seed regulation was issued; and in 2000, the seed proclamation was declared (HoPRs 1997; HoPRs 2000). These policy documents emphasize the importance of improving seed quality, and provide the legal basis for ensuring this is achieved. However, full implementation of these policies is lacking partly due to the changing institutional setup. In 1993, a sectorspecific agency, the National Seed Industry Agency (NSIA), was launched to govern the seed sector. In 2003, the agency was merged with the National Fertilizer Industry Agency (NFIA) to form the National Agricultural Input Authority (NAIA); in 2004, this authority was dissolved and the Ministry of Agriculture (MoA) took over the governance of the seed sector. Though the government placed more emphasis on increasing seed production by setting various ambitious goals, the supply of seed is far from hitting the targets. During the period 2005-2008, the supply of maize and wheat seed, the major crops in formal seed production, was $47 \%$ and $26 \%$ of the planned level, respectively (Alemu and Tripp 2010). In 2009/10, the supply of maize seed comprised only $50 \%$ of the demand, showing a considerable gap between planned and actual seed production (Atilaw and Korbu 2012). 
The shift in attention towards seed production, and the changing organizational structure governing the seed sector, also exacerbated the problem of seed quality. As a result, low quality seed, which is below the standard set for certification in terms of germination, moisture, and physical and genetic purity, has been distributed to farmers by seed producers, particularly since 2004 (AGP 2009; Alemu 2011; Bishaw, Sahlu and Simane 2008; IDLO 2010; Sahlu 2012). Seed quality remains to this day one of the major problems of the seed sector. Seed quality is affected not only by the regulatory standards, but also by how these standards are implemented and governed, which needs to be specified in a policy. To overcome the seed quality problem and other challenges in the seed sector, the seed proclamation of 2000 was revised in 2013. However, not all actors working in the seed sector warmly applauded its release. This discontent did not just appear after the launch of the new seed law, but was prominent during preparations of various drafts of the new seed law. This chapter concerns one of the most controversial issues of the seed law: the governance of seed quality. The two central questions of this chapter are: how have different actors framed different governance solutions to the problem of seed quality; and how can these different frames and the decision-making on the governance of seed quality be explained?

To address these questions, this chapter is organized as follows. The next section (3.2) explains why and how the analysis of frames can be helpful for understanding policy making processes. This is followed by a briefing on the methods of data generation and analysis (3.3). The challenges of the Ethiopian formal seed system, as linked to seed quality governance, are then revisited (3.4), followed by a discussion on how different actors have framed governance solutions to the problem of seed quality, and how these frames were used and challenged in the process of revising the 2000 seed law (3.5). A two-layered explanation of the nature and persistence of frames is presented to unpack the paradox of governance solutions for seed quality in Ethiopia (3.6). With this, the chapter concludes its contribution to a better understanding of the complex relationships between policy making and politics in Ethiopia as integral parts of governance issues (3.7).

\subsection{Frames and framing}

Frame analysis can help to analyse how actors involved in the policy making process use language to mobilize key stakeholders to win support for a course of action (Fletcher 2009). The use of language to win support links frame analysis to discourse theory, which in turn is based upon a social-constructivist epistemology that rejects the notion of universal truth and is sceptical about concepts such as objectivity, proof and knowledge (ibid). The concept of frame and associated framing processes has 
thus drawn the attention of scholars in several areas of social sciences, including the study of public policy (White 2013).

This chapter considers problem statements that are used to justify public policies not as something that exists as a fact that one has to discover, but rather as social constructions (Coburn 2006). Thus, the process of policy making can be characterized as a 'wicked problem' in which the finding and formulation of the problem is the problem (Head and Alford 2013; Rittel and Webber 1973). It all depends on how actors perceive a circumstance and frame that as a problem. In the process of framing, guided by value judgements, some aspects of a perceived reality are considered undesired and selected to be a problem. Then, some particular causes and effect are constructed to explain how a selected solution will solve the problem (Entman 2003).

Whereas the framing of a solution can very much reflect the framing of a problem, their relationship is not self-evident. It is very common that during policy making processes different solutions are proposed to address a problem. The process of formulating solutions can refer to another typical characteristic of wicked problems, which is that every problem may be a symptom of a higher level or deeper problem. This means that different solutions to a shared problem may not simply reflect different ways to tackle this problem, but different ways to address a higher-level or deeper problem.

Though frames are often not officially or explicitly referred to during complex and dynamic processes of policy making, they provide a structured narrative and discursive tool that can help to legitimize certain policy measures or governance solutions, and delegitimize and neglect others (Laws and Rein 2003). The way in which a particular policy problem is structured not only creates rationales that authorize some policy solutions and not others (Benford and Snow 2000), but also assigns responsibility (Schneider and Ingram 1993). At the same time, frames are often contested and challenged during policy making processes, possibly leading to the adjustment of a frame or the emergence of a counter frame (Hall 1993; Park, Daly and Guerra 2013). A frame can be used to control negotiations with particular actors, but also to evoke and restructure negotiations, possibly inviting new actors. However, this very much depends on the reflexivity and the extent to which the policy process is deliberative. Reflexivity refers to the ability to reconsider one's frame and to appreciate different frames that are emerging in a policy making process. Similarly, deliberation focuses on the style and nature of problem solving through communication and collective consideration of relevant issues (Fineberg and Stern 1996). 


\subsection{Data generation and analysis}

Empirical data used in this study are based on semi-structured interviews with 40 informants who were involved in the process of revising the 2000 seed law, as well as a desk study of documents related to the Ethiopian seed policy making process between 2008 and 2013. The interviewees include experts in government and nongovernment offices, managers of seed companies, researchers, consultants, and members of parliament. Some of these actors were interviewed more than once. The semi-structured interviews focused on two related sets of issues: first, the perceived problems and solutions for the seed sector in general, and seed quality in particular; and second, negotiations to reach to the final policy document. In addition, different written documents, including reports and minutes of meetings, were used to analyse the policy making process. These interviews and written documents were used to reconstruct frames on governance solutions to address the problem of seed quality. All the interviews were transcribed and uploaded to Atlas.ti for analysis.

Keeley and Scoones (2000) used discourse analysis to show how actors frame different problems and solutions in agriculture in Ethiopia. They indicated that discourses and frames are established through strong networks of actors, which ultimately guided policies in agricultural intensification and the environment in Ethiopia (ibid). Here, the concept of frame is used to show how actors define the cause of seed quality problems and governance solutions. Considering frame as a social construction that refers to a shared reasoning of actors, the languages that actors employ, consciously or unconsciously as a strategy to influence the outcome of the process, were analysed (Schön and Rein 1994; Weick 1995). These languages, consisting of rhetoric and storylines give meaning to the problem of and solution to seed quality in Ethiopia. Following Hardy, Lawrence and Grant (2005), interview transcripts that had rhetoric, sequentially linked in a particular context, were identified and coded in all the transcribed texts as a primary code, and any further explanations were used as a note attached to the primary codes. Since actors do not declare their expression as a frame, this is an interpretive frame analysis of transcriptions of interviews (Vink 2015). These primary codes with all their notes were grouped and regrouped into families, which helped to bring all primary codes with a similar context together. The regrouping continued by dropping less frequent rhetoric and by maintaining more frequent ones. Moreover, different reports were also cross-checked for the existence of these frames. Reflecting on the notion that frames can change and be changed, whether and how different actors adapted their frames during the policy making process were analysed. The different quotations linked to the primary codes and notes were further analysed to understand why actors use a particular frame to describe the problem of and solution to seed quality. 


\subsection{The challenges of seed quality governance in Ethiopia}

Over the last five decades, the Ethiopian formal seed system has passed through different types of governance systems. To better explain the development of the formal seed system and seed quality governance, the duration can be divided into three relatively homogeneous periods: before 1992, 1992-2004, and after 2004. The first is the period in which formal seed production began. Although there were some seed production activities with the establishment of the agricultural research system in 1960s, large-scale formal seed production started in 1979 with the establishment of the Ethiopian Seed Corporation. The Ethiopian Seed Corporation produced seed for state farms, and towards the 1990s the supply of seed was also extended to farmer producers' cooperatives ${ }^{16}$. During the first period, the Ethiopian Seed Corporation was part of, and produced seed exclusively for, the state farms. There was no external regulation for seed production in this period.

The beginning of the second period was marked by the establishment of a new political regime geared towards federalism and market economy. During the second period (1992-2004), the government laid the regulatory foundation for the formal seed system. In 1992, the first seed policy was drafted, which emphasized the coordination and regulation of the seed sector. Moreover, the Ethiopian Seed Corporation was reorganized to operate independently of the state farms as the Ethiopian Seed Enterprise (ESE) in 1992, and it started catering for small farmers.

In 1993, the government established the NSIA to govern the seed sector. The government enacted the first seed regulation in 1997, and replaced this regulation in 2000 with seed law. The law was more comprehensive and clarified roles and responsibilities of the various actors in the seed sector. In this period, seed production increased because of a nationwide extension programme that began in 1995, and which reached 3.8 million demonstration plots in 2000 (Spielman et al. 2010). The extension programme triggered more seed demand, which led, for instance, to an increase in the production of seed by the ESE from 13.6 thousand tonnes in 1995 to 25.3 thousand tonnes in 2002 (AGP 2009). In addition, the government also initiated the Farmer-Based Seed Production and Marketing Scheme (FBSPMS) in 1997, and by 2001 seed production under this scheme had reached 14.8 thousand tonnes (Sahlu 2012). Regardless of the expansion of seed production, there was no external seed quality control until early 2003/4 when the NSIA established

\footnotetext{
${ }^{16}$ In this thesis, unless specified, the term 'cooperative' refers to a multipurpose association of farmers that is organized and registered by the government through a cooperative promotion agency; its business mainly involves supplying inputs required by farmers, and marketing agricultural products.
} 
ten laboratories (Sahlu 2012). As such, seed sold by the ESE was not externally certified before this (McGuire 2005). In 2003, the NSIA was combined with the NFIA to form the NAIA. This authority took on the responsibility of governing both seed and fertilizer, but was dissolved by proclamation 380/2004, and all the roles and responsibilities of the authority were transferred to the MoA.

The third period is characterized by increased seed production to satisfy the demand of the nationwide extension programme, and the start of external certification of seed. During the beginning of this period, almost all seed produced was for the agricultural extension programme (McGuire 2005). The increased seed demand forced the government to reinitiate the FBSPMS in 2004, which had been halted in 2001 , producing about 27 thousand tonnes in 2007, and about 17 thousand tonnes in 2008 (AGP 2009). Moreover, in 2008 and 2009, the regional governments established three more public seed enterprises. As a result, the amount of certified seed produced by public seed enterprises increased from about 25.3 thousand tonnes in 2002 to over 62.9 thousand tonnes in 2012 (ATA 2013). Furthermore, the number of private seed companies increased during this time from only one company in 2003 to more than 30 in 2010. In the ministry, few experts were responsible for coordinating the seed sector. Moreover, the established laboratories and their coordination were transferred to the regional bureaus of agriculture, weakening the link between the ministry and the laboratories.

The increased seed production and weak governance structure resulted in poor seed quality. Several studies and reports on the seed sector in Ethiopia conclude that the quality of seed supplied to farmers has deteriorated (AGP 2009; Alemu and Tripp 2010; Bishaw 2008; IDLO 2010; Sahlu 2012). A 2010 report by IDLO clearly noted the difference between the actual quality of seed and the label. The report stated 'although all commercial seed in Ethiopia is labelled as certified, there is a disjuncture between certification and the actual quality for the majority of seed' (IDLO 2010: p. 4).

A study report on the formal seed system by the Agricultural Growth Program (AGP) described a similar situation, indicating that only a small proportion of seed supplied through the formal seed system is inspected as required to label it as certified (AGP 2009). Others also concluded that the major reason behind poor seed quality was related to the fact that although a policy already existed on paper, it had not been implemented properly (Alemu and Tripp 2010). However, different actors have different perceptions of the cause of the problem. The following section describes how different actors frame the causes of and solutions to the problem of poor seed quality in Ethiopia. 


\subsection{Frames and negotiating frames}

\subsubsection{Frames of causes of the seed quality problem}

This study reveals two different frames that were utilized to explain the main causes of the seed quality problem during the process of revising the Seed Proclamation 206/2000: the decentralization frame and the centralization frame. The decentralization frame is used by ministry officials, and the centralization frame is used by bureaucrats ${ }^{17}$, researchers, experts and the private sector, among other actors in the Ethiopian seed sector. Both frames share the same problem that seed quality has deteriorated in Ethiopia, but they differ on the causes of the problem and subsequent solutions. The users of the centralization frame focus on the lack of national level coordination of the seed sector as the major reason behind poor seed quality. Their proposed solution was the creation of a central coordination structure, details of which they sought to integrate into the new seed proclamation. The decentralization frame is an opposing frame that argues that the poor seed quality was caused by not implementing the decentralization policy of the government. The solution for the seed quality problem according to this frame is to formalize the division of responsibilities and fine tune the existing seed proclamation to the general process of decentralization. In the following sections, the details of both frames are presented.

\section{The centralization frame}

The users of this frame compare the 'strong' centralized seed governance system of the period 1993 - 2004 with the period that followed. They believe that a lack of coordination of the seed sector has affected seed quality. One seed company manager, for instance, attributed the deterioration of seed quality to the low emphasis placed on seed quality control by the government, and subsequently proposed the establishment of a centralized governance structure that will ensure seed quality.

Now there is no owner for the seed sector. No one governs the seed sector. Because of this, quality of seed is declining. Those who work now [in the ministry and in the laboratories] are poorly staffed and facility is poor and thus, if we want to give

\footnotetext{
${ }^{17}$ In this thesis, the term 'bureaucrats' refers to directors or department heads and section heads in the ministry or regional bureaus of agriculture, while 'government officials' refers to representatives of the government at different levels, including ministers, state ministers and regional bureau heads.
} 
attention to seed, a structure should be in place that is responsible for the overall governance of the seed sector (informant 11).

The informant regarded the absence of coordination at national level and the poor service provision at lower level as the main reasons for poor seed quality. Some informants indicated that laboratories were lacking capacity by stating 'it was just dead, and nobody was there' (informant 5). When the regions made an inventory of the number of staff needed to fully capacitate the laboratories in 2012/13, the existing staff comprised only $22 \%$ and $17 \%$ of optimum requirements in Amhara and Oromia regional states respectively (ABoA 2013). The lack of capacity of the laboratories to provide adequate seed inspection services is explained as a consequence of the lack of coordination of the seed sector in general.

One important feature of this frame is the use of the term 'owner' to question the existence and extent to which the coordinating system takes full responsibility. This is very much linked to the changes made to seed sector governance in 2004. From 1993 to 2003, the NSIA (as the agency mandated to coordinate seed), and in 2003/04, the NAIA (as the authority mandated to coordinate seed and fertilizer), were responsible for the overall governance of the seed sector. According to the users of this frame, the seed sector was strong and well organized during this period. Through regulation 380/2004, the government dissolved the NAIA and transferred seed sector governance to the MoA, and the ministry decided to decentralize the governance of seed laboratories to the regions. Moreover, the other components of the seed sector (variety release and registration, seed production and marketing), remained at national level but were divided among two different directorates in the ministry. Users of the centralization frame consider this arrangement as unsuitable for providing the necessary services, and recommended the establishment of an alternative system of coordination:

In case of seed, we have been talking for long to establish an independent body. The current arrangement is not suitable to get services. If there is an issue on seed, where will you go? .... For seed issue, there is no focal point. You call it section, unit, whatever, there is nothing. We always raise this issue, but the government always says what is wrong with the current structure (informant 9).

According to this informant, the suggestion to establish an independent body to coordinate the seed sector is not a new idea; however, the government is not convinced that the current arrangement does not work. 
Although the ministry transferred the coordination of the laboratories to the regional states in 2004, the regions were not ready to take on this role. As one informant stated, 'the laboratories were just given [to the regions]' (informant 5), indicating that the transfer was not planned. For users of the centralization frame, seed sector coordination was neither established at the ministry level nor at the regional state levels after the NAIA was abolished. In the process of transferring some of the NAIA's role from the ministry to the regions, the coordination system was overlooked. For instance, one informant who was in one of the laboratories during this period described the lack of planning and the challenges involved in the transfer process as follows:

Because this is a sudden assignment [the transfer of the laboratories to the regional states], it was difficult for the regional bureau of agriculture to fit the laboratories into the existing structure of the bureau. Everyone [in the bureau] says we are not responsible for laboratory issues and we [the laboratory staff] suffered a lot. The regional bureau of agriculture was not prepared in advance and they didn't know the work load of the laboratories and its complexity. As a result, they couldn't support the laboratories with logistics and budget (informant 25).

Thus, the laboratories did not receive proper attention from the government and lacked the necessary resources and capacity to ensure seed quality (informant 5, 14, $25,30)$. The solution for this problem as presented by this frame is to create an independent structure at national level, which would coordinate the seed sector and provide the necessary resources to ensure seed quality.

\section{The decentralization frame}

As described above, the NAIA was dissolved and the coordination of the seed sector became the ministry's responsibility. However, according to one senior expert in the ministry, the ministry foresaw the difficulty of inspecting seed production with existing manpower in the ministry and, therefore, decentralized this role to the regions (informant 7). Although the management of the laboratories was decentralized to the regional states, this was not legalized, and there was no clear demarcation of roles and responsibilities between the ministry and the regional bureau of agriculture with respect to seed quality assurance. In late 2008, the ministry decided to start the process of revising Seed Proclamation 206/2000, and from the ministry side this was to demarcate the roles and formalize the decentralization. 
The decision to revise the seed proclamation was further supported by the observation amongst officials that the proclamation no longer matched 'the current developments of the country' (informant 14). In 2000, when seed proclamation 206/2000 was developed, regional states were not considered strong enough to assume all responsibilities as anticipated in the constitution that established the federal system in Ethiopia. As a result, no specific role regarding seed was given to the regional states in Seed Proclamation 206/2000. Since the establishment of the regional states in 1995, the regions gained experience and assumed more roles, and thus the ministry concluded that the role of quality assurance could be transferred to the regions. Given the increased strength of the regions and the fact that the ministry had already transferred the coordination of the laboratories to the regions, the 2000 seed law was considered outdated. The ministry had drawn experts from different government offices to draft a new proclamation in late 2008. The ministry explained to the drafting team that they needed to align the seed proclamation to the current development of the country. One of the experts who was in this team explained:

[The ministry representative said] you [the drafting team] are all from the seed system and you know the problems of the seed sector. You have to see [the revision of the proclamation] in terms of government direction, and the current proclamation does not go with the government decentralization system. First, the federal system is now organized and the seed proclamation has to be fine-tuned to this development (informant 4).

This idea was explained again by representatives of the ministry ${ }^{18}$ during the March 2010 workshop that discussed the draft seed proclamation, and again by one of the state ministers of the $\mathrm{MoA}^{19}$ during the public hearing organized by the parliament's ASC in 2012:

When the floor is given [to the state minister] to give briefing, [the state minister said] under current stage of development of the country, the existing proclamation has to be changed.... The existing proclamation does not show clearly the relation between the federal and regional states. With this proclamation [referring to the revised draft], the roles and responsibilities are clearly demarcated.... (ASC, 21 December 2012).

\footnotetext{
18 The director of the APHRD represents the ministry during the discussion about the drafts, with different actors and in different workshops.

${ }^{19}$ In Ethiopia, usually there is more than one state minister accountable to the minister in a given ministry. For instance, during the study there were four state ministers in the MoA.
} 
The public hearing took place towards the end of the revision process, four years after the process had been initiated. The original idea of the ministry, which was passed onto the drafting team, was indeed maintained throughout the whole revision process. The ministry officials wanted to make sure that the new law would be aligned to the federal structure, with roles and responsibilities clearly demarcated between the federal and regional states.

\subsubsection{The process of negotiating frames}

In the process of policy deliberation, where frames are contested and negotiated, actors may choose to reframe in an attempt to influence the course and outcome of the policy process. In this section, the process of negotiating the revision of the seed proclamation in Ethiopia is described. The users of both frames made some attempts to adjust their proposed solution to the seed quality problem in order to make it more acceptable to users of the opposing frame. However, the space for deliberation was narrow as the dominant frames were not openly reflected upon, and the willingness to negotiate towards alternative policy options was very limited.

The drafting team of experts supported the idea of establishing an independent body responsible for seed sector governance. Though the ministry informed the drafting team beforehand that one of the major interests of the government is decentralization, the team proposed the establishment of an independent body at national level. However, the proposal of the team was rejected when experts in the office of the Prime Minister reviewed the draft, as indicated by one of the members of the drafting team:

We [the initial team of experts involved in drafting the proclamation] were informed [by the Ministry of Agriculture] that there is feedback on the draft that we have submitted. We have seen the comment and it is far from what we have done. I think they [the government] have their own way of thinking since it deviates a lot from what we thought. The view that the government has a different perspective became clear now. Our major focus was on establishing an independent body. We thought about one window for the seed sector (informant 4).

The drafting team, after realizing the difference, searched for a way to convince the ministry to create a structure to coordinate the seed sector. However, the ministry rejected the idea, partly because it felt that the proposal would not be in line with the government's reform programme of business process re-engineering (BPR):

We [the drafting team] told the ministry that the seed administration is the critical gap and we suggested a national forum to discuss on our proposal [creating an independent body]. Because our proposal was not in line with BPR, the ministry did 
not agree. ... They said it is not possible to organize the seed sector independently..... We said, let us organize a national forum and let the stakeholders decide whether establishing an independent body is useful or not. If they [stakeholders] do say so, we have to include it in our proposal (informant 4).

BPR is a national reform programme that started in 2003. BPR is considered by the government as a major vehicle to overcome the structural problem of providing efficient services in government offices. The BPR mainly focused on reducing lengthy processes of service delivery, and aimed to merge different departments and sections. The transfer of responsibilities from the NAIA to the MoA in 2004, and the minimum number of staff working on seed after the transfer, was considered to be in line with this reform programme. Therefore, the proposal of the centralization frame users to establish an independent body at the national level to coordinate the seed sector was considered to go against the reform programme and was not accepted by the ministry.

Moreover, while no technical justification for the termination of the NAIA had ever been provided, the proposal to establish an independent unit was indirectly a request to reinstate the NAIA. The head of the NAIA found out that his institution was being dissolved only when the decision ${ }^{20}$ had already been made public (informant 37). None of the other informants, including those in the ministry, could or would explain the reasons why the NAIA had been dissolved. Below, one informant shares his experience:

I remember once I asked the same [why the NAIA was dissolved] to the state minister and the state minister said 'Yes, many raise the same question to me. Government analysed and decided this is good. Why you raise this? What is wrong [with the current structure]? We [the government] are doing a better job. ...... The government does what the government believes is right.' I remember one of the state ministers said like that. He was very much disappointed by my question (informant 9).

In this case, the state minister did not explain why the NAIA had been dissolved but simply emphasized that the government has the authority to do what the government believes is right. The users of the centralization frame came to understand that due to a lack of political will, there was little chance that their plan to introduce a new organization similar to the NAIA would be accepted. According to another informant, there was no doubt about the importance of having an

\footnotetext{
${ }^{20}$ Proclamation 380/2004.
} 
independent body, but since there had been no justification for dissolving the NAIA, it would be difficult for the MoA to justify the establishment of a new structure with a similar mandate:

The big challenge [of the seed sector] is the organizational setup. With respect to the organizational setup, there is no political will to reinstate an organization that was abolished. Everybody believes in the first place the three [seed marketing, variety release and quality control] should be organized as one. But they [the ministry] abolished the agency and it was difficult to reinstate it (informant 13).

Peculiarly, experts in the ministry also agreed to the need of having a separate organization to govern the seed sector (informant 15). The team responsible for drafting the new seed proclamation also included experts from the ministry, and they supported the idea of establishing a centralized governance structure to coordinate the seed sector. However, according to some informants, these experts could not officially or publicly sympathize with this view (informant 7,31 ).

In response to repeated calls to establish an independent body to coordinate the seed sector, ministry representatives suggested to include an article in the proclamation that would give the ministry the responsibility to define how the seed sector would be governed in the future (informant 4). Similarly, the users of the centralization frame started to propose different ideas, which included having a coordinating unit under the ministry, regardless of its status as indicated by one informant: "It does not matter whether it is an independent agency or within the ministry or something else, but someone has to coordinate the seed sector" (informant 13). In a presentation made at a national workshop on seed sector development in 2011, Gorfu et al. (2012) proposed the establishment of a seed inspection system at least to the level of the seed agency that used to govern the seed sector, with some levels of decentralization.

Although it was hoped that these proposals would narrow the gap between the two frames, differences still remained on how to include the new proposal in the proclamation. While the ministry representatives proposed to only indicate that the ministry would decide how the seed sector would be governed in the future, the centralization frame users were not sure if the ministry would eventually establish such a structure, and voiced their opposition by saying: " no, this is not possible... we don't leave that [the decision as to how the seed sector will be governed in the future] open" (informant 4). Instead, the users of the centralization frame wanted to specify the coordinating structure in the proclamation, to make sure that the ministry would establish it. As the users of the centralization frame were not able to agree with the proposal of the ministry representatives, they requested the ministry representative 
to leave the final decision to the officials (informant 11). This strategy was explained by one of the drafting team members as:

Since the ministry gave us the responsibility [to draft the seed proclamation], we have to suggest an efficient and effective institutional setup. We have to say this is the way the seed sector is governed in the world, and recommend what is good for Ethiopia. If they [the ministry officials] do not agree, they can cancel it, but you [the representatives] do not have the right to cancel our proposal (informant 4).

When the proposal was eventually taken to the minister, however, users of the centralization frame got a negative response, as described by one informant:

When it was taken to the minister, the minister said you take this idea out. When we asked why, the minster indicated that establishing such office is the authority of the ministry, and therefore it should not be included in the law (informant 15).

According to the minister, the ministry already had the authority to establish such an office, and so it should not be included in the proclamation to be approved by the parliament. Furthermore, during a public hearing, the state minister also indicated that if it is necessary to establish a different organization, it will be treated separately from the proclamation:

Although the seed quality inspection is done at both federal and regional levels, there was no time when we did not have the problem of seed quality..... Thus, it is difficult to say the ministry alone will handle all the seed farms and laboratories. At the same times, establishing branches [offices under the ministry] is not economical. Thus, it is important to link the quality inspection issue to the regions. .... With respect to who will oversee the regions, under the existing condition, it is the ministry. If the question is to establish a different structure for this purpose, this will be an organizational issue to be treated differently (ASC, 21 December 2012).

So, the state minister neither accepted the idea of establishing an independent body at national level, as supported by the users of the centralization frame, nor did he accept the counterproposal made by ministry representatives to include a provision in the new proclamation that would authorize the ministry to specify how the seed sector will be governed. Instead, he emphasized that it would be impossible to do either of these because of procedural reasons. However, one informant from the ASC of the parliament indicated that the structure of the seed sector could be part of the seed proclamation if it was included in the objectives of the draft (informant 34). So, the state minister's rejection of the proposals of both the users of the centralization 
frame and the ministry representatives, on the basis of procedural reasons, was probably merely an act of non-deliberation.

\subsection{Analysis}

A two-layered explanation can be used to describe the nature and persistence of the two frames. The first layer concerns the limitation of deliberation and reflexivity in policy making processes in Ethiopia. Whereas an analysis of this layer can explain the persistence of the two frames, it does not explain their nature, which forms the second layer and presents a paradox embedded in the two frames - namely that those holding power, and who are usually criticized for centralizing power, argue for decentralization, while those not holding power urge for centralization. A key organizing principle of policy making in contemporary Ethiopia is analysed in order to unpack this paradox.

\subsubsection{Lack of reflexivity and deliberation in policy making}

An analysis of the process of negotiating the revision of the 2000 seed proclamation shows that no consensus could be reached about the governance solution for the problem of seed quality. The users of the decentralization frame and the centralization frame were unable to convince each other of their rationale, and did not change their definition of the main cause and solution to the problem. The following characteristics of the negotiation process and actors involved explain why consensus could not be reached, and why the two frames were persistent. All these characteristics suggest limited deliberative policy making and reflexivity.

Deliberation combines different forms of argumentation and communication, such as exchanging observations and viewpoints, weighing and balancing arguments, offering reflections and associations, and putting facts into a contextual perspective. The term 'deliberation' implies equality among the participants, the need to justify and argue for all types of claims, and an orientation towards mutual understanding and learning (Dryzek 1994; Habermas 1987). However, in this policy process very few opportunities were created for deliberative policy making involving the minister and state ministers, as well as actors working in the seed sector. Most of the discussions held during the revision process were organized between representatives of the ministry and other actors. The final and actual decisionmakers (minister and state minsters of the MoA) do not usually participate in such meetings; and if they do, this is to open a discussion and to give directions. More importantly, they do not organize opportunities to deliberate on issues that need further discussion. 
Furthermore, the minister and state minister seemed reluctant to openly discuss their policy position, or reflect on alternative governance options. The rationale behind the direction set by the minster is not always clear to those who represent the ministry. For instance, the state minister finally explained that establishing a separate coordinating structure for the seed sector cannot be part of the seed proclamation because of procedural reasons. Instead, this should be done through a separate proclamation if necessary. Regardless of whether the justification provided by the state minister is right or wrong, during the four years of discussions, the representatives of the ministry did not mention this procedural reason. In fact, this was only made clear to experts in the MoA when they were preparing to submit the document to the CoM and the stakeholders during the public hearing at the end of the revision process.

While the representatives were only presenting the position of the ministry, based on the information available to them, the state minister barely defended or explained the ministry's strong preference for decentralization. The ministry set its preferred policy option in the beginning and maintained that position till the end. This process of only presenting and promoting its own policy position highlights the nondeliberative nature of the policy making process in Ethiopia.

Moreover, the process of policy making was not reflexive. Termeer et al. (2013) define reflexivity as "the capability to appreciate and deal with unstructured problems and multiple realities" (p. 6), which also includes one's willingness to take a step back. Hendriks and Grin (2007) also indicate that to be reflexive is the capacity to turn or bend back, which can be achieved by reconsidering one's practices and frames when ideas and opinions are exchanged and discussed. Reflexivity encourages actors to "loosen their grip on the desire to control problems" (p. 334). The lack of reflexivity limited the possibility of redefining the cause of the problem and the subsequent solution. In the drafting process, the drafting team (centralization frame users) suggested the establishment of a governing body at national level, without convincing the ministry officials, which had already decided to go for decentralization. Similarly, the ministry officials disregarded the proposal of the drafting team without discussing it with the team, or understanding why the team suggested the establishment of a governing body at national level. Thus, both groups were not willing to understand each other's perspectives, or to look for an alternative option if necessary.

Similarly, the ministry was not prepared to look back over past decisions, like the termination of the NAIA, and there was a firm belief that what had been decided was simply the right thing to do, without giving further explanation. This is partly 
because major decisions are made politically within a small circle making it difficult to reconsider such decisions. For instance, none of the informants, including those in the ministry, could explain why the NAIA had been dissolved, even though some of them are responsible for advising the ministry officials. Similarly, the head of the NAIA at that time was not aware that the authority was going to be dissolved, showing that the decision making was not open. In addition, the decision to implement the BPR programme was another decision that the ministry was not willing to reconsider. While the proposals made by users of the centralization frame implied a reconsideration of these past decisions, the ministry considered the decisions as final. This blocked the possibility of observing the alternative frame positively.

These observations are further confirmed by previous studies on governance and policy making processes in Ethiopia. Keeley and Scoones (2000), for example, observed government inflexibility with regards to reconsidering its policy option regardless of any rational argument that may come from other actors. As further noted by Halderman (2005), the government resists any arguments that do not support the pre-set policy, regardless of who makes the arguments. According to Lefort (2013), all decisions have to be made according to party interests, indicating the challenge to change or reverse previous decisions. Similarly, Wolde (2005) concludes that in Ethiopia public policy represents the interests of power holders. While the observations made here on the lack of reflexivity and deliberation in policy making processes in Ethiopia are confirmed in the existing literature, they are not well explained; the second layer of the analysis elaborates on the nature of the frames.

\subsubsection{The paradox and unpacking the paradox}

Whereas the lack of reflexivity of both groups of actors, and the practice of political leaders to avoid deliberative policy making explain the persistence of the two frames, a paradox remains: those holding power, who are criticized for strongly centralizing power, want to be less in control, and those not holding power want the power holders to be more in control. The decentralization frame of the federal government also seems to go against the political history of the Ethiopian state. Following the creation of modern Ethiopia towards the end of the nineteenth century, Ethiopia was a highly centralized unitary state (Dickovick and GebreEgziabher 2010; Halderman 2005; Tewfik 2010; Zimmermann-Steinhart and Bekele 2012). In the following paragraph, we unpack this paradox by identifying factors that could be seen as higher-level or deeper problems in current policy making in 
Ethiopia, and as processes that constrain deliberations and reflexivity on governance solutions for the seed quality problem.

Although Ethiopia is home to more than 80 ethnic groups, former governments of Ethiopia neglected this diversity, and focused solely on promoting the concept of a homogenous Ethiopia until 1991 (Aalen 2006; Tewfik 2010; Zimmermann-Steinhart and Bekele 2012). As noted by Green (2011), "[i]n contrast to previous governments, the Zenawi regime has focused its efforts on promoting rather than neglecting ethnicity, as it created a system of ethnic federalism enshrined in its 1995 constitution" (p. 1095). The introduction of ethnic-based federalism not only meant to transfer powers from the national to the regional level, but was also a political strategy of the current government to disparage the political ambitions of those promoting the concept of a 'homogenous Ethiopia'. Not surprisingly, the new political principle evoked strong resistance from different actors:

Opposition groups and many of the country's intellectuals have vehemently opposed EPRDF [Ethiopian People's Revolutionary Democratic Front, the ruling party since 1991] plans to devolve powers to ethnically based administrations because of concerns that these moves would bring about the dismemberment of Ethiopia, although the front argued that such criticisms represent a rear-guard attempt to protect Amhara hegemony (Young 1998: p. 194).

Young's explanation clearly shows the power struggle between the past and the present. The government adopted a contrary argument, saying that recognizing ethnic diversity would safeguard the country from disintegration. To accommodate ethnic diversity, Tigray People's Liberation Front (TPLF) established other ethnicbased political parties and founded the Ethiopian People's Revolutionary Democratic Front (EPRDF) at national level as a coalition party. As a founder, TPLF provided ideological direction and leadership for the coalition (ibid). Thus, a de facto one-party system was established at regional and national level, which meant that the party officially transferred powers to regional level but without losing control at both levels (Chanie 2007).

The frames of decentralization and centralization as governance solutions for the shared problem of seed quality mirror the political debate on ethnic-based decentralization that has taken place since 1991, and the power struggle of bureaucrats to have decision-making power at national level. The decentralization frame has its deepest roots in the political strategy of the ruling party. As a result, it cannot be expected that political leaders will easily adopt the centralization frame in the policy making process of the seed sector. Likewise, the promotion of the 
centralization frame by bureaucrats, researchers and the private sector is part of the general opposition to decentralization, but also has to be approached through another perspective. Beyond addressing the problem of seed quality, this promotion may also be interpreted as an interest to hold power in the sector at national level, as indicated by Dickovick and Gebre-Egziabher:

Bureaucratic politics at the ministerial level is an additional complicating factor, with some (though not all) ministries and central government officials resisting or otherwise hindering the decentralization process. This can be both a political incentive to retain power in some circumstances and a lack of capacity in other circumstances (Dickovick and Gebre-Egziabher 2010: p. 19).

As explained by Gebre-Egziabher, the interest to hold power is also related to guiding the sector in which the bureaucrats in the ministries have no control:

While the decentralization program in Ethiopia has elaborated the powers and duties of the national and regional executive bodies and ministries and bureaus, there is little guidance outlining the functional relationship that needs to exist between regional bureaus and national sector ministries. The latter are expected to design national policies and strategies regarding their particular sector. However, the absence of functional integrations with the regional bureaus will deny them knowledge of the regional operations that are needed for appropriate policy and strategy designing (Gebre-Egziabher 1998: p. 41).

The paradox can be further unpacked by reconsidering what the ruling party considers to be the role of the state in governing the country. According to Young (1998), "the EPRDF continues to see the state as the best means to pursue its programme and maintain a dominant position in the largely fragmented Ethiopian society" (pp. 200-201). Similarly, the late Prime Minister, Meles Zenawi, firmly believed that Ethiopia needed a "capable state to lead development" (de Waal 2013: p. 152). Our findings match these earlier observations that there is a strong belief that the government has its policy direction, and thus will only consider input from other actors when these are in line with the set policy direction. This is also what Chanyalew (2015) refers to as 'Ethiopian indigenous policy'. Regardless of the strong interest to control power, which is in line with the history of the country, the government's policy of only accepting ideas that fit in with the pre-existing policy is part of the paradox. The NAIA was dissolved, and the BPR policy is already being implemented, and neither are in line with the centralization frame. Thus, there has been little interest from the government to open up for discussion, or to reflect on alternative policy options. 


\subsection{Discussion}

To better understand the complex relationships between policy making and politics in Ethiopia as an integral part of governance issues, two different levels of analysis can be distinguished, each followed by a different perspective on changing policy making processes and their outcomes.

The first level distinguishes how different actors frame and challenge governance solutions to a shared problem in a more or less limited span of time; for instance, covering the process of drafting a proclamation. In this study, such analysis has not only revealed two opposing frames, but also the characteristics or mechanisms of the policy making process that explain why different groups of actors working in or for the seed sector were unable to openly discuss and to possibly reconcile these two frames, or to identify a shared, third frame. The perspective on changing the policy making processes and their outcome, which can be linked to frame analysis of a policy making process, is to explore how reflexivity of different actors could be strengthened and how deliberative decision-making can be organized. As indicated by Schön and Rein (1994), reflexivity can help to appreciate different perspectives that emerge in the process of policy making, to continuously reconsider dominant and less dominant frames, and to bring about a redefinition of solutions. If not coupled with deliberative decision-making, policy making processes can hardly benefit from reflexivity of actors and newly emerging ideas. Making room for reflexivity and deliberative decision-making, however, requires actors to try to give up their beliefs about the 'best' governance solution at the beginning of a policy making process, and to accept that a solution will be found through deliberation with other actors.

The second level is to identify and study the organizing principle of a political system, and the ruling party in particular, over the course of a period - longer than that of a policy making process. In our study, such analysis has led to the identification of ethnic-based decentralization or federalism that is not only the organizing principle of the current political system of Ethiopia, but also a characteristic of politics, which explains why the government has framed its governance solution to seed quality in terms of decentralization. Moreover, the belief that Ethiopia needs a strong government that leads development is in line with the centralization frame, but against the organizing principle. This has limited the government in its openness to external ideas. The centralization frame can be seen as an expression of an alternative policy option, which shares the need to have a strong government. These show that policy making in Ethiopia can be a very complicated if not impossible task, certainly when all the actors working for or in 
the seed sector show little reflexivity and cannot develop solutions through a deliberative policy making process. Deliberation in seed policy making is important to optimize the outcome of the policy making process, but there is no guarantee that a deliberative process will end up with different policy options than what is currently selected. It all depends on how well the actors convince each other.

It can be concluded that the combination of the two levels of analysis can contribute to a better understanding of policy making processes and their outcomes under the current political system in Ethiopia. As for the two perspectives on changing the policy making processes and their outcomes, I cannot recommend that political leaders, or other actors engaged in policy making processes, follow one perspective, or even combine them; this is what they have to find out themselves, hopefully through deliberation. 


\title{
Chapter 4.
}

\section{Organizing changes in the centrally managed seed market system through collaborative governance: piloting direct seed marketing in Ethiopia}

\begin{abstract}
Over the last two decades, the seed market system in Ethiopia has been centralized by the government. The system is rooted in the notion of the 'developmental state' and reflects the government's belief in centralized planning. However, seed sector stakeholders generally agree that the system is inefficient. To overcome its limitations, regional seed core groups introduced direct seed marketing (DSM) in 2011 as a pilot. By 2016, over a third of hybrid maize seed in three regional states of Ethiopia was being sold through DSM. The two questions addressed in this chapter are: How did the regional seed core groups introduce DSM from below in the top-down governance culture of Ethiopia? And how have they been able to expand DSM given competing discourses about seed marketing? The analysis revealed that the regional seed core groups provided a 'safe' space to discuss policy issues and empowered the bureaucrats to influence decision makers. The role of the Integrated Seed Sector Development (ISSD) project as an external actor was critical for introducing the 'new' idea. The positive results of the pilot coupled with strategic management of the process helped the expansion of the pilot to wider areas.
\end{abstract}




\subsection{Introduction}

The government of Ethiopia has developed various seed-related policies to ensure that farmers get the right seed at the right place and time (Simane 2008). However, the seed sector has not adequately addressed the country's increasing demand for seed where shortage of seed is often cited as a common phenomenon (Lakew and Alemu 2012). The government is strongly involved in the seed sector and uses central planning and a central distribution system to fairly distribute the available seed across the country (Alemu 2011). The centralized distribution system has resulted in inefficiency, seed left over despite farmers' demands not being met, poor quality seed, lack of accountability, more work for government offices and consequently high associated costs (Alemu and Tripp 2010; Astatke et al. 2012; Atilaw and Korbu 2012; Lakew and Alemu 2012). The centralized distribution system is related to a top-down governance culture and the government's development approach, which considers that government involvement in the economic sector as a precondition for economic development. The government's developmental state approach favours centralized planning and implementation to guide economic development. The top-down governance culture and hegemonic thinking on centralized planning and distribution of seed do not favour seed marketing and other ideas for improvement emanating from below. On the contrary, it focuses on the top-down implementation of the distribution plan. When an idea not in line with the centrally planned activities is put forward, the government often labels it as 'anti-development', thus narrowing the room for discussing the suggestions that come from below (Fantini 2013; Gebresenbet 2014).

Despite the top-down governance culture and hegemonic thinking on centralized seed distribution, in 2010, the Integrated Seed Sector Development (ISSD) project ${ }^{21}$ established regional seed core groups in the regional states of Amhara, Oromia, SNNPR and Tigray ${ }^{22}$ to create space for discussion among seed sector actors. The seed core groups can be considered as a collaborative type of governance structure. The regional seed core groups addressed the seed market problem by introducing and piloting DSM in 2011 (Hassena and Joep 2012). Over the years, the area in which seed is sold through DSM has steadily increased (Astatke et al. 2015; Benson,

\footnotetext{
${ }^{21}$ ISSD is a project run by a consortium of five Ethiopian organizations (four universities and the Oromia Seed Enterprise) and the Centre for Development Innovation (CDI) of Wageningen University and Research (WUR), with the main objective of creating a vibrant and pluralistic seed sector in Ethiopia.

22 Ethiopia is a federal state with nine regional states and two city administrations. Amhara, Oromia, SNNPR and Tigray are considered as agriculturally important regional states of Ethiopia.
} 
Spielman and Kasa 2014; Getahun et al. 2014; Nefo et al. 2015). Seed marketing data from Amhara, Oromia and SNNPR shows that in 2016, on average $36 \%$ of the hybrid maize seed in these regional states was sold through DSM. This chapter sets out to answer two research questions: how have the regional seed core groups introduced DSM from below in the top-down governance culture of Ethiopia; and how have they been able to expand DSM even though the hegemonic discourse on the developmental state does not favour liberal seed marketing?

Below, the theoretical concept used to organize the data is introduced (4.2), followed by the sources of data and how the data were analysed (4.3). The seed marketing system is then presented in terms of the theoretical concepts introduced (4.4). A description is given of how the regional seed core groups introduced and expanded DSM alongside the centrally planned distribution system widely operational in Ethiopia (4.5). The result of the data analysis is then provided with the help of the aforementioned theoretical concepts (4.6). In conclusion, the major outcomes of the process are summarized by answering the research questions, and some gaps worthy of future research are identified (4.7).

\subsection{Transition and transition management}

System change is the reconfiguration of elements of the system that function, which is an evolutionary process (Geels 2002). Rotmans, Kemp and van Asselt (2001) used multi-level perspective (MLP) on transition to show how the introduction of a new idea changes the system. The MLP presents a system model of three inter-connected levels - niche, regime and landscape - to represent a socio-technical system, and transition is seen as the result of the development of alignments between these multiple levels as shown in Figure 4-1 (Geels 2011; Geels and Schot 2007). "The term 'socio-technical' is used to accommodate both the humans and non-humans that create functional configurations that work" (Geels and Schot 2010: p. 45). In MLP, a regime is a dominant operational system that in practice serves the societal need; it is a semi-stable system that can be changed. "It refers to the semi-coherent set of rules that orient and coordinate the activities of the social groups that reproduce the various elements of socio-technical systems" (Geels 2011: p. 27). The regime is not only limited to the practice of serving the societal need but also extends to its structure and actors within it (Geels and Schot 2010; Haxeltine et al. 2008). A niche is a flexible and fluid idea that emerges in the system and may have the potential to solve a societal problem. It is a deviation from the regime's rules of the game (Geels 2004). A landscape is an exogenous environment to a regime, but provides the context for stability or change of a regime (Fischer and Newig 2016; Geels and Schot 2007; Geels and Schot 2010). These are the social, political, economic and natural 
environments on which niche and regime actors have less influence, but nonetheless operate within. The landscape is a slow-changing societal process, but sometimes a sudden change occurs, directly affecting both the niche and the regime (Geels and Schot 2010).

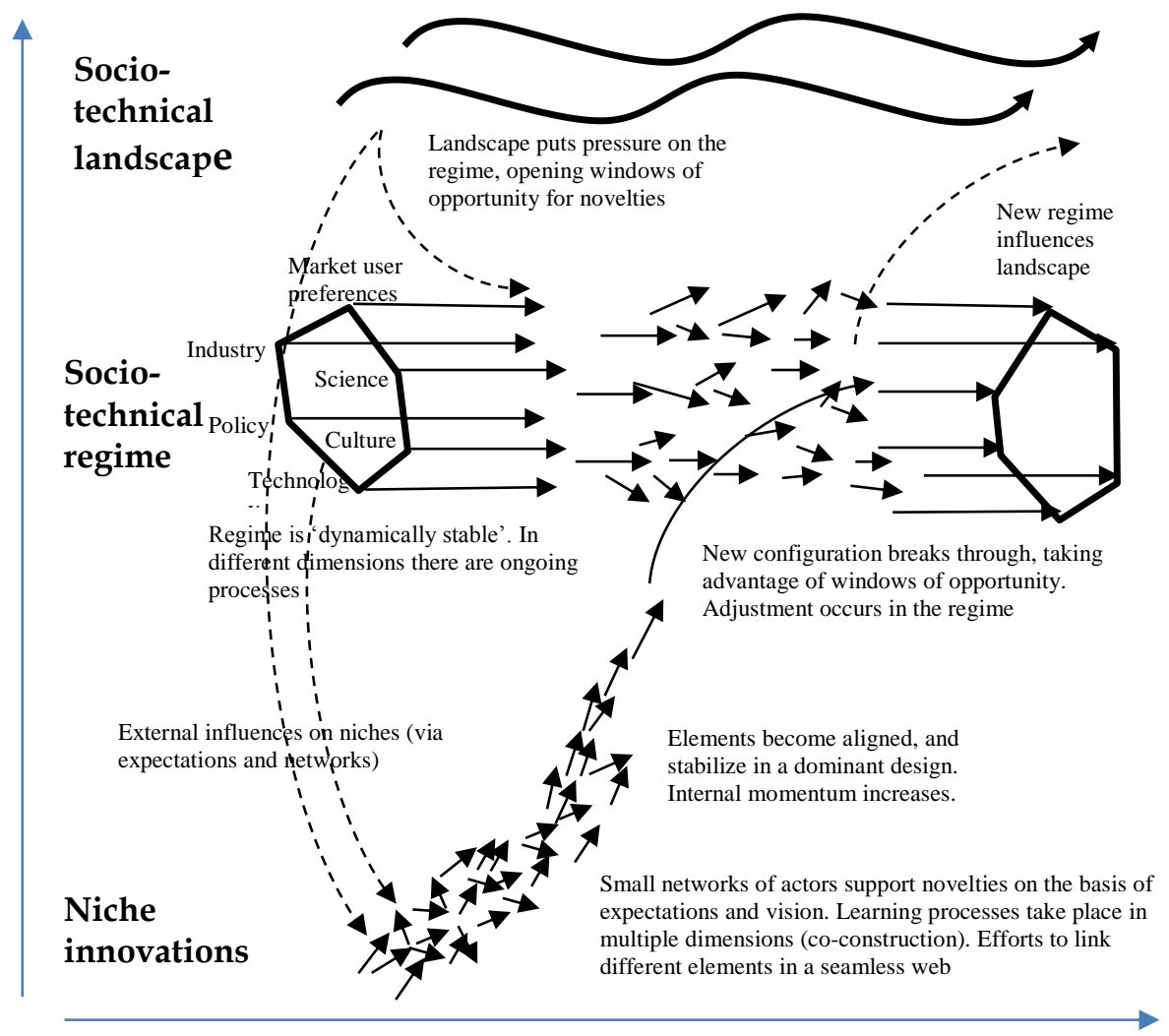

Figure 4-1. Multi-level perspective on transition

Adapted from Geels and Schot (2007: p. 401)

To satisfy a societal need, the concept of MLP suggests focusing on regime change. Based on this concept, regime change comes about either by niche development from below, transformational agendas imposed from the top, or the interactions between these levels (Fischer and Newig 2016; Geels and Schot 2010; Jørgensen 2012; Kivimaa and Kern 2016). Actors within the regime may start a niche activity by deviating from the regime's rules of the game to transform a regime, but often internal initiations do not materialize (Garud and Gehman 2012; Geels 2011). 
Instead, external actors are important to initiate and develop a niche that has a potential to change a regime (Ceschin 2013; Jørgensen 2012).

As the niche grows, and especially when powerful actors take part, the niche achieves more legitimacy and its internal momentum increases (Geels 2012; Geels and Schot 2007). Such processes also lead to a recognizable niche-regime constellation or empowered niche (de Haan and Rotmans 2011; Haxeltine et al. 2008). However, when there is no pressure from the landscape, the regime "remains dynamically stable and will reproduce itself" (Geels and Schot 2007: p. 406). Thus, the MLP concept suggests that regime change happens when fruitful coupling develops among the three levels; the changes differ, depending on the timing and nature of the coupling (ibid).

The MLP concept on transition discussed above focuses on how an innovation at niche level leads to change in the regime and also influences the landscape. However, the concept treats transition as a 'quasi-static' process, although it takes account of the change over time (de Haan and Rotmans 2011: p. 91). Regime change is not a simple move from one constellation to the other: there are reactions against the niche and interactions within the regime that lead to change. MLP does not explain how these changes happen and how the different processes are managed towards change. To explain these dynamics, the concept of transition management is used.

Although studies in transition management are typically linked to technological innovations, recent studies have also used the concept of transition management to study system innovation, which is much broader than technological innovation. A system is a functioning interaction among actors and structures intended to contribute to a societal need (de Haan and Rotmans 2011; Rotmans and Loorbach 2010). System innovation is a co-evolutionary process which involves changes in the different elements of a system in order to respond better to the societal need leading to system change (Geels 2005; Rotmans, Kemp and van Asselt 2001). Linking this concept to the MLP concept discussed above, transition management is about changing a regime that does not adequately respond to a societal need through niche development. It is an attempt to influence change by resolving the persistent problem (Rotmans and Loorbach 2010).

The role of transition management is to make sure that intermediate outputs lead to the long-term objective while managing a sensitive dynamic process in the system. In this process, actors have the power to speed up or slow down the process, and transition management is about knowing the capacity of actors and managing the 
dynamics (Rotmans, Kemp and van Asselt 2001). The entire process of transition management is an interaction between three levels of management that operates at strategic, tactical and operational levels (Kemp, Loorbach and Rotmans 2007). At the strategic level, the focus is on creating a transition arena, defining the problem and developing a vision. Creating a transition arena helps to establish a venue in which problems are discussed and solutions are proposed without being limited by actors' organizational setup. It also helps to create access to political power to influence policy (Cohen and Naor 2013). The need to create access to political power indicates that transition arenas or collaborative governance structures are not independent; rather, they depend on the vertical government structure to attain their vision (Agranoff 2006; Carboni and Milward 2012; Resh, Siddiki and McConnell 2014). The creation of a transition arena establishes a foundation for tactical and operational level management.

The tactical level includes developing networks, compiling an agenda and deciding on transition paths. The operational level is about operationalizing the transition paths, where actors experiment with an innovation and learn from it (Kemp, Loorbach and Rotmans 2007; Rotmans, Kemp and van Asselt 2001). However, the three management levels are not a stepwise process instead a given management is used whenever necessary, and the result of one level of management will be fed into another to attain the target vision. Implementing incremental steps through these different levels of management together with the interaction between these levels is how transition management is expected to bring about radical change. This is because immediate radical change will trigger maximum resistance from the regime, and what should be changed at a given step is determined by the capacity of the actors to absorb change (Rotmans and Loorbach 2010; Werbeloff, Brown and Loorbach 2016).

\subsection{Data generation and analysis}

Empirical data to answer the above research questions were generated through interviews and document reviews. Interviews were conducted at national and regional levels in Amhara, Oromia, and SNNPR regional states, where piloting had been going on for at least four years by the time of the data collection in 2015 . Interviewees were seed sector actors involved in the piloting activities, as well as national actors who have stakes in the seed sector. At the regional level, interviews were conducted with representatives of regional seed core groups, bureaus of agriculture (BoAs), the cooperative promotion agencies (CPAs), ISSD, the Agricultural Transformation Agency (ATA), cooperative unions, and state-owned and private seed companies. At the national level, interviews were conducted with 
experts and bureaucrats in the Ministry of Agriculture (MoA) input Directorate, the AGP, the ATA, and the Ethiopian Institute of Agricultural Research. In addition to the interviews, a desk study was done in order to understand the problems of seed marketing and the practice of DSM. Different reports of ISSD, the ATA and a discussion paper produced by the International Food Policy Research Institute (IFPRI) on DSM, in particular, were reviewed.

Interview data were transcribed and uploaded into Atlas.ti for analysis. The data were coded focusing on the main research question of how the regional seed core groups introduced and expanded DSM. All texts that describe the process and strategies used were coded depending on how they were expressed. New codes were included whenever new ideas and reasons emerged. These primary codes were grouped and regrouped into families to make a structured and detailed description of the process of introducing and expanding DSM using the quotations attached to the codes. The process of change was further analysed using the concept of MLP and transition management introduced above.

\subsection{The seed market system}

Since the MLP concept discussed above is a general concept, and the term 'system' can refer to different levels of conceptualization (Geels and Schot 2007), it is important to explain the existing seed market system and the different levels (landscape, regime and niche) in the system, before going into the process of organizing change in the seed market system. This helps to visualize how the seed marketing operates, providing a context for the process of change.

\subsubsection{The seed market landscape}

In the case of the seed market, the landscape is the economic development approach plus the political system that influences seed market practices. Ethiopia is a federal government with autonomous regional states that have the power and authority to formulate and implement economic policies within the framework of national policies (HoPRs 1995). However, Ethiopia still tends to be a unitary government and development activities are designed at the centre and implemented by the regional states. Although there are regional state-owned seed companies, and these are managed by the regions, the policies that apply to the seed sector are all federal. Economic policies in Ethiopia generally promote private sector development. However, the volume of seed supply in the seed sector is currently dominated by state-owned seed companies. Four state-owned seed companies dominate seed production in the formal seed system of Ethiopia. They produce $60-70 \%$ of hybrid maize and over 90\% of non-hybrid seed (Alemu and Tripp 2010; Spielman, Mekonnen and Alemu 2013). The remaining seed is produced by about three dozen 
private companies and a few cooperative unions. The private companies mainly produce hybrid maize.

The Ethiopian government follows a developmental state political economy approach to support economic development. Agriculture remains the top priority sector, as more than three-quarters of the population derive their livelihood from agriculture, and it contributes about $40 \%$ of the real GDP (World Bank 2016). Since seed is a critical input in agriculture, the developmental state approach gives leverage for the government to decide on the seed market system for major food crops. Moreover, setting development targets is common practice in Ethiopia and executives at different levels are responsible for achieving these targets. These responsibilities give the executives the leverage to frequently intervene in the implementation of policies. Actors in the landscape are government officials at both regional and national levels, who have the power to set the seed market landscape. Landscape actors of particular importance for the seed market system are the minister and state ministers of the MoA at the national level, and the heads of the BoAs at the regional state level.

\subsubsection{The seed market regime}

The centrally managed system commonly referred to as seed distribution is the seed marketing regime. It encompasses the process of estimating seed demand and production, allocating seed, guaranteeing credit, facilitating transport of seed to the store, selling seed and collecting credit repayment (Figure 4-2). To be precise, the seed that is allocated and disbursed through the centralized system is not provided free to farmers. Rather the seed is sold to farmers through a centralized process of allocation and disbursement. Regardless of the existence of different seed producers, the supply of seed of the main food crops in Ethiopia is managed by the MoA at the national level and the BoA at the regional level. In recent years, the MoA has only been allocating seed produced by the ESE and Pioneer Hi-Bred. In the regions, in addition to the BoAs who lead the process, CPAs, zonal and district ${ }^{23}$ offices of agriculture, cooperative unions, and primary cooperatives are active players in this seed market regime.

Given the federal structure, the regional BoAs play the dominant role in this process. They collect seed demand data through their official structure (from village to the region), beginning at least six months before planting time. The BoAs submit the seed demand data to the MoA to be used as a basis for seed allocation. At the same time, both the BoAs and the MoA compile data on the amount of seed produced in

23 'District' refers to an administrative unit that comprises a cluster of villages. 
the country. Based on the demand from the regional states and the amount of seed available, the MoA allocates the seed to the regional states. In turn, the BoAs allocate seed to zones and then to districts (Atilaw and Korbu 2012; Lakew and Alemu 2012). Information on the allocation of seed is given to the district office of agriculture and seed producers, so as to facilitate the disbursement. Once the allocation of seed for different crops and varieties for each district is known, the district office of agriculture designates a primary cooperative or union to collect seed from companies. The representative of the district collects the seed from the companies based on the allocation (informant 77). If cooperatives are not active in the district, the district office of agriculture itself collects the seed from the companies and sells to farmers. 


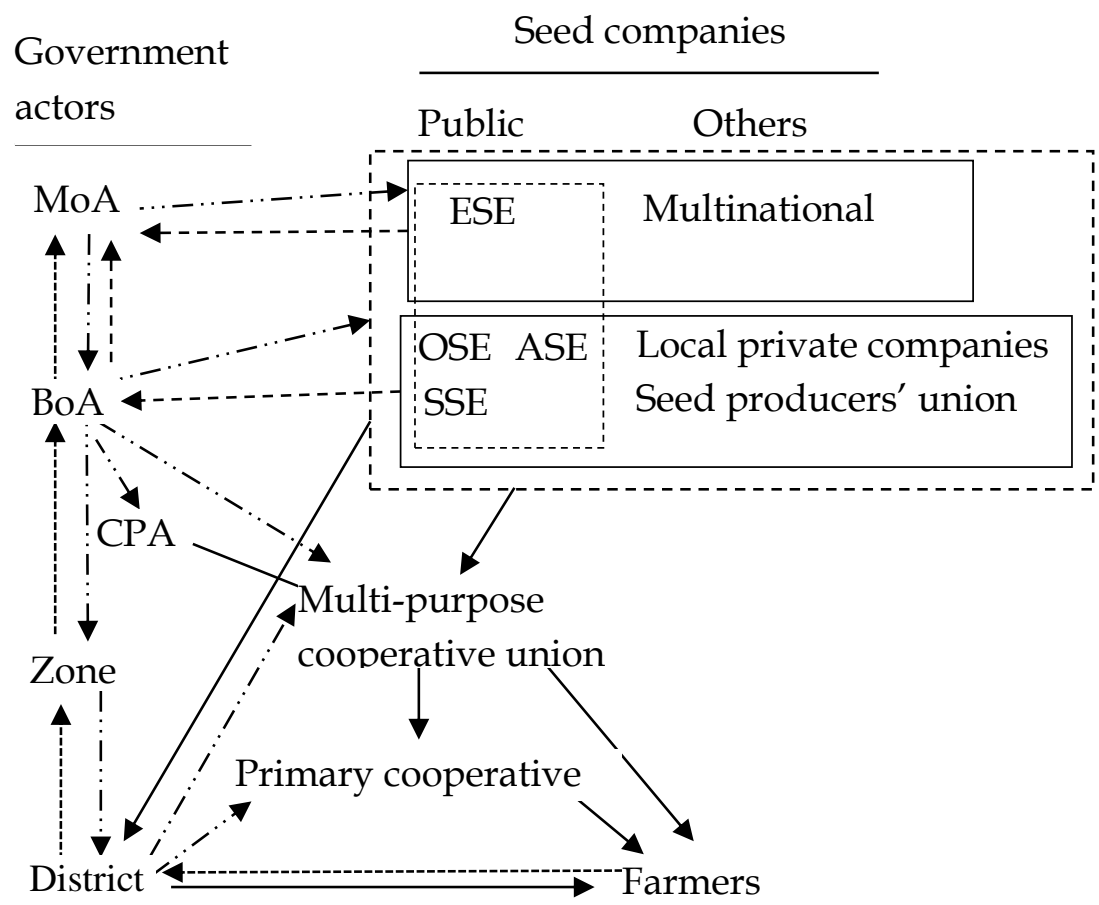

\begin{tabular}{lll} 
Legend & ASE & Amhara Seed Enterprise \\
Facilitating tinancial arrangement & BoA & Bureau of agriculture \\
by CPA & CPA & Cooperative promotion agency \\
\hdashline- Demand data estimation & ESE & Ethiopian Seed Enterprise \\
\hdashline$-\cdots$ Information on seed allocation & MoA & Ministry of agriculture \\
$\longrightarrow$ Physical product flow & OSE & Oromia Seed Enterprise \\
\hdashline Information on production & SSE & South Seed Enterprise
\end{tabular}

Figure 4-2. The seed market regime in the Ethiopian formal seed system

For cooperatives/unions, the regional government guarantees its budget as collateral so that the cooperatives/unions can get credit from a bank to buy seed (Spielman, Mekonnen and Alemu 2013). Although unions or cooperatives are authorized to collect and sell seed to farmers, government offices assist the unions and cooperatives to make sure that the seed is made available in the stores. Making seed available at the local store is a top priority of government offices at all levels during planting, and they use all possible means to ensure that the representatives 
of the district transport the seed to the local store. The seed is then sold to farmers either for cash or on credit, depending on the arrangements made by the regional government (Alemu and Tripp 2010; Astatke et al. 2012; Atilaw and Korbu 2012; Lakew and Alemu 2012). In recent years, seed has mainly been sold for cash to avoid credit default. In the case of credit, the cooperative/union and district administration are jointly responsible for collecting the loan and repaying the bank. If there is a default, the Ministry of Finance transfers the amount from the regional budget to the bank (Admasu and Paul 2010). Thus, even if the seed is physically handled by a limited number of actors, other actors are involved in the allocation, approval and facilitation processes, making the process longer and blurring the accountability of the actors involved.

Seed price is decided by the four state-owned seed companies through consensus at a meeting held annually before the planting season. At this meeting, each company proposes a price for the varieties the company has produced; and the agreed price is reported to the MoA for endorsement. Since all seed producers except for one multinational company use the same public varieties, the price endorsed by the MoA applies to all (Benson, Spielman and Kasa 2014). Pioneer Hi-Bred, the only multinational company in Ethiopia, determines the price of its seed.

\subsubsection{The niche in the seed market system}

DSM, the niche in the seed market system currently being piloted, involves the producers themselves selling seed to farmers directly or through their agents. As shown in Figure 4-3, DSM is basically a streamlined version of the long process of the seed market regime presented in Figure 4-2. Compared with the seed marketing regime, fewer actors are involved in DSM and the process is shorter, since the seed producers take on the major role of seed marketing. Once the core group has decided on the pilot district, companies identify and use commission-based sales agents to sell seed in villages. The sales agents include both private business people and cooperatives. Although companies obtain an indication of seed demand of a specific district from the BoA, they calculate their own estimates in consultation with their sales agents and make supply decisions accordingly. The companies also take into account the amount of seed supplied to the villages by other companies. 


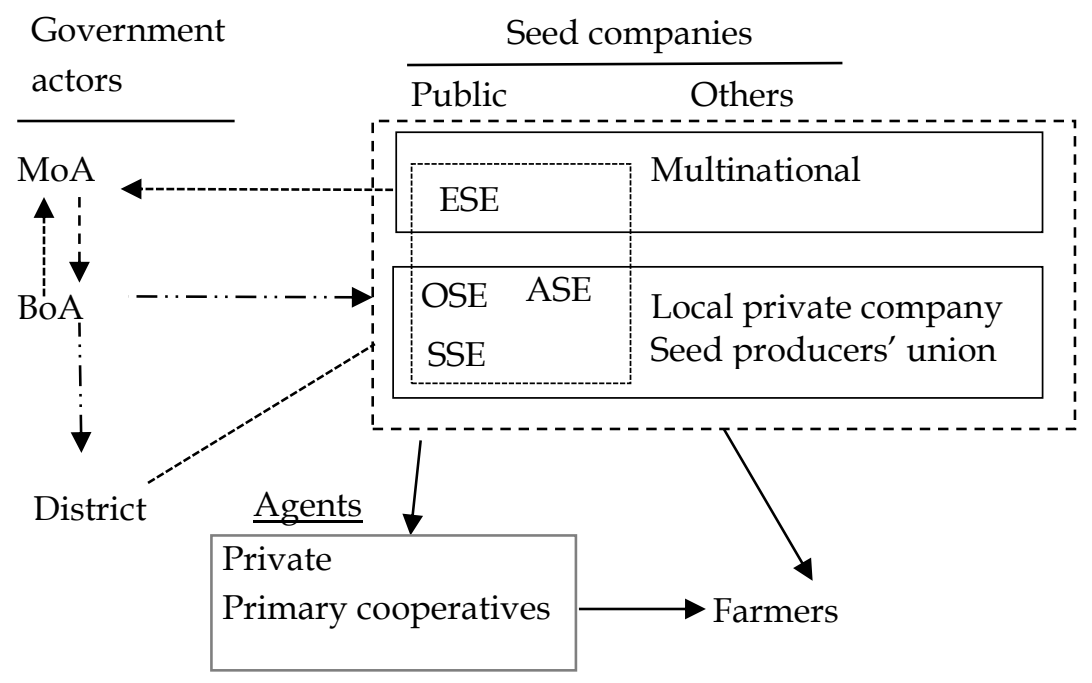

\section{Legend}

------- Estimate of seed production

$-\cdots-$ Information on districts under DSM

$\longrightarrow$ Physical product flow

------ District facilitating linkage

$-\cdots$ Seed allocated to the region
ASE Amhara Seed Enterprise

BoA Bureau of agriculture

ESE Ethiopian Seed Enterprise

MoA Ministry of agriculture

OSE Oromia Seed Enterprise

SSE South Seed Enterprise

Figure 4-3. DSM - the niche in the Ethiopian seed market system

Except for Pioneer Hi-Bred, both public and private companies use the price endorsed by the MoA under the distribution system as a starting point to determine the sales price at a given village. Depending on additional costs and competition in the village, companies adjust their selling price. The companies transport seed to the stores of their agents and the agents sell the seed directly to farmers at a price decided by the company. The companies are also responsible for transporting any unsold seed back to the stores. Under this system, there is no process of allocation except at national level, no approval is required for disbursement and no facilitation is necessary, which makes the process short - mainly between seed producers, agents, and farmers. Under DSM, it is common practice to make companies accountable whenever they supply low-quality seed, as farmers know the source of seed. 


\subsection{Organization of changes in the seed market system}

For the seed sector stakeholders, the inefficiency of seed distribution is a persistent problem, but for a long time it was not possible to change this scenario. The advent of support from the Dutch government in 2008 to strengthen the seed sector of Ethiopia provided an opportunity for rethinking the development of the seed sector. With this support, a local seed business project was initiated in 2009, which was redesigned as ISSD at the end of 2011 (CDI 2011). The project established a regional seed core group in four regional states - Amhara, Oromia, SNNPR and Tigray through which some 'new' ideas, including DSM, were introduced to the seed sector.

\subsubsection{Establishment of regional seed core groups}

In 2009, ISSD started to support farmers' cooperatives in producing and selling seed to the neighbouring farmers. However, different challenges limited the cooperatives' ability to operate as intended. Some of the major problems included limited access to basic seed, no seed inspection services and problems in accessing markets (Thijssen et al. 2011). These problems required the attention of stakeholders, but creating a coalition of actors to deliberate on and solve systemic problems of the seed sector was not easy for the ISSD project. ISSD is hosted by four universities and one state-owned seed company in Ethiopia. Universities have limited authority to coordinate the stakeholders in the seed sector. Thus, ISSD had to work carefully, step by step, to gain legitimacy and to establish a collaborative type of governance structure. ISSD requested seed sector supporters at district level to support seed producer's cooperatives. However, these district-level supporters indicated that solving most of the challenges was beyond their capacity and referred to the regional offices to solve the problems. In response, ISSD organized regional workshops in which seed sector supporters at district level presented the problems of the cooperatives in their district and indicated problems that were beyond their ability to solve. These problems were similar across the districts, and reflected systemic seed sector problems within and across regions (Hassena and van den Broek 2012). The regional authorities, the head offices of these district-level supporters, acknowledged that addressing these systemic challenges was indeed the responsibility of the regional offices. This acknowledgment opened the door for discussions on the strategy of solving the seed system challenges with the regional authorities mandated for this purpose.

In mid-2010, ISSD established four regional teams, composed of major stakeholders, in Amhara, Oromia, SNNPR and Tigray. Unlike the committees, ISSD envisioned having a collaborative type of structure that would provide continuous support to seed sector development (Thijssen et al. 2011). The regional team is referred to as 
regional seed core group, and is an institutional arrangement intended to overcome the persistent challenges of the seed sector in Ethiopia. The groups are comprised of members of organizations that have a stake in the seed sector. In each region, the core group includes the BoA, regional research institute, CPA, state-owned seed company, a representative of private seed companies, a representative of nongovernmental organizations (NGOs) involved in the seed sector, a university hosting ISSD, and an ISSD expert (Figure 4-4). Most of these actors - except ISSD, the NGOs and the universities - are active in the seed market regime.

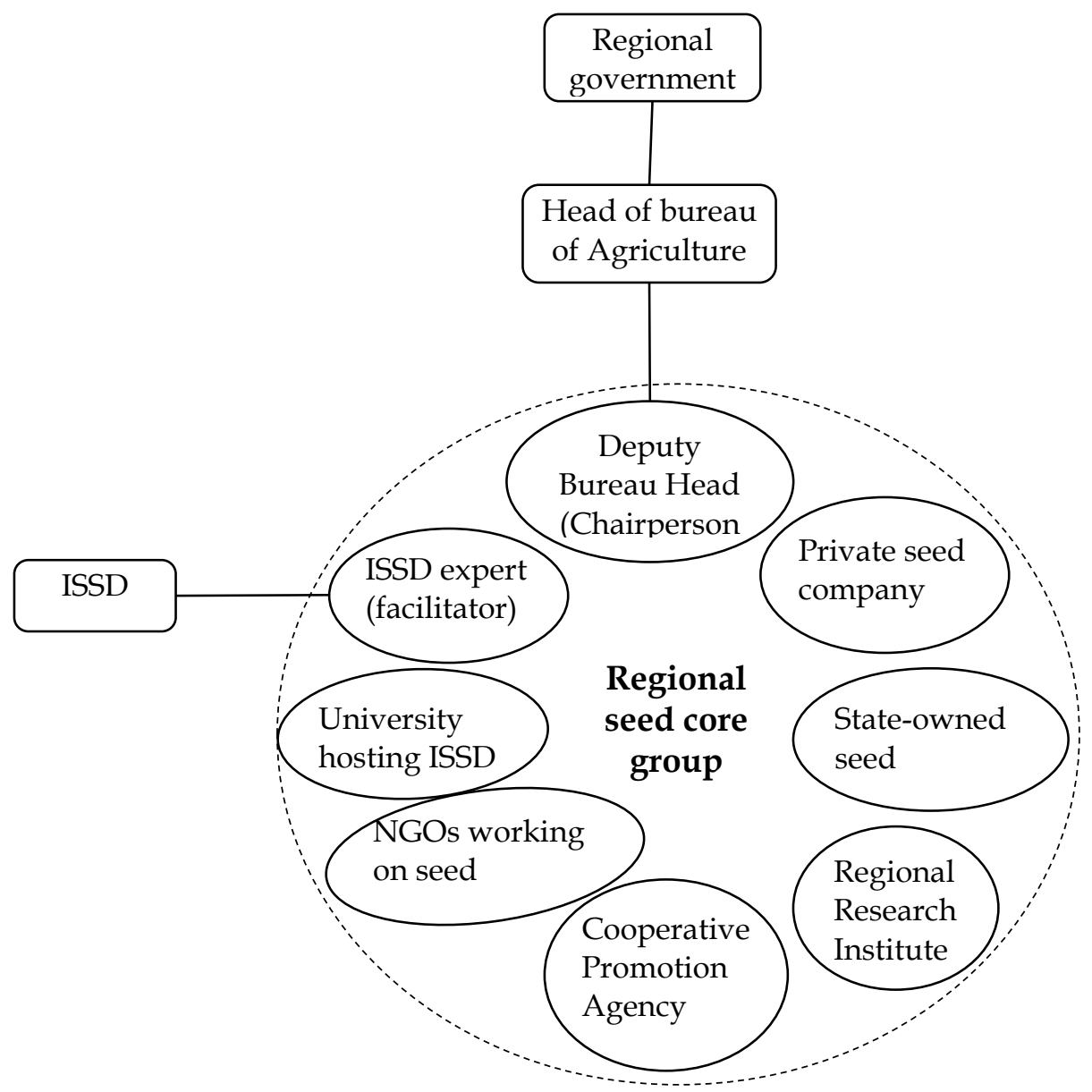

Figure 4-4. Regional seed core group and its link to the regional bureau of agriculture and ISSD 
Given the coordinating role of the BoA in the seed sector, the deputy bureau head, who represents the BoA, was made chairperson of the seed core group. The deputy bureau head is expected to communicate the outcome of discussions of the core group to the head of the BoA, who is the vice president of the regional state. In each of the four regions, ISSD designated one expert to exclusively facilitate the process of establishing the regional seed core groups, with some coaching provided from the national level to back up the facilitation process. The overall goal of the core group was to solve systemic problems of the seed sector in the region. The major activities of the regional seed core group include identifying and prioritizing systemic bottlenecks in the seed sector; identifying ideas that help to overcome the bottlenecks and agreeing to implement them; asking relevant experts or organizations to design an activity plan; making sure the appropriate organization implements the activities; learning from the process; and providing recommendations if necessary to policy makers (Hassena and van den Broek. 2012). After the establishment of the regional seed core group, several problems were identified and prioritized in each region. The three most common problems across regions were seed quality, the supply of early generation seed, and inefficiencies in the seed market (ibid). The following analysis focuses on the issue of seed market.

\subsubsection{Introduction of DSM}

\section{Steering towards seed marketing}

Initially, solutions that the core groups proposed to address the inefficiency of seed distribution focused on improving the existing distribution system, including better estimation of seed demand, improved capacities of cooperatives and better coordination (Hassena and van den Broek 2012). Although the suggestion to try seed marketing was tabled, it was not a top priority, since the distribution system was taken for granted. Many actors in the core group also believed that marketing is not in line with the government's intention and so would not be accepted by the government. Thus, seed marketing was not the first option of the core groups in all regions.

Since the solutions at the top of the priority list were not new and seed marketing was deemed unorthodox, it was dropped and the facilitators had to conduct bilateral discussions with core group members to try to convince them to use seed marketing. They proposed piloting DSM, with the understanding that they would abandon this if it did not solve the inefficiencies in the seed market. The bilateral discussions and negotiations succeeded in achieving a consensus to pilot seed marketing, which was subsequently endorsed in the core group meetings (ibid). Following this consensus, the BoA was asked to draft a concept note elaborating the details of implementing a 
pilot for seed marketing. The concept note was mainly drafted by facilitators of the core groups. During the preparation of the concept note, the term 'direct seed marketing' was used intentionally, to emphasis the involvement of the producers themselves in the marketing of seed. This was based on the recognition that the government focused mainly on seed distribution and that government discourses are generally not in line with open seed marketing (Gebresenbet 2014).

After the concept note had been drafted, there was renewed resistance from the seed companies and representatives of the BoA. Seed companies seemed to think that DSM would result in them being faced with all the marketing costs and challenges. The representatives of the BoA were also uncertain as to how the government would view DSM. However, as it was only a pilot, the core groups agreed to give it a try, but on condition that approval was obtained from the regional agricultural bureau head. Interestingly, other activities introduced by the core group, such as an early generation seed supply system, had been implemented without requiring such approval. In this case, the main reason to nevertheless ask approval was that DSM was expected to be out of line with the existing seed distribution system and approach of the government.

\section{Securing approval for piloting DSM}

Although agreement to pilot had been reached in each of the core groups, bringing the proposal to the attention of the bureau heads for approval was not easy for the groups. The difficulty was related to the reluctance of the chairpersons to present the concept note to the bureau heads (informant 57). However, in the three regional states, the processes and outcomes were different. In SNNPR, although the chairperson of the core group was expected to present the core group's decision to the bureau head, the chairperson reopened the discussion about DSM, and the core group changed its decision. The major argument for changing the decision was that DSM would take the seed market out of the government's control (informant 57). Some of the core group members believed that the government's aim was to supply seed directly and to have total control over the entire process. They believed that leaving this activity to the seed companies would affect the government's performance (informant 43,57).

Similarly, in Oromia the core group's decision was not presented to the bureau head early on, as the chairperson was reluctant to do so. The regional core group facilitator used another opportunity to present the idea of the core group to the bureau head, and in the presence of the bureaucrats, it was unanimously agreed to start the pilot. However, the bureaucrats had a discussion with the bureau head in the absence of 
the facilitator and decided not to start the pilot (informant 46). Moreover, the bureau head was transferred to a different bureau, making it difficult for the facilitator to follow-up on the case. Because of the reluctance of the bureaucrats and lack of time for discussion with the new bureau head, it was not possible to start piloting in Oromia in 2011 (informant 10).

In Amhara, as soon as the core group had decided to pilot DSM, the facilitator took the initiative to present the decision of the core group to the bureau head. The bureau head agreed with the idea of piloting, and the result of the discussion was to prepare a memorandum of understanding (MoU) describing the responsibility of each actor taking part in the pilot (informant 79). Four relatively strong companies were identified to participate in the pilot, and an MoU was prepared. However, none of the companies nominated to be involved was ready to sign the MoU. The facilitator then took the MoU to the bureau head, who was the first to sign the MoU, and then the others followed suit. Finally, two companies implemented the pilot in two districts in 2011, and Amhara regional state became the trailblazer for DSM in Ethiopia.

Although it was not possible to pilot DSM in 2011, in both Oromia and SNNPR, bilateral and multilateral discussions continued on how to start the pilot in 2012. In addition to the frequent discussions about DSM, the core group members were taken to visit Amhara regional state, where the pilot had started, and to other African countries (Kenya and Zambia) where seed marketing is commonplace (CDI 2012). During the familiarization visit in Amhara regional state, the core group members from Oromia, SNNPR and Tigray visited the two districts where the pilot was being implemented. They held discussions with the district office of agriculture, the district administrator, development agents and farmers. After these familiarization visits, the core groups in both Oromia and SNNPR decided to pilot seed marketing. The visit paved the way to obtaining the approval of the bureau heads without the involvement of facilitators. 


\subsubsection{Piloting and expansion of DSM}

Starting the pilot in the regional states

The first DSM pilot was initiated in 2011, when two companies sold seed ${ }^{24}$ in two different districts of Amhara regional state. Each company was assigned to a different district, so as to be able to monitor company performance, and make the companies accountable for any problems encountered. Both the core group at the regional state level and the office of agriculture at district level supported the two companies by giving them access to the stores of cooperatives free of charge (CDI 2012). Both companies temporarily deployed their staff to sell seed in the selected districts. The few staff members they deployed had to shuttle between the different selling points. This is indicative of the low level of preparedness and low marketing knowledge of the companies (Astatke et al. 2012). However, district-level actors and farmers were satisfied with the performance as, in comparison to their past experience, the farmers received their seed in time (Benson, Spielman and Kasa 2014).

During the 2012 planning process in SNNPR, some of the regional seed core group members had reservations about starting the pilot. However, in addition to the exposure visit, some actors such as the ESE, which is a federal state-owned company, strongly supported the initiation of the pilot. This was because large amounts of seed remained unsold in 2011 and there were indirect restrictions on the ESE selling seed in certain regional states (Benson, Spielman and Kasa 2014; Getahun et al. 2014; Sahlu, Alemu and Atlaw 2012). The opportunity created by this support was used to start DSM in SNNPR. To avoid the risk of hindering DSM in SNNPR, the district office of agriculture and ISSD assisted the South Seed Enterprise (SSE), a regional state-owned seed company, as much as possible. For the SSE, the main difference with their distribution system was that they themselves, instead of the district office of agriculture, transported the seed to the sale points. All other activities were done either by the district office of agriculture or ISSD. These included assigning staff to sell seed, renting the store, and collecting cash from farmers in advance and depositing it in the SSE's bank account. Unlike the SSE, the ESE used its own staff and sold the seed to farmers on a cash basis; this was because the ESE wanted to sell seed that had been left unsold in 2011 (Benson, Spielman and Kasa 2014).

\footnotetext{
${ }^{24}$ DSM was initially piloted in the sale of hybrid maize seed, one of the key crops of the private sector. This crop dominated throughout the pilot, although at a later stage other cereals mainly from state-owned companies were also sold through this marketing strategy.
} 
Similarly, in Oromia, members of the core group had reservations about starting the piloting of DSM. The core group anticipated the need to have more follow-up, because the region lacks the regulatory capacity to ensure seed quality if companies have to sell seed by themselves. Finally, the group decided to pilot DSM in two districts, but taking extra care (informant 10). In Oromia, seven companies (one cooperative union, two state-owned companies, and four private companies) took part in the 2012 piloting activity. As opposed to SNNPR, in Oromia assistance for these companies was limited to helping them to get a sales agent if they were looking for one. Except for two of the companies, which used their staff to sell the seed, all the others used agents, either a primary cooperative or a private agent. The district office of agriculture assisted the companies to identify sales agents in their respective districts, and detailed arrangements were made between the companies and the agents. ISSD and the BoA provided training to the agents on post-harvest seed management and marketing.

\section{Expanding DSM}

The facilitators in the different regions organized different workshops and field visits in the districts where the pilots were implemented, to facilitate a learning process, starting from 2011. Evaluations were held to identify the extent to which the pilot had helped farmers by comparison with the existing delivery regime, and experiences were shared. The district-level workshops were followed-up by regional workshops, to share experience across districts and to create momentum to expand the pilot in each region. In all three regional states, the outcome of the pilot and experience sharing created some enthusiasm to continue (Astatke et al. 2015; Benson 2014; Getahun et al. 2014; Nefo et al. 2015). As a result, the area covered by DSM has been increasing since 2013 (Map 4-1).

In 2013, there were mixed feelings about DSM among actors, particularly in Amhara and Oromia regional states. On the one hand, the expert and district-level actors wanted DSM to continue, since they considered it would solve the challenges they had been facing. On the other hand, the regional core groups planned to implement DSM, but with some reservations. In Oromia regional state, the chairperson of the core group wanted to expand the pilot slowly to avoid any risks. This was partly because of the suspicion that companies might sell poor-quality seed as the region does not have a strong regulatory system (informant 46, 75). If this happened, it might backfire on the chairperson, as the government had not authorized the use of DSM except as a pilot (informant 41,62 ). The idea of slowly expanding the pilot was also supported by the majority of the companies, as DSM burdened them with costs and work. In Amhara regional state, despite planning for ten districts, members of 
the core group were not sure whether the government would restart the pilot in 201325. The case of SNNPR was different: the chairperson of the core group was more interested in using DSM to make seed available to farmers. By contrast, the interest in some of the districts of SNNPR was low. Nevertheless, given the high interest of the chairperson, ten districts were planned for piloting DSM in SNNPR, increasing the total number of districts in the country planned for piloting in 2013 to twentyfive.

While reservations in Oromia and Amhara regional states were a concern for ISSD, the $\mathrm{ATA}^{26}$ was interested in expanding the two years of experience to more areas in 2013. Since interest at regional level in 2013 was not encouraging, having the interest of the ATA was an opportunity for ISSD to reinvigorate DSM. Although ISSD shared the two years of experience with the ATA, it was too late for the ATA to start implementation in 2013. ISSD and the ATA therefore agreed that the ATA would ask the MoA to write to the regional BoA, explaining the need to continue the piloting. Accordingly, the MoA wrote a letter to the regional BoA. For bureaucrats in the regions, this provided an important backup, and they developed confidence because the letter implied that the federal government supported the pilot. Inspired by this, the pilot was implemented in twenty-one districts (seven in Amhara, five in Oromia and nine in SNNPR) with more confidence than in 2011 and 2012. Thus, the expansion of DSM is the outcome of both its potential to solve the problems of the seed market and strategic management of the process.

In 2011 and 2012, the focus was on starting the pilot, and not the extent to which the companies had taken on the marketing roles. In 2013, more marketing roles were transferred to seed companies. The two companies in SNNPR changed their approach slightly in 2013 by making an agreement with staff at the office of agriculture to sell their seed. The district office of agriculture released staff from other work and the SSE paid for their service. Moreover, the SSE sold seed for cash, unlike in 2012 when farmers had paid cash before the seed was transported to the local store. In Oromia regional state, not much changed in the process when compared to 2012, mainly because Oromia had started off at a better level (Benson, Spielman and Kasa 2014). Amhara regional state restarted DSM in 2013, and five companies (one public and four private) joined the piloting. While the regional seed

${ }^{25}$ In Amhara, the piloting of DSM was discontinued in 2012 because of the huge amount of leftover seed in 2011, which the regional government decided to dispose of at any cost, including free distribution.

${ }^{26}$ During its establishment, the ATA had proposed the use of DSM but using the concept of agro-dealer. The idea was rejected by the government at that time, on the grounds that cooperatives should be used to distribute inputs (informant 15) 
core group identified and informed the piloting districts, the districts linked the companies to the cooperatives in the districts that were to be used as sales agents. In Amhara, instead of using their staff, companies used cooperatives as sales agents in 2013. Thus, in 2013, in addition to the increase in area covered, there were also changes in terms of roles.

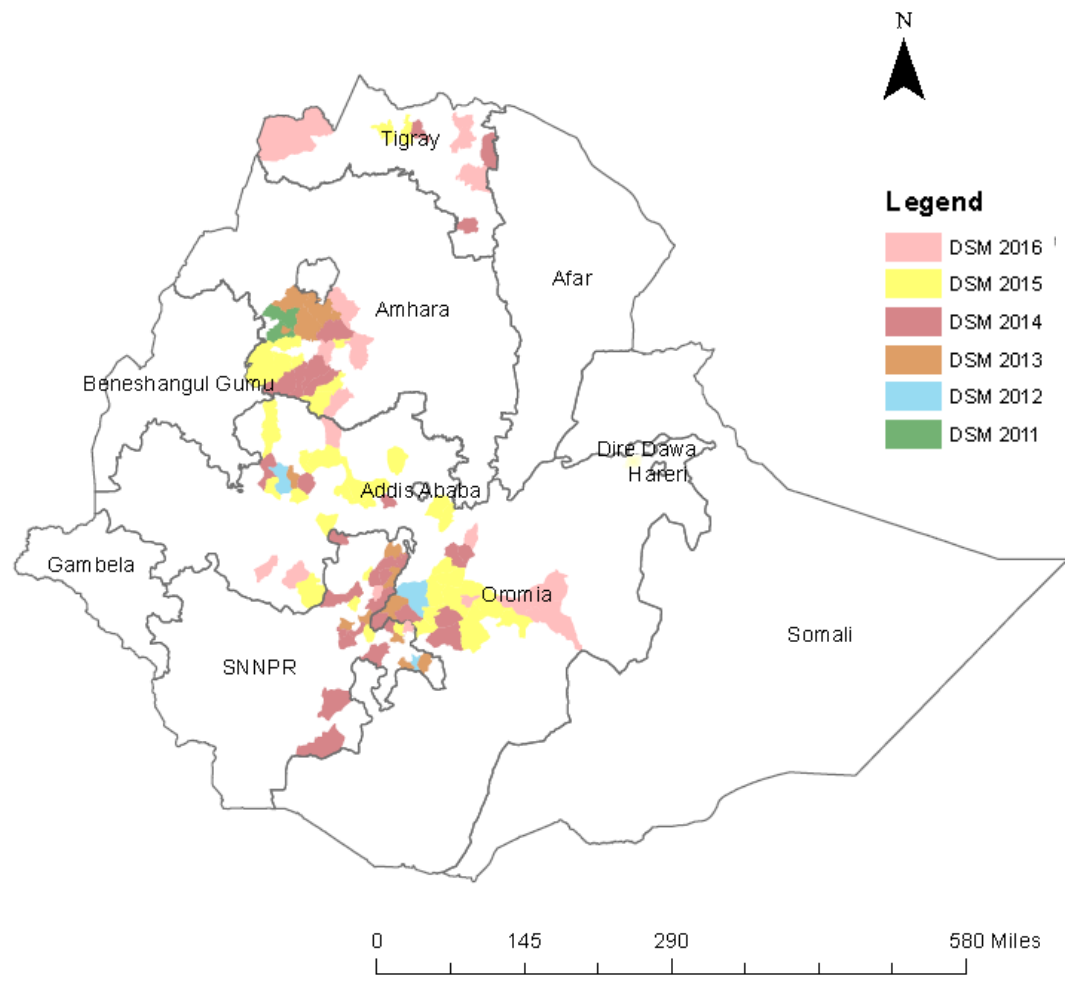

\section{Map 4-1. Expansion of DSM districts in Ethiopia (2011 - 2016)}

Source: based on data from regional ISSD units

In 2014, the ATA also invested in the piloting of DSM by assigning regional staff to augment the efforts made by ISSD; consequently, the number of districts increased to fifty-one. This is more than double the number of districts that were involved in 2013, and it created an opportunity to disseminate the concept of DSM across a wider area. Companies that had not previously participated also joined the piloting activity in 2014. Amhara Seed Enterprise (ASE), a large state-owned company in the region, did not join the piloting until 2014. The regional BoA insisted that the regional state-owned seed companies participate in DSM. In 2014, companies also 
started selling the seed of crops other than maize. This accelerated the process of transferring marketing roles from government to companies.

One other significant change made in 2014 was that companies in SNNPR moved away from their dependence on the government system to sell their seed. Both companies started to use agents instead of staff from the district office of agriculture. This change occurred mainly in response to pressure from the BoA (and thus from the core group chairperson) rather than as an initiative of the companies themselves (informant 18). Wearing two hats (as chairperson of the core group and representative of the BoA, which also implies representing the regional government), the chairperson has power to exert pressure on companies to participate. Thus, chairpersons have the power to influence the pace at which the pilot moves. Similar to the other regions, in SNNPR the district offices of agriculture helped the two companies to identify agents, and the regional BoA started checking the suitability of the store for seed. In all the regional states, the trend to certify agents started in 2014 and was intensified in 2015, which was also related to the establishment of regulatory authorities, at least in Amhara and SNNPR. The most important criteria for a company to be accepted as an agent are the availability of suitable storage for seed and trustworthiness. Starting in 2014, the core group in Amhara regional state decided on the number of districts to be included in the pilot mainly on the basis of the amount of seed produced by private companies, and it instructed the private companies to sell their seed solely through DSM in the pilot districts (informant 73). 


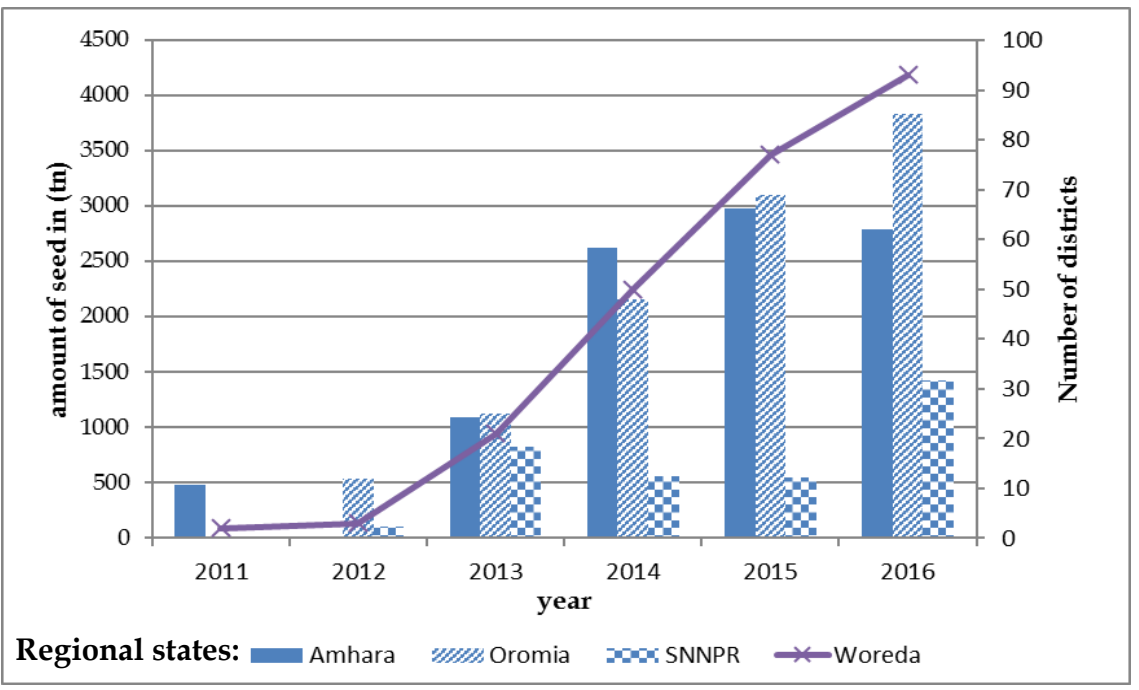

Figure 4-5. Increase in number of districts and amount of maize seed sold through DSM across regional states (2011 - 2016)

Source: based on data from regional ISSD units

The number of districts covered by the DSM pilot in the three regional states reached seventy-seven in 2015, and ninety-three in 2016 (Figure 4-5). Over the years, in these regional states the types of crop seed sold through DSM increased from only maize in 2011 to four crops in 2016. By 2016, the amount of hybrid maize seed (the major crop in the pilot) sold through DSM had reached about $36 \%$ of the total hybrid maize seed sold in the three regional states.

\subsection{Analysis}

\subsubsection{Transition management}

As indicated by Kemp, Loorbach and Rotmans (2007), transition is managed at three levels: strategic, tactical and operational, but they do not have a fixed sequence of implementation. Rather, transition is the result of interaction between these levels of management, where the output of one level of management is fed into the other levels that help to bring about change (ibid). The goal of transition management at the strategic level is to establish the appropriate arena, define the problem, and make sure that members in the arena focus on the same vision (ibid). In our case, establishing the regional seed core group as a form of transition arena was initially a challenge, mainly because of the relatively weak position of the Ethiopian universities to coordinate the seed sector stakeholders. However, once the regional core groups had been established, the universities were instrumental as a new actor 
in the arena to pull the discussion towards the systemic challenges facing the seed sector, rather than the operational problems the regime actors had been dealing with for so long. Such an arena is important to create a venue in which challenges are discussed and solutions are proposed without being limited by actors' organizational setup. It also creates access, directly or indirectly, to political power to influence policy (Cohen and Naor 2013). Our analysis revealed that the regional seed core group created an opportunity for bureaucrats to express their ideas, which they could not do when they were immersed in the implementation of day-to-day activities. At the same time, it also created an opportunity for other actors in the seed sector to discuss issues related to seed policy with bureaucrats.

Members of the core group defined seed market problems in terms of inefficiency. However, identifying the transition path was a challenge. Given the influence of the overarching government development approach, actors in the core group tended to limit the options to solve the seed market problems within the frame of the distribution system. To pull actors out of this frame, the facilitators used informal bilateral discussions with core group members, which helped many of the core group members to think outside the box. Being outside their organizational setup, it was possible to discuss among various actors and agree on an idea outside the existing frame, which otherwise might not have come into the picture. This is because, as indicated by Emerson, Nabatchi and Balogh. (2012), such an arena creates a 'safe' space for deliberation. In the deliberation, an unorthodox and possibly useful idea like DSM may also emerge.

Given the reluctance of the core group chairpersons to present the idea of DSM to the bureau head, the processes followed to obtain approval from the regional bureau heads differed among the regional states. In Amhara, the long working experience of the facilitator in the BoA helped the facilitator to easily present the idea to the bureau head in 2011 and get approval. In Oromia and SNNPR, where the facilitators have not worked in/with the BoA before, it was not easy to present the idea and get approval in 2011, and the process had to be supported by experience sharing. This implies facilitators require not only the technical capacity but also a good network in the system to manage the process better. Moreover, the reluctance of the core group chairpersons implies that bureaucrats were not using the opportunity of having access to the bureau head to present policy options, particularly when the ideas were outside the frame of the government. However, through the core group, it was possible to present 'new' policy ideas to the bureau head, revealing the core group's role in strengthening the power of the bureaucrats within their organizational setting. 
Nonetheless, the need to obtain approval from the bureau head shows that the regional seed core group is not independent, but depends on the vertical structure of the government. This dependency affected the functioning of the core group in the 'safe' space created. This is because to obtain approval the core groups took into account the interest of the bureau head or the government at large in their discussion and decision. This is strongly related to the policy implementation frame of the government. As noted by Ohno (2009), in Ethiopia the notion of the developmental state is much more than a concept; it legitimizes and guides the government officials to formulate and implement public policies. Based on this guidance, government officials are preoccupied with the implementation of framed activities from the centre (Simon 2011). The core group members knew that DSM was not on the executives' agenda. As a result, initially there was no interest in using DSM as a solution. Even after reconsidering it to be a solution, the bureaucrats were reluctant to present it to the bureau head to decide on. In SNNPR, the core group changed its plan of piloting DSM. This reflects how actors in the 'safe' space anticipate the interest of the vertical structure even if they are outside the organizational setup.

In addition to the notion of the developmental state, which gives power to executives, the reluctance of actors in the core group is also related to the difference between policy rhetoric and policy practice in Ethiopia. Over the years, both the policies on paper and government rhetoric have been pro-private sector and have encouraged more private involvement in the agricultural sector. However, the government of Ethiopia has not significantly changed its position to actually involve the private sector in strategic sectors such as input supply (Berhanu and Poulton 2014). Such a difference between the rhetoric and practice of policy has given rise to the perception that executives will not accept an idea that is not in line with the government's plan. Regardless of the fact that policies on paper support seed marketing, such an attitude affected the confidence of the core group members. Despite starting the pilot with the permission of the bureau head, the uncertainty among core group members and bureaucrats continued during the expansion of the pilot in 2013. The bureaucrats at regional levels were not sure whether the bureau head and the government at large would accept the expansion. This indicates that discussions and decisions of the core groups about DSM faced uncertainty. The power of the core group was limited because they were not granted the authority from the bureau head to change a system. Rather, they were working as a technical group to solve problems. This is in line with many observations that horizontal governance structures are not independent, but depend on the vertical governance structure (Agranoff 2006; Carboni and Milward 2012; Resh, Siddiki and McConnell 2014). 
Experience-sharing activities, the alliance with the ATA, and getting a supporting letter from the MoA was important tactical management in the process. Linkage with these key actors was possible because of the positive outcome of the pilot in 2011 and 2012. The results of this tactical management were used to influence the process in the regional states. It was only after observing the experience of Amhara that the other two regional core groups started piloting DSM. Given the top-down system of Ethiopia, and the role of the MoA in setting the seed sector landscape, the letter from the MoA changed the scenario with respect to implementing the pilot in the regional states. The facilitators fed the results at this level to the operationalmanagement level, to influence the pace of change. All achievements, whether inside or outside the regional process, were learned from and used to plan and implement the next step. Since the outcomes differed between regions, and the dynamics within the regional core group also differed, the planning and implementation of each step towards seed marketing varied across the regions. Oromia regional state started off in 2012 with a better level of marketing practice, where companies operated with minor support (Benson, Spielman and Kasa 2014). In SNNPR, initially there was a minor difference between the practice of the pilot and the distribution system, and so it was not until 2014 that the companies in SNNPR reached the stage at which Oromia regional state had started in 2012.

The capacity of the companies and the dynamics of the core group determine what change must be implemented at a given time. In Amhara regional state, the companies were instructed to sell all their seed exclusively through DSM in 2014, but the other two regional states were still not at this level. Over the years, companies took on more and more responsibilities, while public actors stepped back into facilitation roles. These processes are in line with the concept that the role of transition management is to direct the process by implementing incremental steps to attain radical change (Rotmans and Loorbach 2010). Again, this incremental step is related to the concept of not going beyond what the actors can absorb at any one time, as otherwise strong resistance to change will emerge (Rotmans and Loorbach 2010; Werbeloff, Brown and Loorbach 2016). The whole process discussed above confirms the overall concept of transition management. As indicated by Rotmans, Kemp and van Asselt (2001), managing transition is not about implementing predefined activities; rather it is about navigating through the dynamic current of actors' behaviour and intermediate outputs in the process leading towards the vision. 


\subsubsection{Niche development and regime change}

Before the piloting of DSM, the formal seed market for major food crops was through the centralized distribution system. The description of data in section 4.5 illustrates how the scenario has changed over the years. In 2016, 36\% of the hybrid maize seed sold in the three regional states was through DSM. This shows that the near absolute dominance of the centralized distribution system has changed to partial marketing, with all variabilities of marketing across the regional states. Section 4.6.1 above analysed how the process of change was managed using the concept of transition management. This section examines the development of the niche using the concept of MLP. To understand DSM development over time, the concepts of system transition of Rotmans, Kemp and van Asselt (2001), and niche development of de Haan and Rotmans (2011), are used to categorize the changes into four phases: initiation (2010-11), take-off (2011-2012), acceleration (2013-2014), and empowered niche (2015-2016) (Figure 4-6).

The initiation phase is the stage at which the most divergent ideas emerge from actors in support of, or against, a new initiative. Despite the persistent nature of the seed market problems, the idea of DSM only entered the picture because of the existence of the external actor - ISSD - in the coalition. Yet it was not easy for core group members to decide to use DSM to overcome the problems of the seed market because of the influence of the well-developed centralized distribution system, the signal emanating from the landscape, and the dynamics in the core group. The analysis of transition management discussed above shows how ideas about the use of DSM have been changing and how network management has been used to get actors to think beyond their current idea of seed distribution. This is grounded in the theoretical concept that actors in the regime are commonly stuck in the existing frame, and change initiated internally seldom works (Ceschin 2013; Geels 2011; Jørgensen 2012).

It took different lengths of time for the different regions to transit to the take-off phase, the start of the pilot in the region. Only the regional core group in Amhara was able to overcome resistance against the new idea in the first year. The other two regions took longer to start the pilot. In addition to the actors' resistance, this delay is partly related to the network of the facilitators within the BoA, which was relatively weak in Oromia and SNNPR. The outcome of the take-off phase inspired actors, particularly at lower levels. At this stage, the practical learning process and exchange of experience took place, which helped DSM expansion in the subsequent years. In the acceleration phase (2013 - 2014), the initial outcome in all regions attracted more actors to join the piloting. In addition to the companies that joined 
the process, influential actors like the ATA and MoA started giving support for the expansion of DSM. This was also followed by the regional bureau heads advising the regional state-owned seed companies to participate actively in the piloting. The support from the landscape actors (the MoA and BoA) increased the confidence of actors in the niche, and the pilot picked up momentum and expanded to more areas. By 2014, the pilot had reached a level at which it could be recognized nationally by covering 51 districts in the three regional states, and involving nearly all seed producers. The Tigray regional state also started piloting in 2014. The fast expansion was mainly because the ATA invested in the process to expand the pilot in more areas. This is in line with the point made by Geels (2012) that the involvement of influential actors in the process adds to the legitimacy of the niche and creates internal momentum for niche development. 


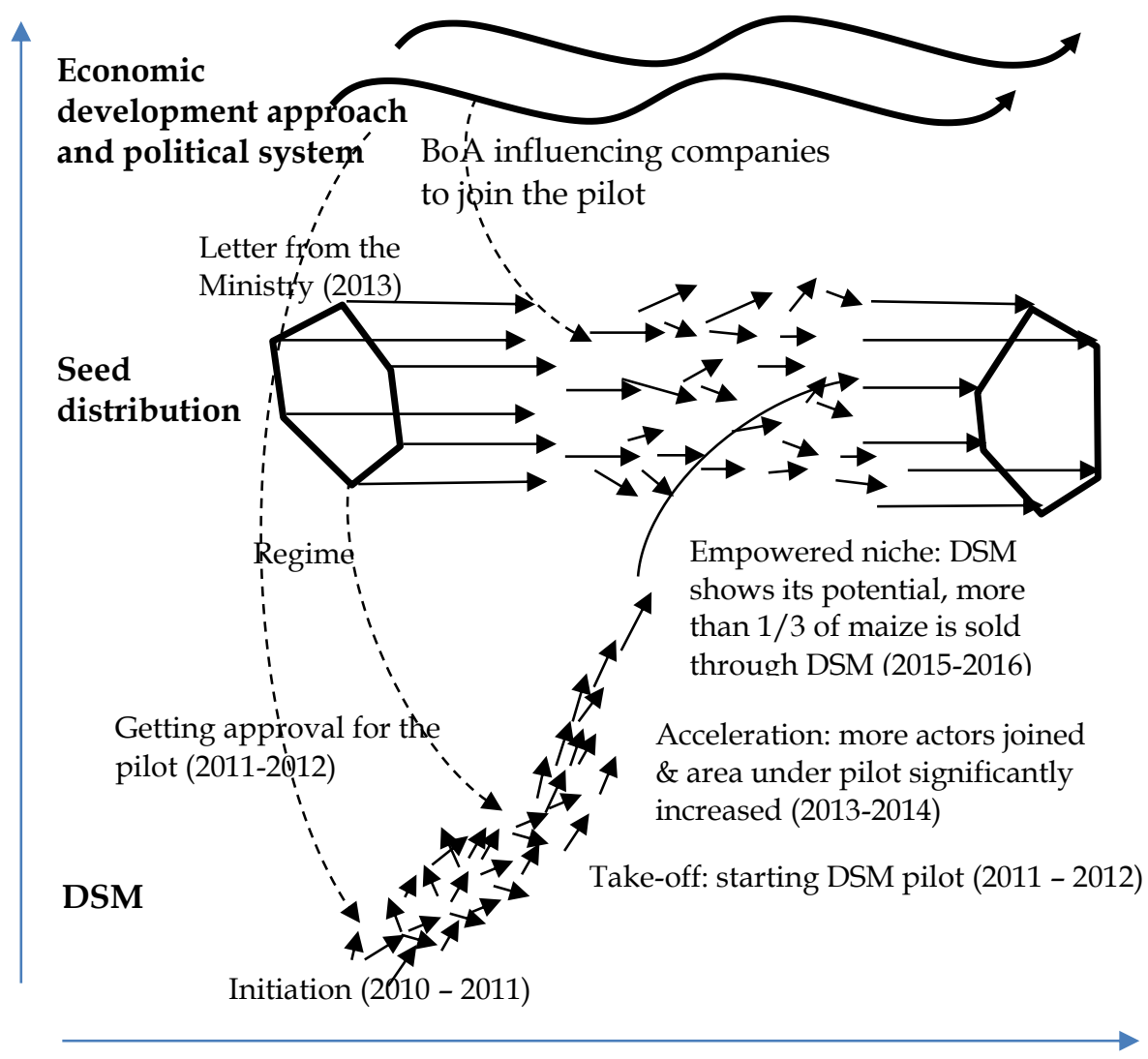

Figure 4-6. Multi-level perspective on the transition process in Ethiopian seed marketing

Source: adapted from Geels and Schot (2007; p. 401)

While DSM is labelled as a pilot, more than a third of hybrid maize in Ethiopia has been sold through DSM since 2015. Although most of the public and private companies prefer to sell their seed in bulk through the central distribution system, they have been using DSM by default to overcome the problem of seed being left over. Private companies in particular do not rely on the government alone to sell their seed. State-owned seed companies, who also supply the bulk of their seed to the centralized distribution system, use DSM as an option. Whenever they feel that they have excess seed and the central distribution system might not able to collect 
the seed in time, they sell directly, to minimize the amount of seed left over. The current use of DSM shows that in terms of leftover seed, DSM performs better than centralized distribution. This is what Haxeltine et al. (2008) and de Haan and Rotmans (2011) called an empowered niche: a niche that can already respond to the societal need.

\subsection{Conclusion}

This research set out to answer the research questions of how the regional seed core groups introduced DSM from below in the top-down governance culture of Ethiopia and how they have been able to expand DSM even though the dominant discourse of seed distribution does not favour liberal seed marketing. It can be concluded that the regional seed core group has created a venue for deliberating on different ideas from different actors. While it was possible to introduce the idea of DSM into this arena because of the presence of an external actor, the arena created the possibility to set the new idea as a vision. Yet the introduction and deliberation were carefully managed, starting from the framing of the concept of DSM as well as the approach used to implement DSM. DSM is used as a frame of the 'new' idea, distancing its connotation from that of liberal seed marketing, which is not in line with the distribution system. Instead, DSM has the connotation that the current seed producers sell their seed directly to farmers, but this does not entail seed market liberalization. Moreover, most of the seed is produced by state-owned seed companies, where the term 'direct' implies that the state-owned companies sell seed directly. Also, the decision was to pilot, and piloting could be abandoned if it did not help to overcome the problems of the seed market. These frames helped the actors in the core group to agree on the idea of piloting DSM. To introduce DSM into the seed market system, the autonomy of the regional state was used, and the head of the regional bureaus of agriculture authorized the start of the pilot.

DSM has expanded as a result of the evidence of its potential to solve persistent problems, careful management of the process, and the interest of influential actors in supporting the pilot. The first effort was to start and demonstrate DSM's potential, which helped to create interest among actors, thus facilitating the continuation of the pilot. The intermittent reservations were managed through tactical linkage at the national level, and that level supported the continuation of the process. Thus, it was the interplay of the different processes that led to the expansion of DSM in Ethiopia, regardless of the major discourse against liberal seed marketing.

DSM has developed to the extent that it has demonstrated its potential, particularly for hybrid maize. For hybrid maize, where private companies are active, a significant proportion of seed is sold through DSM. If the government cannot or does not want 
to channel the produced seed through the centralized seed distribution system, companies can find a way to sell their seed to farmers as they now have much more experience than they had before the start of the pilot. DSM is now generally seen as an alternative channel that can be used by seed producers to market their seed directly to farmers. However, although the DSM pilot is mature and regime actors are using it, there is no realignment of the landscape to the changes at the other levels. According to Geels and Schot (2007), a regime changes when there is coupling between the three levels of the system. In the case of the seed market system, regime actors are unsure if their current use of DSM is a temporary activity or something that they have to continue for the future, and thus they expect the government to make a decision. So far, there has been no alignment of the three levels in this regard. In the absence of a decision by the government, the regime remains dynamically stable and will reproduce itself. This is because within the regime there is a perception that it has inherent potential to solve problems, and therefore the same system will continue. Given the current level of development of DSM and its role in the seed market system, the next logical question is: why has it so far been impossible for the Ethiopian government to formally decide on the future use of DSM? The next chapter answers this question. 



\title{
Chapter 5.
}

\section{The rise of seed marketing and its uncertain future in Ethiopia: facing ambiguous policy making and institutional lock-in ${ }^{27}$}

\begin{abstract}
Although public policy promotes a market-based seed supply, in practice the Ethiopian government fosters a centralized seed distribution system. This system is characterized by several inefficiencies, resulting in untimely delivery of seed, seed left over even though demand has not been met, and supply of poor quality seed. Direct seed marketing (DSM) was introduced as a pilot in 2011 to overcome the inefficiencies of seed distribution, and the area covered by the pilot increased over the years. Despite support from executives to expand DSM, and the fact that market-based seed supply falls squarely within Ethiopian seed policy, it remains unclear as to why the government has not fully embraced this approach. This chapter analyses why decision making on the future of DSM has been excluded from the agenda of the executives, and discusses how the reasons for exclusion are linked to the strategy of the developmental state and to the political strategy of the ruling party. These linkages not only show the complexity of policy making but also create uncertainty about the future of seed marketing in Ethiopia.
\end{abstract}

\footnotetext{
27 This chapter is based on an article submitted to the Journal of Eastern African Studies as: Mohammed Hassena, Otto Hospes and Bram De Jonge, 'The rise of seed marketing and its uncertain future in Ethiopia: facing ambiguous policy making and institutional lock-in'.
} 


\subsection{Introduction}

Since 1997, the seed-related legislative policies of Ethiopia have described seed of agricultural crops as a commercial commodity to be marketed by seed producers (CoM 1997; HoPRs 2000; HoRPs 2013). However, the marketing policy has never been fully implemented. On the contrary, seed production and supply have remained centrally designed, top-down and state-directed (Alemu 2011). The government uses a centralized seed distribution system to make sure that seed is made available at distribution centres. By means of centralized seed distribution, the government allocates seed produced by private and government-owned seed companies as well as by cooperative unions. The government purchases or facilitates the purchase of this seed and distributes it to farmers through primary cooperatives or cooperative unions, or through district offices of agriculture (Atilaw and Korbu 2012). Although the cooperatives and unions physically handle the seed distribution, government offices facilitate the process of purchasing and distributing the seed, including arranging for credit (Spielman et al. 2010). In spite of the government's unreserved efforts to make seed available to farmers through the distribution system, there are many challenges, including inefficient seed distribution and distribution of poor quality seed (Alemu and Tripp 2010; Astatke et al. 2012; Atilaw and Korbu 2012; Lakew and Alemu 2012). Common inefficiencies are the late delivery of seed, the mismatch between seed demand and supply, and seed being left over even though farmers' demand has not been met. Another persistent problem in the Ethiopian seed sector has been poor seed quality (Spielman, Mekonnen and Alemu 2013).

Different solutions to the challenges of centralized seed distribution have been proposed by different actors at various times at national and regional state levels. At the national level, the most common solutions proposed are improving the accuracy of seed demand estimation and giving cooperatives the capacity to distribute seed better (Gelaw 2012; Lakew and Alemu 2012). In addition, as discussed above in Chapter 4, DSM was proposed by the regional seed core groups in Amhara, Oromia, SNNPR and Tigray and has been piloted since 2011. Over the years, DSM has shown potential to overcome the persistent problems of inefficiency in seed distribution, and has also contributed to seed quality improvement (Benson, Spielman and Kasa 2014). The results seem to be appreciated not only by those who directly supported the piloting, but also by executive leaders at both regional and national levels (Astatke et al. 2015; Benson, Spielman and Kasa 2014; Getahun et al. 2014; Nefo et al. 2015). Currently, both seed distribution and DSM operate in parallel. As the pilot is now in its sixth year (2011-2016) and the share of DSM is about 36\% for hybrid maize, actors in the seed sector expected the government to officially endorse DSM 
(Chapter 4). However, the government has neither officially endorsed DSM nor rejected its use as an alternative system beyond piloting. This chapter examines why the Ethiopian government has still not formally endorsed the use of DSM in Ethiopia, despite the positive results of the pilot and the fact that the initiative falls within the government's policies on seed. It describes the reception of DSM by relevant stakeholders and analyses the reasons for the Ethiopian government's delay in making an official decision on the future of DSM after piloting.

In the next section (5.2), the theoretical lens used to structure and analyse the data is presented. This is followed by a description of the methodology used for data generation and processing (5.3). Before presenting how DSM was introduced and expanded, the challenges of centralized seed distribution are detailed (5.4). Section 5.5 discusses the perceived benefits of DSM. Two contrasting scenarios are then described (5.6): the first shows how the executive leaders at both regional and national levels supported the expansion of the pilot; the second identifies the signals of the rejection of DSM by the executives. Section 5.7 explains the reasons behind the non-decision of the executives at two levels:- the lock-ins and deep-rooted structural problems. The final section (5.8) concludes by reiterating how institutions influence public policy decisions, and how this is deeply embedded in the structure of the system.

\subsection{Institutional lock-in}

This research started with the point that public policy making is complex, nonlinear, dynamic, and sometimes chaotic and messy (Arts and Tatenhove 2004; Enserink, Koppenjian and Mayer 2013; Keeley and Scoones 2000; Young 2005). Decisions depend not only on rational arguments but are also subject to political deliberation and choices (Byerlee et al. 2007). Decision makers are also confronted with competing and even conflicting policy objectives, which make it difficult to choose one. When objectives are competing and/or conflicting, individuals tend to be ambiguity-averse and shy away from making a decision, not only because of ignorance of the outcome of a particular decision, but also to minimize risk (Camerer and Weber 1992; Ghosh and Ray 1997). Thus, decision making can be ignored when the decision maker is ambivalent about choices, leading to non-decision making. Non-decision making is commonly organized through institutions that systematically exclude the issue from the agenda (Bonal 2012; Burnell 2002). Thus, the decisions or non-decisions of those in power may be unclear or even ambiguous, as these are the outcome of a mix of visible and invisible institutions that guide the decision making (Duffield 2007; Geels 2004; Mulé 1999). Institutions are "the shared concepts used by humans in repetitive situations organized by rules, norms and 
strategies" (Ostrom 2007: p. 23). They structure how members interact, and as such determine what is right and what is wrong, directing the actor to think and act in a certain way (Duffield 2007; Khan 2013; Klein 1998). These are both formal (constitutions, laws, regulations, official procedures) and informal (norms, values, taboos, beliefs, and conventions) institutions that guide the process of interaction (Khan 2013).

Some of these institutions, such as norms and beliefs, may not be obvious from the outset but are important in defining other institutions (Duffield 2007; Schmidt 2010). This is because norms and beliefs are ideologically internalized by an individual, and thus sometimes remain tacit to the individual. By shaping the thinking and actions of an actor, institutions limit an actor to perform a particular set of actions and not another, or to think in a certain way (Duffield 2007; Geels 2004; Mulé 1999). Thus, institutions are "humanly devised constraints that shape human interactions" (North 1990: p. 3). By default, institutions block actors from acting outside the existing sets of norms and rules (Cantarelli et al. 2010; Geels 2011; Klitkou et al. 2015).

Coming from the standpoint of discursive institutionalism, Schmidt (2010) argues that institutions are not static and changes are not expected to occur through external pressure only. There could also be institutional change brought about by internal discursive interactions of actors to reform and transform the rules and norms, there by promoting the interests of members of a given institution (Geels 2004; Schmidt 2010). Therefore, institutions also change, but at a given time they keep their restrictive nature, as the rules of the game and norms are fixed for some time, preventing actors from seeing beyond the frame. Institutional lock-in becomes an issue when an institution becomes inflexible and continues to restrict the consideration of other alternatives (Nordensvärd and Urban 2015). By limiting the consideration of other options, institutional lock-in leads to the use of sub-optimal policies even though alternative policies may be available (Cantarelli et al. 2010; Geels 2011; North 1990). Thus, actors continue to do the same without noticing the alternatives or without seeing their advantages. Cantarelli et al. (2010) distinguish over-commitment, self-justification, and inflexibility as indicators of institutional lock-in. Even if actors notice an alternative and acknowledge the benefits of a new system, they present the commitment already made to the existing system as a reason to continue the same. To justify remaining in the existing system, actors may also focus on specific outputs of the existing system that could not be attained by the new arrangement. Moreover, since actors maximize the short-term benefit, a symbiotic relationship between actors and the existing system over a longer period also favours the continuation of the same system (North 1990). These are the 
different indicators of institutional lock-in that lead to the use of sub-optimal alternatives and cosmetic changes rather than to a fundamental shift in policy or system, as a result of actors' inflexibility that blocks the opportunity for considering alternative ways to organize changes.

While acknowledging the importance of the institutional lock-in to system change, it is also necessary to examine the root causes of lock-in, which involves unravelling how institutions function. As indicated by Geels (2004), a system does not exist without interacting with other systems, and thus it cannot change on its own. Rather, it is deeply interwoven with other systems as well as with the institutions that provide the background to the system (North 1990). Some of these institutions give meaning to the existing system, and also shape how actors view the existing and alternative systems, which becomes an important reason for the lock-in (Lee and Gloaguen 2015). For Lee and Gloaguen (2015), in addition to presenting the lock-in, it is also important to examine the causes of the lock-in, which are deeply embedded in the institutions that define societal structure.

\subsection{Data generation and analysis}

Empirical data to answer the current research question - why has the Ethiopian government still not formally endorsed the use of DSM? - were generated through semistructured interviews with informants (see section 4.3 above for the details) and document review. This research question is a continuation of the outcome of the research question discussed in Chapter 4 - how have the regional seed core groups introduced DSM from below in the top-down governance culture of Ethiopia; and how have they been able to expand DSM? In addition to the interviews, a desk study was carried out in order to understand the problems of seed marketing and the practice of DSM. Different reports of ISSD, the ATA and a discussion paper produced by International Food Policy Research Institute (IFPRI) on DSM, in particular, were reviewed.

Interview data were transcribed and uploaded into Atlas.ti for analysis. Data were coded focusing on the main research question of why the Ethiopian government has still not formally endorsed DSM despite the support of its expansion. All texts that describe the reasons behind not endorsing the use of DSM were coded by reading the transcribed interviews. Whenever new ideas and reasons emerged, new codes were included. These primary codes were grouped and regrouped into families, and the quotations attached to the codes were used to make a structured description of the reasons for not endorsing DSM. Supported by the theoretical concepts introduced above, and also referring to the literature on decision making in Ethiopia, the description was further synthesized to illustrate the cause of non-decision making. 


\subsection{The challenges of the centralized seed distribution system}

For the Ethiopian government, agriculture remains a top priority, not only because agriculture plays an important role in economic development, but also because the government sees poverty and food insecurity as major threats and sources of conflict (Alemu and Scoones 2013; Diao and Pratt 2007). In 1993, an NGO called Sasakawa Global2000, piloted agricultural technology packages released by public research organizations. The government applauded the package, and the late Prime Minister Meles used his political power to promote the approach (Keeley and Scoones 2000). In 1995, the government decided to use the approach for its national agricultural extension system, calling it the National Agricultural Extension Intervention Programme (Spielman, Mekonnen and Alemu 2013). Under this system, the number of participating farmers in the extension programme increased from 32,000 in 1995 to 3.8 million in 2000, and to 4.2 million in 2002 (Spielman et al. 2010). Executive leaders at all levels were given the responsibility of implementing these centrally planned activities of technology promotion (Alemu 2011; Gebremedhin, Hoekstra and Tegegne 2006a).

The agricultural technology promotion activities dramatically increased the amount of seed required for the demonstration plots, as well as for supplying seed to farmers who had adopted the technology. However, the state-owned seed enterprise, the major seed producer, and the few private companies in existence at that time, were unable to satisfy the increasing demand for seed (Sahlu, Alemu and Atlaw 2012). The Ethiopian government initially started seed distribution to allocate available seed fairly. Under this system, seed producers sell their seed in bulk to a representative of a district (for details see Chapter 4). The regional government, in collaboration with the unions and cooperatives, arranges the logistics so that seed is made available for farmers (Gebremedhin, Hoekstra and Tegegne 2006a; Lakew and Alemu 2012). Towards the end of the 1990s, the government put effort into increasing seed production and significantly changed the scenario (Alemu 2011). However, the government remained involved in seed distribution and it has become clear that since 2001 the government of Ethiopia has been following a developmental state political economy model, which means that the government takes the lead in economic development (Simon 2011). The government continues to support seed production and to strengthen farmers' cooperatives to be used as a channel for seed distribution. By 2006, cooperatives were distributing 70\% of the inputs required by farmers, and the target is to reach $90 \%$ (Tefera, Bijman and Slingerl and 2016). The regional governments were also encouraged to coordinate the supply of agricultural inputs (Gebremedhin, Hoekstra and Tegegne 2006a). In some regional states where cooperatives are not well organized, the district office of agriculture buys the 
allocated seed and sells it to farmers (Benson, Spielman and Kasa 2014; Chanyalew 2015). Seed distributed under such a system is mainly for major food crops, chiefly cereals (maize, wheat, teff, barley), and limited amounts of pulses and oil crops.

Despite the government's efforts to distribute seed, there have been persistent challenges. The major challenge in this system is the inefficiency of seed distribution, which is attributable to untimely delivery of seed, and a mismatch between supply and demand, which results in seed being left over in the stores. Paradoxically, seed has commonly remained unsold even though farmers' demand has not been met (Atilaw and Korbu 2012; Gelaw 2012). Data from Oromia regional state shows that while maize seed supply met only $29 \%$ of the demand in $2011 / 12$, 38\% of the maize seed supplied to this regional state was left unsold (Gelaw 2012). Similarly, in Amhara regional state, 63\% of seed made available in 2011 was left unsold (Astatke et al. 2015). At the national level, half of the 28,493 tonnes of hybrid maize seed produced was left unsold in 2010/11 (Atilaw and Korbu 2012). The production of different classes of seed (pre-basic, basic and certified) is centrally planned, contributing to the mismatch between production and the actual demand, both in terms of volume and varieties (Lakew and Alemu 2012).

Seed is left over because of the inaccuracy of demand estimation, poor timing, and above all the lack of accountability in the distribution system (Atilaw and Korbu 2012; Gelaw 2012; Spielman, Mekonnen and Alemu 2013). The chain from demand estimation to final sale of seed is very long, and the entire process involves many actors, blurring the accountability. The major actors are the BoA including its district offices, the CPA and its branches, cooperative unions, and primary cooperatives (Chapter 4). An error in the chain made by one of the actors leads to seed being left over. Whenever necessary, different government officials at different levels intervene in the process, to ensure the transport of the seed to the stores. These interventions further complicate the distribution system.

While the shortage of seed and late distribution are common challenges that force farmers to use grain as seed, the quality of the seed delivered is also poor. In addition to the low capacity of the regulatory system to ensure quality, this is also related to lack of accountability in the process of seed distribution (Alemu and Tripp 2010; Astatke et al. 2012; Lakew and Alemu 2012). In the first place, cooperatives are only asked to collect and distribute the seed, and thus it is not their responsibility to check the quality. Secondly, the involvement of many actors makes it difficult if not impossible to pinpoint the cause of the problem. In such cases, farmers may complain about the low quality of seed, and development agents and district offices of agriculture may do likewise, but specifying who along the supply chain created 
the problem remains a challenge. Even if identification is possible, the actor responsible is rarely held accountable. As such, the poor seed quality remains a cost to the farmers.

\subsection{DSM and its benefits}

In DSM, producers supply seed to their agents at market centres; there is no lengthy process of seed allocation, and communications requiring approval from different government officials are no longer necessary. These improvements have helped reduce the delay in supply, and farmers now also buy directly without having to wait for approval. The results indicate that DSM has contributed in addressing the main challenges faced through the centralized seed distribution system. Since the start of DSM as a pilot in 2011, the area covered and seed sold through DSM have been steadily increasing. Nearly all the seed producers in the three regional states of Amhara, Oromia and SNNPR are taking part in the pilot, and DSM is now considered as an alternative channel of seed marketing (Chapter 4). In addition to using different opportunities and strategies that have contributed to its expansion, the advantages of DSM over the centralized distribution system have contributed to its expansion (Benson, Spielman and Kasa 2014; Getahun et al. 2014). Beyond changing the role of actors and the seed marketing system, there are other aspects that actors mention as benefits of DSM. Benson, Spielman and Kasa (2014) reported that farmers who planted hybrid maize in the districts where DSM was being piloted expressed high levels of satisfaction with the quality of seed and the process of accessing seed. They also noted that the timely delivery of seed reduced the amount of seed being left over, and they highlighted a reduction of public costs and workload as major advantages of DSM. Other studies not only confirmed these findings but have also added efficiency of service and accountability resulting in enhanced access to quality seed as important benefits of the pilot (Astatke et al. 2015; Getahun et al. 2014; Nefo et al. 2015). These benefits are further elaborated below.

\subsubsection{Reduction of leftover seed}

Companies try their best to supply seed in time, update estimates of seed demand frequently, and only transport the amount and type of seed that the agents are sure of selling (Astatke et al. 2015; Nefo et al. 2015). So, the companies replenish seed from time to time, taking account of changes in demand as well as of the amount of seed made available by other companies at the selling point. This process has helped the companies to reduce the amount of unsold seed left in the agents' stores. According to the report of the ATA (2015), DSM reduced the unsold seed to "less than $5 \%$ in nearly all outlets compared to a historical average of almost $20 \%$ in other traditional seed distribution centres" (p. 46.) Moreover, the companies transport any seed left 
unsold from the sales centre where there is no demand, to other centres where there is demand (Astatke et al. 2015; Nefo et al. 2015). This practice is virtually impossible under the centralized distribution system, as the seed allocated to a district is related to the district budget, which cannot be transferred to another district. In the case of credit default, the value of unsold seed is deducted from the district budget, which limits the transfer of unsold seed in one district to other districts (Astatke et al. 2015; Gebremedhin, Hoekstra and Tegegne 2006a).

\subsubsection{Enhanced access to quality seed}

Another major contribution of DSM is improved seed quality, as a result of the accountability embedded in DSM (Astatke et al. 2015; Getahun et al. 2014; Nefo et al. 2015). As opposed to the centralized distribution system, in which companies are not accountable for a quality loss because of lack of practice, with DSM companies are directly responsible if the seed does not meet the required standard. This is because in DSM the seed is only handled by the seed producer and agent, making it is easy to identify the producer in cases where there are problems with quality. In the three regional states of Amhara, Oromia and SNNPR, there have been cases where poor quality seed has been traced back to specific companies, and the farmers have subsequently been compensated (Astatke et al. 2015; Getahun et al. 2014; Nefo et al. 2015). Learning from this experience, in 2014 a company that supplied low quality seed in Amhara, was made accountable under the centralized seed distribution system (Astatke et al. 2015). In the past, it might have been possible to identify a particular actor, but actors were not held accountable for supplying poor quality seed. In addition to the complexity of identifying the actor, this is very much related to the lack of putting policies in practice. The DSM forces producers to consider their production system, to make sure that they supply good quality seed. Moreover, all seed producers, except one international company (Pioneer Hi-Bred), produce the same varieties of maize ${ }^{28}$ released by public research institutes, and the government supplies basic seed to the seed producers. For these companies, the major competition factor is the quality of their seed. Thus, companies make all possible efforts to supply better quality seed, to attract more farmers. The embedded accountability has indirectly contributed to an improvement in seed quality when compared to the seed produced during the period when the companies were selling

\footnotetext{
${ }^{28}$ Currently, maize dominates DSM activity, mainly because this is the only crop seed produced by different companies including private. The production of seed for other food crops is often limited to public companies (one at national level and one in each of the regional states).
} 
in bulk to the central distribution system (Astatke et al. 2015; Getahun et al. 2014; Nefo et al. 2015).

\subsubsection{Reduction in public expenditure}

A final benefit of DSM is related to a reduction of public expenditure. DSM has a demonstrably clear financial advantage for the government over the central distribution system. Every year, the regional state governments allocate a budget for the purchase of seed, to be recouped by selling the seed. Oromia regional state, for instance, allocated about USD 22.95 million in 2010/11 and USD 32.17 million $^{29}$ in 2011/12 (Gelaw 2012). With DSM, it has not been necessary to allocate a budget for purchasing seed. Furthermore, DSM has helped the government save money previously lost because of unsold seed and unpaid loans ${ }^{30}$ (Astatke et al. 2015; Getahun et al. 2014). Regional governments underwrite seed and fertilizer credit, and they have paid out large sums of money annually because of loan defaults and unsold seed (Chinigò and Fantini 2015; Fantini 2013; Spielman et al. 2010). In addition to paying the value of unsold seed to the bank, the leftover seed could not be used because of poor storage, implying a loss of public resources. In 2014 and 2015 in Amhara regional state alone, seed with a value of about USD 70 million, which was left unsold, was destroyed as it had spoiled as a result of being poorly stored for some years (informant 79). With DSM, the risk of unsold seed or unpaid credit is borne by the companies instead of by the government's budget. Companies make all efforts to minimize these costs, but in the case of the government, there is hardly any effort to minimize the costs. Last but not least, DSM has reduced the workload of government offices involved in allocating seed, arranging credit, accessing seed, tracking its transportation and delivery to farmers, and arranging credit repayment if necessary (Benson, Spielman and Kasa 2014; Nefo et al. 2015).

\subsection{Dangling to institutionalize DSM}

The results of the analysis indicate that executive leaders at different levels recognize the stated benefits of DSM, which is evident in measures taken by these executives. Regional bureau heads in the three regional states have requested their regional seed enterprises to become actively involved in the piloting (informant 51, 54, 79). In 2013, the MoA wrote to the BoAs, requesting that the piloting be continued. When preparing the second five-year Growth and Transformation Plan (2016-2020), ${ }^{31}$ the

\footnotetext{
${ }^{29}$ Figures converted from local currency to United States dollars (USD) using an average exchange rate for the period (1 USD $=17.34$ Birr).

${ }^{30}$ Recently, some regions such as Oromia have stopped providing seed on credit, to minimize loan defaults.

31 GTP II is the second five-year government plan for the period 2015/16 - 2019/20, with different development targets and means to achieve them.
} 
MoA included seed marketing as one of the strategies for efficient seed distribution, and the plan was cascaded to the regional states (informant 65; FDRE 2015). At various meetings, the achievements obtained through DSM have been discussed and deemed a success by government officials, and the area covered by the pilot has expanded over the years (informant 59,65). However, so far, no official approval has been given to using DSM beyond piloting. About 75\% of the interviewees doubted whether DSM would be adopted as an official system in parallel with or to replace the existing seed distribution system. This doubt arose because of various reactions and actions of the executive leaders, and policy decisions that do not seem to support DSM.

What is striking to some interviewees is that executive leaders have not reacted as proactively as they normally do when they observe the potential of a given pilot (informant 15, 29, 48, 61, 62). Experience shows that if the claimed benefits of a pilot attract the attention of the government, executive leaders exploit this to design a policy or an approach, and the pilot is then changed into full-scale implementation. One commonly cited example in Ethiopia is the change of extension system to the National Extension Intervention Programme after observing a scheme piloted in the 1990s, as described earlier. In that case, the government adopted the system even before the pilot had ended. Using experience from elsewhere is still common practice in Ethiopia. Examples include adopting a developmental state approach, based on experiences from East Asian countries (Fantini 2013; Fourie 2013); developing an agro-industrial zone and establishing agricultural technical vocation education and training, based on experiences from China; restructuring the agricultural research system, based on experiences from India; and promoting a bioenergy strategy, based on experiences from Brazil (Alemu and Scoones 2013). However, despite the support of executive leaders at regional and national levels to expand the pilot sites, the executive does not seem to be interested in adopting DSM as a system beyond piloting (informant $48,61,62$ ).

The actions of the executive leaders also reveal a lack of intention to use DSM in the future. BoA and MoA officials regularly monitor DSM activities. However, in this monitoring process, attention focuses on seasonal physical targets, (the amount of seed planned to be made available for farmers), and the discussions focus on whether this target has been achieved (informant 52, 59). This process misses a critical evaluation of the approaches used to make the seed available, and therefore there is no evaluation that could lead to the decision of whether or not to continue to use DSM (informant 56). Moreover, during the piloting of the last six years, the BoAs have not taken the initiative to plan and implement DSM. Instead, the BoAs 
only coordinate DSM activities with the initiation and support of ISSD and the ATA (informant 52,57). This shows a lack of internal motivation in the BoAs to use the experience of the pilot to help in deciding whether to use DSM as an approach in the future. So far, the government's interest in supporting the pilot has been limited to its contribution to achieving the annual seed delivery targets (informant 15, 47, 50).

The government's decision to exclude details about seed marketing from the seed regulation that was enacted in 2016 further confirms its lack of commitment to officially make DSM one of the marketing channels in the future. While the regulation deals in detail with variety registration and quality control, the issue of seed marketing is excluded. In fact, the only relevant article in the regulation, Article 17 , says " $[\mathrm{t}$ ] he distribution of seed shall be carried out in accordance with the detail implementation directive to be issued by the ministry" (CoM 2016: p. 8843). Article 17 of the regulation implies that the ministry intends to continue seed distribution, but there is no indication of using seed marketing. Given the experience from the pilot and the provisions of the seed law regarding seed marketing, the regulation could have included the regulatory details to facilitate the implementation of seed marketing. Moreover, Article 17 does not specify how seed distribution should be carried out; this is also left for a future directive, showing that issues related to seed marketing have been systematically excluded from the regulation.

From the above, it is clear that the executive leaders support the DSM pilot, but are not interested in formally adopting DSM as one of the official approaches for seed marketing. There has been little interest from the executive to use the experience of the pilot for deciding whether to use DSM in the future. Similarly, the government has not included the issue of seed marketing in the new seed regulation to facilitate the smooth implementation of seed marketing. However, despite these signs of not adopting DSM beyond piloting, no decision has been made against the use of DSM either. Such ambiguity indicates that there are competing or even conflicting objectives regarding the use of DSM, leading to non-decision. The following section explains why a decision has not been made about DSM in Ethiopia.

\subsection{Non-decision explained}

Analysis of data generated in the interview shows that the non-decision making of the executive is related to both institutional lock-ins, whereby the issue of DSM was omitted from the decision-making agenda, and a deep structural issue, which guided the decision-making process. These two issues explain non-decision making at different layers of cause, and are discussed in the following sub-sections. 


\subsubsection{Three institutional lock-ins}

Over the last six years, except for the piloting, the issue of DSM has not been presented to the executives for decision. This is reminiscent of one of the theoretical concepts discussed above: non-decision making is organized through institutions that systematically exclude a particular issue from the agenda (Bonal 2012; Burnell 2002). The analysis revealed three major reasons behind excluding the issue of DSM from the decision-making agenda, including the interest of bureaucrats to have a decision without their contribution; the symbiotic relationship between the existing system and actors; and the perception that distribution is the only way to achieve developmental targets. These reasons are further elaborated below.

\section{Bureaucrats want the decision to be made without their contribution}

According to many informants, the DSM pilot started with the objective of testing whether DSM serves the seed delivery objective better than seed distribution. Among the three quarters of interviewees who doubted DSM would be continued, $58 \%$ expressed the need to have a directive for its implementation. Accordingly, the pilot needs to be concluded by presenting the pros and cons of the two seed marketing systems to the executives (informant 45, 57, 59,61). The conclusion will help the executives to formally decide whether to use DSM or not. If the decision is 'yes', a directive for its wider implementation will follow. To implement DSM beyond piloting, implementers in the regional states seem to be waiting for the official conclusion of the pilot and subsequently a written directive from the MoA. This indicates that at the regional level, DSM will remain a pilot until the ministry provides the regions with an implementation directive. However, the idea of having a directive was contested by a high-level bureaucrat from the ministry (informant 12). According to this bureaucrat, although there is no regulatory detail, the existing policy does not restrict the implementation of DSM. The regional states can use DSM to improve the efficiency of seed supply without an additional policy directive.

The arguments of the bureaucrats at both levels seem to avoid the issue of DSM at their level by pushing it to the other level: if the issue is handled at the other level, the bureaucrats are not required to provide the executive at their own level with a recommendation about the decision. Confirming this behaviour of the bureaucrats, many interviewees argue that the bureaucrats in the ministry and bureaus are not confident about presenting a clear recommendation to the executives (informant 57, $62,75)$. Instead, bureaucrats at all levels practice self-censorship, and only focus on the implementation of the given activities (informant 57, 77). The major lock-in is that bureaucrats expect a decision but do not wish to contribute to the decision, and 
this has systematically limited the bureaucrats from presenting a recommendation for decision about DSM.

\section{There is a strong symbiotic relationship between actors and the seed distribution system}

Seed distribution is a well-established system that has also developed a symbiotic relationship with actors in the system, making it difficult to easily withdraw from it. The main functions of the MoA and BoAs, concern extension service and regulation. The primary objective of the extension service is the transfer of knowledge. However, experts and bureaucrats in these organizations tend to provide seed to farmers so as to see the outcome of their extension service (informant 46). As such, they have been providing farmers with agricultural inputs, including seed, for a long time (Belay 2002; Bishaw 2004; Kassa 2008). Thus, seed has been in the grip of the extension service, and the system has become well established. The current approach of the government, as a developmental state, has strengthened this already welldeveloped culture of supplying seed through the government system. This approach added amount of seed to be distributed as a target, established a coordinated system for input distribution, and increased the numbers of agricultural extension workers, to the centralized seed distribution system.

The target amount of seed to be distributed is set for each district annually, and this is coordinated by a structure established from district to national level. In turn, this is supported by extension workers in the village. With over 60,000 agricultural extension workers, Ethiopia has the lowest ratio of farmers to extension workers in the world (Alemu and Tripp 2010; Berhanu and Poulton 2014; Davis et al. 2010; World Bank 2016). This has routinized the process of the seed distribution system. For those involved in the system, it is a job for which they are employed, creating a symbiotic relationship between the actors in the extension structure and the distribution system (informant 51, 62, 78). This symbiotic relationship supports the continuation of the same system rather than adopting a system that will affect the jobs of these actors. As a result, the bureaucrats have not provided a recommendation to the executives to change the system. This means that although the bureaucrats recognize the increases in efficiency gained through DSM, and they have no objection to the use of DSM, it is hard for them to initiate a decision that would affect their job; consequently, they have not yet presented the executives with a recommendation to use DSM.

The symbiotic relationship is not just limited to the bureaucratic structure but also extends to the seed companies, which hinders them from exerting pressure for change. Currently, the companies have neither the capacity nor internal motivation 
to sell seed directly to farmers. This is because they have not developed a marketing capacity, as they are dependent on the government for the marketing of seed, to the extent that some of the state-owned seed companies see themselves as part of the regional BoA. Some private seed companies consider themselves as out-growers of the government. This is partly because in the distribution system, they take basic seed from the BoA and supply the certified seed through the distribution system. In the distribution system, seed companies, both state-owned and private, do not incur the cost of marketing (informant 73). The distribution system has put these companies in a comfort zone, as they transfer all marketing costs and risks to the government, and the companies have not developed the capacity for marketing (informant 19, 67, 72, 78). Moreover, at least in the short term, both state-owned and private companies do not see any economic incentive in being involved in seed marketing. Involvement in marketing increases their costs, workload and risks, but these have been shouldered by the government. For state-owned companies in particular, the distribution system guarantees they will make profit, as they have the leverage to decide on price through simple consensus among themselves (Benson, Spielman and Kasa 2014). Because of this economic incentive for the companies to remain in the distribution system, they do not put pressure on the government to change the existing system.

Seed distribution is perceived as the only way to achieve development targets

The government has different development targets to achieve. One is the amount of seed to be made available at distribution centres. Executive leaders at all levels are given these targets to attain, and their performance is evaluated accordingly (Alemu 2011). The targets are cascaded throughout the structure, and the bureaucrats implement different activities to make sure that they are achieved. As opposed to this, DSM is perceived by bureaucrats as market liberalization. Moreover, although the major suppliers of seed in Ethiopia are state-owned companies, DSM is associated with private companies, which in turn are perceived as solely focused on profit. Because of these perceptions, DSM is expected to preclude direct involvement of the government bureaucracy in the seed supply process. If they have no direct control over the process, bureaucrats are not sure whether they will achieve the targets (informant 15, 75, 79). Instead, the government has established cooperatives in most parts of the country, which the bureaucrats can control. The ATA's proposal to set up and strengthen an agro-dealer network during its establishment at the end of 2010 was rejected by the government on the grounds that there were already many cooperatives in the country that could be used for seed distribution (informant $15)$. 
Another target related to seed distribution is the issue of equity. Although Ethiopia is a federal state, the central government plays a major role in guiding economic development. Beyond economic development, the central government also wants to ensure that the available seed is fairly distributed across the different administrative units. This strategy started when ESE, a state-owned seed company under the national government, dominated seed production. With this strategy, the allocation of seed starts at the national level, to ensure that the regional states get their fair share of the available seed (informant 80). This avoids complaints at all administrative levels. The government continues to follow the same strategy despite the increase in seed production with the establishment of the regional seed enterprises. Bureaucrats consider that if seed marketing is left to the companies, it will be difficult to distribute seed fairly, not only among the regional states but also among districts within the regional states (informant 12, 43, 62, 63). Given the general shortage of seed, the bureaucrats expect that if companies were allowed to sell, they could sell all their seed in the accessible areas alone, and the inaccessible areas might not get any. To avoid such imbalances and the resultant complaints, the government allocates seed to all distribution centres, and according to these interviewees, DSM does not guarantee this output.

The bureaucrats are committed to these targets, which are important for the government as a developmental state. The targets are critical outputs at all levels, and the implementers need to have control over the process. As long as the bureaucrats are given these targets to attain, they will continue to use the existing system over which they have control, rather than to rely on a system over which they have no or less control. The system of delivery is thus routinized and there are investments in the infrastructure, including the development of cooperatives at local level. Such a routinized system and commitment to attain targets through control will continue to prevent the bureaucrats from presenting a new idea for change.

\subsubsection{Deeply rooted structural challenges}

The above discussions show how the idea of DSM has been excluded from the decision-making agenda of the officials. As a result, the pilot has continued without an official decision being made about its use. But one could also ask whether the reasons used for excluding DSM from the agenda have something in common. Returning to the concept of non-decision making, if the lock-ins discussed above systematically omit the issue of DSM from the decision-making agenda, then they may have a common origin.

During the initial stage of introducing DSM, the major topic of discussion was not whether or not DSM helps to overcome the problems of seed distribution 
inefficiency, but whether or not DSM is in line with the government's approach. Moreover, presenting the idea of DSM to the bureau head was difficult, mainly because it was assumed that the bureau head would not accept DSM, because DSM is perceived to be outside the government approach (Chapter 4). This shows the existence of underlying reasons at a more structural level from which the lock-ins emanated. Such underlying reasons, as indicated above, are not part of a specific policy on paper but rather form a general policy direction, which may not be equally clear for all. These are the economic development approach and political system, which together guide the making and implementation of economic policy in Ethiopia. That is why the regional core groups referred to the bureau heads for the approval of piloting DSM in 2011.

Ethiopia follows two different economic development approaches simultaneously. The first, a market-oriented economic system, has been followed since 1991. As reported by de Waal (2013), the late Prime Minister Meles "clearly stated that there should be no confusion that the EPRDF's mission is to build a capitalist state" (p. 151). However, despite a series of proclamations that emphasize the importance of the private sector, control of the agricultural input market began when the private sector in the fertilizer market was crowded out by the ruling party holdings in 1998 (Gebremedhin, Hoekstra and Tegegne 2006a; Hagmann and Abbink 2011; Rashid et al. 2013). Moreover, while vegetable seed is still sold under a liberal market system, as only a limited number of farmers use it, the government is heavily involved in the distribution of seed of major food crops (Hassena and Dessalegn 2011).

By 2001, the Ethiopian government had declared itself as a developmental state to speed up economic development and eradicate poverty (Gebresenbet 2014; Hailu 2014; Simon 2011). This is the second system currently followed that is critical particularly in policy making and implementation in Ethiopia. Theoretically, the developmental state concept places emphasis on the capacity of the state structure (organizational, technical, administrative and political) to effectively implement the hegemonic developmental project created by elites (Fantini 2013; Mkandawire 2001). To this end, it is important to have a competent bureaucracy based on merit and with long-term professional career prospects (Evans 1995; Fritz and Menocal 2007; Rauch and Evans 2000). However, as argued by Lefort (2012), the version of the developmental state in Ethiopia does not include this concept as a necessary condition. Lefort (2012) further explains that the executive leaders of Ethiopia believe that they can formulate policies on their own and guide their implementation. This policy making approach denies experts and bureaucrats the capacity and power to operationalize hegemonic development projects as well as to 
give constructive suggestions in the decision-making process, particularly when the idea is outside the frame of the government. Instead, they are limited to implementing activities to achieve the given targets. The lock-ins are linked to the power relations between executives and bureaucrats in the system; and in the following paragraphs, the lock-ins are discussed against this background.

Because they have limited power, there is a high level of self-censorship among the bureaucrats and experts at all levels, to ensure they do not stray outside the frame of the government (Kassaw and Weldselassie 2015). The bureaucrats know that seed marketing falls outside the seed distribution frame of the government. Promoting an idea that is outside the frame of the government brings the risk that the experts and bureaucrats will be labelled as 'anti-development,' which is undesirable (Fantini 2013; Gebresenbet 2014; Vaughan 2011). Thus, regardless of their capacity, bureaucrats do not want to make suggestions when technical issues are dominated by political imperatives (Alemu 2011). This is directly related to one of the lock-ins: bureaucrats at both regional and national levels expect a decision to be made without their contribution. While both the ministry and the regional state have been issuing different regulations and directives, bureaucrats at both levels have been pushing the issue of developing a directive for seed marketing to the other level, instead of drafting one and putting it on the table of their superiors. By doing so, they want the decision to be made at the other level without requiring them to contribute.

Similarly, because of the power difference and the wish to remain within the frame, bureaucrats do not want to suggest different ways of attaining the targets. Different targets are set and cascaded to the lower levels as an approach to development, and bureaucrats at all levels are responsible for achieving them. These targets are given to the bureaucrats together with the means (extension and cooperative systems) to attain them. The use of the extension system for input delivery has long been criticized, as it influences the effectiveness of extension work (Belay 2002; Gebremedhin, Hoekstra and Tegegne 2006b; Kassa 2008). However, for bureaucrats, these are the structures over which they have control to implement development plans and attain the targets. Given the power relations they have with executives, the bureaucrats lack the courage to suggest different ways of achieving these targets.

Another issue that is strongly linked to the distribution system is that of equity, where different administrative units have to receive a fair share of the available seed. This is related to one of the objectives of using the developmental state approach: poverty eradication, which officials are obsessed with. To achieve such an objective, the top officials wish to ensure that inputs are distributed fairly across the different 
administrative units. This critical output can be achieved under their control through the distribution system, and bureaucrats have no confidence that it would be attained through DSM. The process of trying to achieve the targets (amount of seed and equity) leads to the other lock-in: the routinization of the input delivery system in the agricultural extension structure. In some cases, the extension structure distributes the seed, and in other cases it assists the cooperative structure to distribute the seed. Thus, the lock-ins are related to the developmental state approach used in Ethiopia.

Currently, one of the concerns of government officials in relation to the equity of seed distribution is the potential of DSM to cover marginal areas and minor crops. This emanates from the view that DSM is a substitute for the current distribution system, which is standing at one end of the complex system, closing the door not only to the final decision to use DSM, but also to deliberation about reconfiguring the seed marketing constellation. Given its business orientation, DSM cannot address marginal areas and minor crops that have less economic return for the seed companies. This calls for reconfiguring the seed marketing constellation, and identifying a different marketing system that targets different geographical locations and crops. However, lack of interest from the bureaucrats to present a recommendation on the future of DSM closed the opportunity to deliberate on the future of the seed marketing constellation with the executives, resulting in no decision being made.

To gain a comprehensive understanding, it is necessary to go one layer deeper and reveal the importance of seed as a political commodity. Although the government has decided to develop a market economy, this is through a selective partial liberalization process (Bach 2011; Chinigò and Fantini 2015). For the current ruling party, which emerged from a Marxist-Leninist background, marketing policies for strategic sectors are designed and implemented in recognition of the importance of neo-liberalism, to avoid being hostile to the 'West' (Alemu and Scoones 2013; Bach 2011; Vaughan 2011). However, as will be discussed in the next paragraphs, seed for food crops is such an important commodity that it also has political value for the government and thus should remain under government control. Seed distribution is part of the government's developmental state approach, which frames poverty as an avalanche. Such framing has much deeper implications in terms of the role of government in controlling economic activities. As reported by Ohno (2009), the developmental state in Ethiopia is not simply a concept, but entails "very pragmatic and action-oriented guidelines to inform the legitimacy and the policy formulation and implementation of the present Ethiopian government" (p. 2). The 
developmental state gives power to the executive leaders to promote, drive and control the process of economic development, to address two goals at the same time: the attainment of economic development goals as discussed above, and political control (Chinigò and Fantini 2015; Fantini 2013).

Chanyalew (2015) reported that the ruling party maintains core institutional units that are related to the farmers and uses them as politically influential segments of society, thus maximizing its political gain by creating a strong link with them. As also noted by Vaughan (2011), the direct coalition with the people is what the late Prime Minister Meles set as an important strategic direction. Moreover, according to de Waal (2013), the late prime minister believed that "the peasant is the bedrock of a stable developmental coalition" (p. 155), which is the cornerstone of the strategy of the ruling party. In the revolutionary democracy and the programme of the ruling party document, farmers are considered as important supporters of revolutionary democracy (EPRDF 2001). It is thus important for the ruling party to directly provide agricultural inputs, including seed, as one of the strategies for attaining and maintaining strong links with farmers. Prior studies in Ethiopia have shown that agricultural input and extension services are used as a means to favour a certain group of farmers, showing the government's vested interest in remaining in the process of seed distribution (Berhanu and Poulton 2014; Chanie 2007; Chinigò and Fantini 2015; Lefort 2012). Thus, the distribution of seed of the major food crops is used as a strategy for creating a strong political link with the majority of the farmers, and for attaining economic growth. This is in line with the argument of Berhanu and Poulton (2014) about the extension service that investment in agricultural extension in Ethiopia is to attain two objectives:

The formal objective has been to enhance the productivity and production capacity of smallholder farmers so as to stimulate broad-based growth. The unstated objective has been to extend the political control of the EPRDF throughout the country (Berhanu and Poulton 2014: p. 209).

Therefore, the reason why no decision has been made about the use of DSM is related to the use of seed distribution for both economic development and political control. The above discussions also strengthen our starting point: that policy making is inherently complex, and that a given problem may be understood differently at different levels. 


\subsection{Conclusion}

On the one hand, executives in the MoA and BoAs have seen the benefit of DSM and accordingly support the expansion of the pilot. The pilot has been implemented for six years, the area under the pilot has expanded, and seed producers in particular consider DSM as an alternative seed delivery channel. On the other hand, our analysis shows that various lock-ins have hindered the embracing of DSM as one of the channels or approaches to delivering the available seed to farmers. Defining the challenges behind the lack of a decision about seed marketing in Ethiopia is complex, as the observed lock-in at the operational level is the reflection of the deeper structure that created these challenges. Although this is a common phenomenon of complex societal challenges, in the Ethiopian case the inseparability of the government and the ruling party adds to the complexity.

Many have observed that there is no separation between the government and the ruling party in Ethiopia (Bach 2011; Fantini 2013; Veen 2015). Fantini (2013) points out that "a single Amharic word, menghist, indicates at the same time the state, the government and the party in power" (p. 4). The government and the ruling party are closely related, as the government policies are a reflection of party objectives; as noted by Veen (2015), in Ethiopia "the state becomes partly an instrument of the party" (p. 23). Thus, the institutions reinforce each other, and in the context of this study, this is through the developmental state approach. The ruling party puts its political value into practice through the government bureaucratic structure, and the bureaucratic structure uses the values in the ruling party to strengthen its rules of the game. This is in line with the systems change concept of Geels (2004) that systems are not autonomous; rather they are the outcome of a co-evolutionary process of different systems and are deeply embedded in the structure of the society.

This analysis also confirms that policy makers do not necessarily opt for everything that contributes to economic development. The policy decision is made not only because of the observable benefits that may be brought to society, or because of rational arguments, but also because of the political value and its implications (Byerlee et al. 2007). Thus, despite acknowledging the role of DSM in providing seed for farmers efficiently and contributing to economic development, no immediate official decision on the use of DSM has been forthcoming. The reason for this is if DSM is accepted because of its economic benefits, the political interest of the party (creating and maintaining strong ties with the majority of the farmers) is at stake. Regardless of the benefits they observe in using DSM, when deciding about DSM, the executive leaders are constrained by the interests of the ruling party. This shifts the decision about DSM from the government context to the party context. Although 
both are the same in the Ethiopian context, this adds to the complexity of the decision-making process. Therefore, the use of seed distribution for both economic development and political control, with competing objectives, has complicated the decision about seed marketing in Ethiopia. 


\section{Chapter 6.}

Conclusion and discussion 


\subsection{Introduction}

Since its commencement in 1991, the current Ethiopian government has focused on agricultural development, and it has developed several policies both for agriculture in general and for the seed sector in particular. In the case of the seed sector, the first specific policy was the 1997 regulation; this was revised and enacted as a law in 2000, and revised again in 2013. Despite the policies, there have been persistent challenges in the Ethiopian seed sector, including a shortage of seed, the mismatch between demand and supply, seed left over despite not satisfying the demand of farmers, and poor seed quality. Different studies identified technical gaps that limited the performance of the seed sector. In Ethiopia, a limited number of studies have considered policy aspects of the seed sector. These studies have focused on the extent to which policy responds to existing problems, and the extent to which what is in the policy document is implemented. However, why the existing policies have not addressed some of the problems, and why some of the policies on paper were not implemented have seldom been discussed, limiting the full understanding of the challenges of the Ethiopian seed sector.

Policy making and implementation are not value free. Policy options are not selected and implemented only to overcome the problem at hand. Actors in the process prefer to have policies that are in line with their values and interests, which are not necessarily in line with the values and interests of others. Thus, actors in a policy making process can include a certain policy option while excluding others, which from the view of other actors may not help to solve the problem at hand. If the problem persists after the implementation of the policy option selected, it implies that the policy either did not target the problem properly or the policy was meant to serve another, unfolding goal. Similarly, actors who are supposed to implement a policy may intentionally implement some parts of a policy on paper but not others, which others may interpret as policy implementation gap. Actors have different reasons as to why they prefer certain policies, both in the formulation and implementation, and not others. This study goes beyond the identification of 'gaps', and analyses how actors influenced by institutions include and exclude options in policy making and implementation. By analysing how actors and institutions influence policy making and implementation, this thesis contributes to the understanding of seed sector policy challenges in Ethiopia. The main research question focused on addressing how actors and institutions influenced the formulation and implementation of seed policy in Ethiopia from 2008 to 2016.

The study covered both seed policy making and implementation. In relation to policy making, the research reconstructed the process of revising the 2000 seed law 
from 2008 to 2013. The research reconstructed the policy making process, and examined how actors negotiated their preferred policy options and how these negotiations were influenced by the different arenas used in the process (Chapter 2). In this case, the study focused on seed sector governance and variety registration, conducting a detailed analysis. The rounds model and the concept of policy arenas were used to analyse the outcomes of a series of negotiations. To have a clear understanding of the institutions behind the negotiation process, the research further focused on one of the problems of the seed sector that the law aims to address, namely seed quality. The study analysed how actors defined the problem of seed quality in different ways and opted for different solutions (Chapter 3). Frame analysis was used to understand how actors defined the problem differently and preferred alternative solutions. The research also analysed the institutions that shape the frames of actors. These analyses helped to explain how actors influence policy making and the institutions that guided their influence.

The other set of research questions focused on analysing how actors and institutions influenced policy implementation. The process of introducing and expanding direct seed marketing (DSM) in the country, from 2011 to 2016, to overcome the challenges of seed supply was investigated. The research on the implementation process comprised two parts. The first part of the research aimed at understanding the process of introducing and expanding DSM, under the top-down governance culture of Ethiopia and competing discourses on seed distribution versus seed marketing. The concepts of multi-level perspective on transition and transition management were used to understand the process and the outcome. Although the findings of this research indicated an increasing use of the DSM approach in the period 2011-2016 (Chapter 4), there has yet to be an official decision by the government on its future. The second part of the research was based on this finding, and involved analysing the reasons behind the lack of a decision on DSM. The concept of non-decision making and institutional lock-in were used to explain how institutions lead to non-decision (Chapter 5). The analysis of the change process and lack of decision were useful to understand how actors influence the implementation of the existing policies and the underlying institutions that shape this influence.

The aim of this concluding chapter is to summarize the findings of the research by answering the main research question, and to discuss the overall outcome of the research. The main research question - how did actors and institutions influence the formulation and implementation of seed policy in Ethiopia from 2008 to 2016 - was broken down into four specific research questions (Chapter 1). Addressing the specific research questions also included uncovering the institutions that are important in 
shaping actors' influence in seed policy making and implementation. The findings help to broaden our understanding as to why some of the options were not included in the seed-related policy documents and why some policies specified in the documents were not implemented.

Beyond answering the main research question and widening our knowledge, this concluding chapter also discusses the overall outcome of the research, focusing on the existing tension between seed distribution and seed marketing, and between topdown decision making and stakeholders' involvement in the policy making process. Based on the discussion and the understanding of the complex challenges in the seed sector of Ethiopia, this chapter finally provides some suggestions that may help to overcome the problems in seed sector policy making and implementation, and establish the seed sector on solid ground.

\subsection{Conclusion}

Different actors take part in policy making and implementation. However, not all actors have equal influence over what has to be included in or excluded from the policy document. Similarly, actors do not only define what has to be implemented, but also how it has to be implemented. The influence of actors in policy making and implementation depends on the roles and power of those actors as defined by institutions in the system. The following sub-sections discuss how actors and institutions together have influenced seed policy making and implementation in Ethiopia.

\subsubsection{Negotiation of policy options and frames}

The influence of actors on the content of a draft policy document depends on the composition of the actors, as well as the institutions shaping the process. This is mainly because public policy making is neither a one-off effort nor a one-actor role; rather it is a process that involves different actors at different times in different arenas. Not all actors are present in all arenas, and the composition of actors in a given arena determines the output of that particular event. The revision process of the 2000 seed law took about four years of negotiations, and different seed sector policy actors participated at different times. There were several rounds of revision in which drafts were produced and revised by actors in different arenas. The analysis revealed that different policy arenas provided opportunities for different actors to place their preferred policy options on the table, and to get these incorporated into the draft working document (Chapter 2). Focusing on variety registration and the governance of the seed sector, the analysis revealed that the content of the draft working document changed depending on who dominated a particular arena showing the opportunities that actors were using. When experts 
from public organizations dominated the arena, exemption of 'export-only' varieties was excluded in favour of registering all varieties, and establishing a centralized governance system was included in the draft document. In the arenas where the EHPEA was present, exemption of 'export-only' varieties was included in the draft policy document. Similarly, in the arenas where the government officials were present, the establishment of a central governance structure was excluded in favour of decentralization. While such inclusion and exclusion processes are positive steps towards a deliberative policy making process, the final decision remained in the hands of the executive branch of the government. Policies are decided with little consideration of the outcomes of the policy drafting arenas. This is mainly related to the loose connection between the drafting arenas and the decision arenas, and the blurred separation of power between the executive and the legislature.

Decision arenas are in the Council of Ministers (CoM) and the House of Peoples' Representatives (HoPRs), where the draft policies from different agencies are presented and approved. During the negotiation process on the content of the revised seed policy, there was a lack of reflexivity among actors. All actors seemed to pursue their own idea to the end. None of them was willing to give up his/her stronghold and accept the ideas of others, nor agree to find a solution in a compromise. For the expert group, there was a 'right' policy to be followed to change the seed sector, and this was backed by the desire to manage the seed sector. For the government, non-reflexivity persisted because the executive branch of the government has the power to decide on policy by default, although this is formally the role of the parliament. This informal rule, which gives more power to the executive branch of the government, gives leverage to the executive branch not to accept views of others, affecting how policy decision is made. In the first place, there is no strategic link between the processes of the drafting arena and the decision arena. This disconnect blocked the critical decision-making arena from taking into account the views of different actors. The CoM, the arena where critical policy decisions are made, made its decision on the seed policy based only on the content of the draft and briefing provided by the ministry. The framing analysis showed that actors had different views of the problems and thus also suggested different solutions. The ministry was just one of the many actors with their own frames, and the ministry was not expected to present the perspectives of other policy actors, when presenting its policy option to the CoM. Thus, the system of decision making did not allow different actors to participate in the critical decision-making arena to present their preferred policy option, nor did it forces officials from the ministry to present views that had been contested in the drafting arenas. 
Another reason that also explains the disconnect between arenas is related to the blurred separation of power between the executive and the legislative branches of government. The executive branch of the government is dominating the policy making processes. The informal rule is that the legislative branch accepts the exclusive power of the executive branch in policy making and does not critically review the decisions of the executive. This explains the dominant role of the executive and the lack of deliberation and reflexivity in the process. Under such conditions, the ideas of other actors are only considered if they are in line with the values and strategies of the executive branch of the government. Thus, the positive move towards deliberation during the policy-drafting process was not fully utilized by actors in the Ethiopian seed policy making process.

Actors in the policy making process have different perceptions of the problems and accordingly frame the problems and solutions to fit their perceptions. Using a governance perspective, this study identified two dominant frames that describe the cause of poor seed quality, implying different governance solutions (Chapter 3). These frames are labelled as the centralization and decentralization frames, referring to the two main governance solutions favoured by actors. The centralization frame, which is used by experts and bureaucrats, inside and outside the ministry, indicated the lack of centralized seed sector governance as the main cause of poor seed quality in the country, providing the rationale for establishing a central governance structure. From the other side, the decentralization frame, which is used by government officials, emphasized the lack of alignment of seed sector governance with the regional government structure, implying the need to decentralize the governance structure of the seed sector.

This study found that the frames persisted through the whole period of seed policy revision (2008-2013), reflecting a lack of deliberation and reflexivity during the process of seed policy making. The lack of deliberation and reflexivity was aggravated by the fact that the government was only interested in accepting ideas that fitted in with existing political policies. One major policy that the government did not want to overturn was the policy that dissolved the National Agricultural Input Authority, an authority that centrally coordinated the seed sector prior to 2005. The centralization frame of the experts and bureaucrats is, in fact, to have a similar coordinating structure at the national level, which is not in line with the decision made by the government. This closed off any possibility of negotiating for this option, and both groups continued using their initial frame. Therefore, in addition to the perception of the actors that their proposed option would solve the problem better, both frames were embedded in the overall interest and strategy of the actors 
promoting the frames, which resulted in limited deliberation and absence of reflexivity during the process of policymaking.

The frames linked to the problem of seed quality by both groups of actors seem a paradox from the outset. Those who are commonly blamed for centralizing power (the executives) proposed decentralization, while those who have no formal power (experts and bureaucrats) proposed centralization of the governance structure. Decentralization is the strategy of the government. The process started in 1991 and culminated in the constitution that ratified the establishment of regional states in 1995. However, influenced by the long history of central government, the governance in Ethiopia still tends to be centralized. At both regional and national levels, the central government has control of the process, through its regional and national structures. Thus, although the executives at national level promote decentralization of seed sector governance, this does not necessarily means their intention is to give up power. Rather it is a strategy to manage the seed sector at the regional state level as opposed to the national level. The decentralization frame is thus embedded in the institution that created a federal structure in Ethiopia, which was formalized in 1995. Though the government structure has been decentralized, the central government controls activities in the regions through additional structures like the party system and the Command Post ${ }^{32}$.

In the case of those who promoted centralization, this is related to an interest in leading the seed sector, as bureaucrats and experts based at federal structure currently have no control over seed sector activities in the regions. The bureaucrats at the centre have been detached from implementation activities in the seed sector since 2004 when the NAIA was dissolved, although there was a disconnect even before then, following the establishment of the regional states in 1991. Given the federal structure and general decentralization process, bureaucrats and experts in the centre have no control over the activities in the regions. Since the government follows the developmental state approach, the experts and bureaucrats in the centre are required to guide the sector over which they have little direct control. However, such roles of the experts support their efforts to regain the power to lead the seed sector. Thus, they valued the importance of their role in governing seed quality and proposed the centralization of the governance system that guarantees their control over the sector. The formal principle to follow the constitution, the principle to lead

\footnotetext{
${ }^{32}$ Command Post is a parallel structure to government offices from district to the Prime Minister' s office delegated to get up-to-date information and make decisions on specific tasks. The structure is usually for specific sectors and is organized from the relevant government offices in those sectors.
} 
economic development guided by the concept of developmental state, and the principle of state control over the seed sector are important institutions, which are critical in defining actors' interest, and influencing how actors frame the seed quality problem and associated solutions.

The framing of the problem of seed quality and its governance solution not only showed how different groups of actors viewed the problem of seed quality, but it is also a reflection of the political debate on (de)centralization in Ethiopia. Aligning government services to the regional state structure is important for the current government, which introduced and practiced federalism as a political institution in Ethiopia. Thus, in addition to the objective of solving seed quality problems, federalism as a formal institution shapes actors, in this case the government, to decentralize roles and responsibilities from federal to regional state level. However, this is against the old tradition of centralism in Ethiopia and also affects the power of bureaucrats and experts at the centre, leading to the use of the centralization frame by these actors. For the users of the centralization frame, this is not just about ensuring seed quality: it is about reproducing an old institution of centralism and also about their own empowerment at the federal level.

\subsubsection{Policy implementation through collaborative governance}

Influencing the content of a policy document is an important step, but may not necessarily imply actors' influence on the policy outcome. Actors shape policies at all stages of policy making and implementation. This research analysed the process of initiating and implementing an existing policy to solve one of the persistent problems of the seed sector, namely the inefficiency of the seed supply. The result highlighted how seed sector actors and associated institutions influence policy implementation. On the one hand, the current seed supply regime (centralized seed distribution) is not mentioned in the seed-related policy documents, but it has been in use extensively at least since the end of the 1990s. On the other hand, free seed marketing, which has been provided for in the policy document since 1997, has not been facilitated. This is despite the fact that the sector faces problems of inefficiency in supplying seed to the farmer (Chapter 5).

Since 2011, regional seed core groups, a collaborative governance structure, started piloting DSM at the regional state level and it is currently widely used (Chapter 4). Since 2015, more than a third of hybrid maize seed has been sold through DSM. This research showed that actors had to pass through a complex process to implement the seed marketing policy that had been in the policy document since 1997 (Chapter 4). During the initial stage of introducing DSM, the main issue was not whether DSM would solve the problem of seed supply inefficiency or not. Rather, it was whether 
the government would accept DSM or not. Such discussion indicates that DSM is not considered to be in line with government interests or strategy and thus could be rejected, suggesting that the government did not want to put seed marketing into practice. Consequently, the core groups needed to get approval from the BoA heads to implement DSM. However, the core group did not require such approval for other new ideas to strengthen the seed sector, like activities in seed quality improvement. Although both are formally in the policy documents, the BoA heads have the power to decide what has to be implemented. This requirement - what has (or has not) to be presented for approval - is not obvious for the stakeholders.

Regardless of the complex institutions behind the seed policy implementation, this research showed the potential to implement policy through a collaborative type of governance that creates room for deliberation among different actors. The collaborative governance structure consists of actors from both inside and outside the seed distribution system. The presence of actors outside the distribution system helped to introduce the concept of DSM in Ethiopia. In addition to the demonstrated potential of DSM for improving the efficiency of the seed supply system, strategic management of the governance process helped to expand the approach. Over the years, a significant proportion of seed has been sold through DSM (Chapter 4). DSM is currently used by default in the districts designated for DSM, particularly by seed producers that aim to overcome the problem of carryover seed.

The research also showed that government officials supported the expansion of DSM in the country (Chapter 5). However, while the top-down culture of Ethiopia calls for formal approval of a new system, this research identified some of the actions of the government that signalled the lack of intent to officially endorse DSM in the near future. The critical action of the government against the official endorsement of DSM was the exclusion of seed marketing from the 2016 seed regulation. Moreover, bureaucrats at both national and regional levels would not bring the issue of DSM for decision before government officials. The major reasons are: bureaucrats do not want to contribute to decision making on DSM because they assume that the government has a strong political interest to remain in the seed distribution system; bureaucrats need the seed distribution system to achieve the targets set by the government; and there is a symbiotic relationship between actors, the extension service as well as seed producers, and the seed distribution system, and thus actors want to maintain the distribution system (see Chapter 5 for further details). These perceptions and practices have created an institutional lock-in that prevents bureaucrats from presenting the recommendation to government officials, thereby leading to a non-decision about the future of DSM in the country. 


\subsection{Discussion}

The research has shed light on how different institutions have shaped actors' influence on the processes of policy making and implementation and their outcome. As deeply rooted in cognitive and normative mind-sets, institutions shape actors' views and day-to-day action. In the seed policy making and implementation, institutions affected the definition of problems, agenda-setting processes, identification and scope of solutions, and decision-making spaces and processes. As different institutions reflect different beliefs, values and lines of thinking that underlie policy processes, they can explain incomprehension, disappointment, conflict, and power struggles. This means that a major challenge in the making and implementation of policies is how to cope with these divergent institutions. In the following sub-section, the challenge of coping with divergent institutions in policy making and implementation in the seed sector is discussed.

\subsubsection{Divergent institutions}

The outcome of this research highlighted two conflicting sets of institutions in policy making and implementation in Ethiopia. The first set of conflicting institutions is about market-based thinking versus centralized planning as leading principles for economic development. These two institutionalized ways of thinking on economic development influence the thinking and action in the seed sector, and explain why policies on paper are not implemented and why new initiatives are not formally endorsed. Thus, these institutions are both a political belief to promote economic development, and institutionalized systems of operation. Government policies emphasize the importance of the market-based economy, and this is the case for many of the economic sectors. In recent years, the piloting activities of DSM contributed to the increased awareness of the value of marketing in the seed sector too, and currently seed marketing is practiced in the country. As opposed to the market-based economic development, the other approach is the central planning, and in the case of seed this is the centralized seed distribution system. With centralized seed distribution, the government centrally determines the amount of seed that has to be delivered to a given locality and how. This is an institution that has evolved over a long period and is deeply rooted in the political regime. The seed distribution system as an institution is supported by the developmental state concept, where the government plays the leading role in economic development. Although the developmental state concept is not used against market development in the other sectors in Ethiopia, in the seed sector it has been used as a pretext to continue the centralized seed distribution. Actors in the seed sector use these institutionalized systems and accordingly organize the delivery of seed to farmers. These two conflicting institutions - the marketing of seed and the centralized 
distribution of seed- are functional in Ethiopia's seed sector, and are competing for market share regardless of their current official status.

The tension between these divergent institutions increased because of the dual use of seed by the government: the government has used the seed to both promote economic development and at the same time to maintain strong political ties with farmers. Similar to other studies - e.g. Berhanu and Poulton (2014), Chanie (2007), Chanyalew (2015), Chinigò and Fantini (2015), and Lefort (2012) - this study revealed that a major reason behind the status quo of centralized seed distribution, regardless of improvements made in seed supply efficiency through DSM, or the government's commitment to market-based policy, is that the government considers it to be of fundamental importance to maintain strong political ties with the farmers. For the government, seed distribution 'guarantees' the link with farmers, whereas DSM is expected to result in the opposite. The government has used seed distribution as a political means, making the competition between seed distribution and seed marketing complex.

The second set of conflicting institutions relates to authoritarian versus participatory decision making. These are the authoritative decision-making process of the government, in particular the executive branch, and the stakeholders' role in making and implementing policies. The authoritative decision in policy making and implementation of the executives is rooted in both the old Ethiopian culture of hierarchy and the developmental state concept currently used by the government. Given such a background, the executives 'legitimized' their authority to decide on policy as well as to direct its implementation, with less emphasis on the views of others. At the same time, it has become common practice that stakeholders are organized to contribute to the policy making and implementation. The process of revising the 2000 seed law and the regional seed core groups are good example of the roles of stakeholders in the seed policy making and implementation process. However, the contribution of stakeholders is only considered by the executive as long as it fits in the 'frame' of the decision makers. For instance, when the draft seed law was presented to the CoM for their decision, the content of the draft was only based on the frame of the ministry with respect to those contested issues.

Similarly, regardless of policy on paper, the permission to pilot DSM has to come from the BoA heads. At the same time, after piloting, the final decision to widely use DSM is not expected from the government despite its positive result. Thus, while the contribution of stakeholders to policy making and implementation is required, and is currently practiced in the seed sector, the acceptance of the outcome of the stakeholder process is not as expected. The input of stakeholders is only accepted 
when the contribution is in line with the existing policy direction. Considering the policy input of others only when it matches the policy direction of the decision makers, forces other partners to accept only the frame of the decision maker. This creates a sense of being forced, leading to tension between how the government decides and the role of other stakeholders in the policy making and implementation process. When decisions have a political element, stakeholders for instance will not risk treading on such sensitive issues, but rather stay away from it, affecting their contribution to policy making and implementation. Thus, in the policy making and implementation process the stakeholders are not contributing to the decision of the government as one would expect. As a result, policy implementation is affected because of lack of ownership of the policy option.

\subsubsection{Relaxing of the tensions}

The above discussions showed the existence of two sets of divergent institutions that shape how actors view the challenges in the seed sector and subsequently identify solutions. In case of the first set of divergent institutions, on the one hand, there is a strong belief in the developmental state, and thus centralized seed distribution is preferred as the modus to equitably distribute seed across the country. On the other hand, centralized distribution is viewed by others as an inefficient system, and they propose seed marketing. Currently, these two systems are operational in Ethiopia, but the question remains as to whether to go for efficiency gain by adopting DSM, or equity by continuing seed distribution. Currently, DSM is viewed by some actors as a substitute to the distribution system. Such a view frames DSM as a binary option of 'yes' or 'no'. However, it is important to note that DSM cannot replace the existing distribution system in Ethiopia for the foreseeable future for at least two important reasons. Firstly, subsistence farming dominates Ethiopian agriculture, and there are crops that are not economically attractive both for private and state-owned companies. Secondly, there are locations that demand smaller amounts of seed, which are again not attractive for business, and such areas can be better served with more government intervention. Such a diverse agricultural sector requires a combination of distribution and marketing for some time to come. Given the diverse contexts and demands, a one-size-fits-all solution does not serve the interests of Ethiopian agriculture and the seed sector, but rather a mixed constellation serves the purpose.

In case of the second set of divergent institutions, which are related to decision making, there are again two different options. The first option is to make decisions authoritatively and only consider the contributions of stakeholders when the inputs are in line with the policy direction of the authority. The second option is that the 
government remains the facilitator of the process and promulgates the agreement of stakeholders. While the government believes in its policy direction to achieve a target and prefers to decide authoritatively, stakeholders may also have different, possibly better, policy ideas to achieve the same target. At the same time, there is also no guarantee that both policies will not lead to a worsening of the seed sector. Under such cases, the choice of one system of decision making over another is less likely to benefit the sector.

It is important to note that societal problems are not something that exists objectively, which is equally visible for all actors (Coburn 2006). This study showed how different actors view the same problem differently, implying different constructions of cause and effect relationships. Thus, societal problems are a social construction of cause and effect relationships, and different actors construct the problems differently, leading to different solutions being proposed (Benford and Snow 2000; Entman 2003). Although one solution may be better than another, it may not be shared equally by other actors affecting its implementation. Therefore, using authoritative decision making will not help, not because the policy choice is not appropriate, but because the decision may not be equally shared by others. At the same time, stakeholders' contributions should be goal-oriented and managed properly. It is important to note that actors may have dual objectives to identify a given policy option. Consequently, it makes sense to treat decision making as a process of co-creation, leading to joint and agreed formulation of solutions for the shared problem of the seed sector. This calls for deliberation and reflexivity of the process of policy making and implementation (Fineberg and Stern 1996). Though there is no guarantee that deliberative policy making and reflexivity will result in a different policy option, a policy that is shared by policy actors is better owned and implemented than an imposed policy.

In addition to the tensions, the long tradition of top-down governance coupled with the focus on attaining the developmental targets (amount of seed to be supplied) are the important challenges to sustainable seed sector development in Ethiopia. Current government support for the seed sector focused on the physical production of seed to attain the short-term physical targets overlooking long-term seed sector development. The current increasing demand for seed in Ethiopia requires a seed sector that has been developed on solid ground, and that will able to shoulder the pressure. Current support of the Ethiopian government to the seed sector for attaining the annual seed supply target needs to be entwined with strategic support that also targets the long-term development of the seed sector. The experience of regional seed core groups can be used as an example, as these groups focused on 
solving the systematic challenges of the seed sector rather than simply increasing seed production. One of the outcomes of this process was the introduction and expansion of seed marketing, which many considered as impossible. Regardless of its official status, DSM demonstrated its potential to solve the inefficiency of seed supply. Similarly, the core groups have been able to establish a seed regulatory system, which is intended to ensure seed quality independent of the interest to increase seed production.

Focusing on the long-term development of the seed sector, those institutions that have limited the development of the seed sector may need to be reconsidered. Such transformation requires strategic management of the change process, which helps to unlock the different institutional lock-ins in the sector. This leads to and requires the shaping and reshaping of institutions, enabling the smooth functioning of the seed sector. The experience of the regional seed core groups can be used as a stepping stone to gradually create a stronger seed sector in Ethiopia. The basic thinking in the regional seed core groups is the focus on systematic challenges and co-development of solutions. This co-development also includes the catalytic role of external actors in the design and start of the regional groups. Based on these experiences, a national process of transformation could be envisioned, up-scaling the experiences at regional level. This process could generate a self-governing seed sector that adequately responds to the increasing demand for seed without depending on the day-to-day management of the government. To work on this, actors from both inside and outside the seed sector could bring their expertise and insights to foster change. Actors external to the current seed system operations can facilitate the process of change towards creating a stronger seed sector. 


\section{References}




\section{References}

Aalen, L. 2006. Ethnic federalism and self-determination for nationalities in a semiauthoritarian state: the case of Ethiopia. International Journal on Minority and Group Rights, 13: 243-261.

Abebe, M. 2005.A critical assessment of institutions, roles and leverage in public policy making: Ethiopia. 1974-2004. PhD dissertation. Stollenbush: University of Stollenbush.

Adam, S. and H. Kriesi. 2007. The network approach. In: Sabatier, P.A. (ed.)Theories of the policy process: 189-220. Colorado: West Press.

Admasu, A. and I. Paul. 2010. Assessment on the mechanisms and challenges of small scale agricultural credit from commercial banks in Ethiopia: the case of Ada'a Liben woreda Ethiopia. Journal of Sustainable Development in Africa, 12 (3): 323-304.

Agranoff, R. 2006. Inside collaborative networks: ten lessons for public managers. Public Administration Review,66: 56-65. Available athttp:/ / dx.doi.org/10.1111/j.1540-6210.2006.00666.x, accessed 1 July 2017.

Agricultural Growth Program (AGP). 2009. Assessment of the formal seed system in Ethiopia. Addis Ababa. (unpublished report).

Agricultural Standing Committee (ASC). 2012. Minutes of the meeting of ASC to discuss on draft seed law. (unpublished document; 21 December 20112).

Agricultural Transformation Agency (ATA). 2013. Seed system development strategy 2013-2017: vision, systemic challenges, and prioritized interventions. Working strategy document. Addis Ababa: ATA.

. 2015. Agricultural Transformation Agency: progress report covering 20112105 in the GTP period.

Akindele, S. and O. Olaopa. 2004. A theoretical review of core issues on public policy and its environment. Journal of Human Ecology, 16(3): 173-180.

Alemu, D. 2011. The political economy of Ethiopian cereal seed systems: state control, market liberalisation and decentralisation. IDS Bulletin, 42(4): 69-77. Available at http://dx.doi.org/10.1111/j.1759-5436.2011.00237.x, accessed 1 July 2017.

Alemu, D. and I. Scoones. 2013. Negotiating new relationships: how the Ethiopian state is involving China and Brazil in agriculture and rural development. IDS Bulletin, 44(4): 91-100. Available at http://dx.doi.org/10.1111/17595436.12045, accessed 1 July 2017.

Alemu, D. and R. Tripp. 2010. Seed system potential in Ethiopia: constraints and opportunities for enhancing the seed sector. Globalization and Markets program. International Food Policy Research Institute (IFPRI) working paper. 
Alemu, T. 2015. Policy making practice and challenges of House of Peoples' Representatives (HoPRs). Public Policy and Administration Research, 5(1): 136167.

Amhara Bureau of Agriculture (ABoA). 2013. Document to establish seed and other agricultural input quality regulatory and quarantine authority. Bahir Dar. (unpublished).

Arts, B. and J. Tatenhove. 2004. Policy and power: a conceptual framework between the 'old' and 'new' policy idioms. Policy Sciences, 37(3-4): 339-356.

Astatke M., A. Genetu, D. Ayalew and M. Hassena. 2015. Direct seed marketing in Amhara region: performance and experiences 2011-2014. ISSD Ethiopia research report. (unpublished).

Astatke, M., A. Yimam, D. Tsegaye, M. Kefale, D. Mewa, T. Desalegn and M. Hassena. 2012. Observation on direct seed marketing in Amhara region. Seed demand assessment practices: challenges and options. FRG II Project: Empowering Farmers' Innovation. Series No. 5:27-37. EIAR/ FRG II. Addis Ababa, Ethiopia.

Atilaw, A. and L. Korbu. 2012. Roles of public and private seed enterprises. In: Teklewold, A., A. Fikre, D. Alemu, L. Desalegn and A. Kirub (eds.) The defining moments in Ethiopian seed system. Addis Ababa: Ethiopian Institute of Agricultural Research (EIAR).

Bach, J.-N. 2011. Abyotawi democracy: neither revolutionary nor democratic, a critical review of EPRDF's conception of revolutionary democracy in post1991 Ethiopia. Journal of Eastern African Studies, 5(4): 641-663.

Belay, K. 2002. Constraints to agricultural extension work in Ethiopia: the insiders view. South African Journal of Agricultural Extension, 31(1): 63-79.

Benford, R. D. and D. A. Snow. 2000. Framing processes and social movements: an overview and assessment. Annual Review of Sociology, 26(1): 611-639.

Benson, T., D. J. Spielman and L. Kasa. 2014. Direct seed marketing program in Ethiopia in 2013: an operational evaluation to guide seed-sector reform. IFPRI working paper.

Berhanu, K. and C. Poulton. 2014. The political economy of agricultural extension policy in Ethiopia: economic growth and political control. Development Policy Review, 32(2): 197-213. Available at http://dx.doi.org/10.1111/dpr.12082, accessed 1 July 2017.

Bishaw, Z. 2004. Wheat and barley seed systems in Ethiopia and Syria.. PhD thesis Wageningen University.

Bishaw, Z., Y. Sahlu and B. Simane. 2008. The status of Ethiopian seed industry. In: Thijssen, M. H., Z. Bishaw, A. Beshirand W. de Boef. 2008. Farmers, seeds and 
varieties: supporting informal seed supply in Ethiopia: Wageningen: Wageningen University and Research.

Bonal, X. 2012. Education policy and school segregation of migrant students in Catalonia: the politics of non-decision-making. Journal of Education Policy, 27(3): 401-421.

Burnell, P. 2002. Zambia's 2001 elections: the tyranny of small decisions, 'nondecisions' and 'not decisions'. Third World Quarterly, 23 (6): 1103-1120.

Byerlee, D., A. De Janvry, E. Sadoulet, R. Townsend and I. Klytchnikova. 2007. World development report 2008. Agriculture for development. Washington, DC: World Bank.

Camerer, C. and M. Weber. 1992. Recent developments in modelling preferences: uncertainty and ambiguity. Journal of Risk and Uncertainty, 5(4): 325-370.

Cantarelli, C. C., B. Flyvbjerg, B. van Wee and E. J. E. Molin. 2010. Lock-in and its influence on the project performance of large-scale transportation infrastructure projects: investigating the way in which lock-in can emerge and affect cost overruns. Environment and Planning B: Planning and Design, 37(5): 792-807.

Carboni, J. L. and H. B. Milward. 2012. Governance, privatization, and systemic risk in the disarticulated state. Public Administration Review, 72 (SUPPL.1): 36-44. Available at http://dx.doi.org/10.1111/j.1540-6210.2012.02670.x, accessed 1 July 2017.

Carrozza, C. 2011. Italian water services reform from 1994 to 2008: decisional rounds and local modes of governance. Water Policy, 13(6): 751-768.

Centre for Development Innovation (CDI). 2011. Integrated Seed Sector Development in Ethiopia Phase II (2011 - 2015): programme proposal. Wageningen: Wageningen University and Research. (unpublished).

Ceschin, F. 2013. Critical factors for implementing and diffusing sustainable product-service systems: Insights from innovation studies and companies' experiences. Journal of Cleaner Production, 45: 74-88.

Chanie, P. 2007. Clientelism and Ethiopia's post-1991 decentralisation. The Journal of Modern African Studies, 45(3): 355-384.

Chanyalew, D. 2015. Ethiopian indigenous policy and growth: agricultural, pastoral and rural development. Addis Ababa, Ethiopia.

Chinigò, D. and E. Fantini. 2015. Thermidor in Ethiopia? Agrarian transformations between economic liberalization and the developmental state. Echo Géo, 31.

Coburn, C. E. 2006. Framing the problem of reading instruction: using frame analysis to uncover the micro processes of policy implementation. American Educational Research Journal, 43(3): 343-349. 
Cohen, N. and M. Naor. 2013. Reducing dependence on oil? How policy entrepreneurs utilize the national security agenda to recruit government support: the case of electric transportation in Israel. Energy Policy, 56: 582-590.

Council of Ministers (CoM). 1997. Ethiopian Seed Council of Ministers Regulations. Regulation No. 16/1997. Federal Negarit Gazette of the Democratic Republic of Ethiopia. Year 3, No. 31. Addis Ababa, Ethiopia.

2016. Regulation on seed. Regulation No. 375/2016. Federal Negarit Gazette of the Democratic Republic of Ethiopia. Year 22, No. 42. Addis Ababa, Ethiopia.

Davis, K., B. Swanson, D. Amudavi, D. A. Mekonnen, A. Flohrs, J. Riese, C. Lamb and E. Zerfu. 2010. In-depth assessment of the public agricultural extension system of Ethiopia and recommendations for improvement. Discussion paper (01041). IFPRI.

de Haan, J. and J. Rotmans. 2011. Patterns in transitions: understanding complex chains of change. Technological Forecasting and Social Change, 78(1): 90-102.

de Waal, A. 2013. The theory and practice of Meles Zenawi. African Affairs, 112(446): 148-155. Available at http://dx.doi.org/10.1093/afraf/ads081, accessed 1 July 2017.

Dercon, S. 2006. Economic reform, growth and the poor: evidence from rural Ethiopia. Journal of Development Economics, 81(1), 1-24.

Dessalegne, L., Y. Sahalu and F. Mekbbib. 2012. Administering seed industry. In: Teklewold, A., A. Fikre, D. Alemu, L. Dessalegne and A. Kirub (eds.) The defining moments in Ethiopian seed system. Addis Ababa: EIAR.

Dewulf, A. R. P. J., C. J. A. M. Termeer, W. D. Pot, R. A. Werkman and G. E. Breeman. 2009. The value of theoretical multiplicity for steering transitions towards sustainability. Paper read at the First European Conference on Sustainability Transitions: Dynamics and Governance of Transitions to Sustainability, 4-6 June 2009, Amsterdam.

Diao, X. and A. N. Pratt. 2007. Growth options and poverty reduction in Ethiopia an economy-wide model analysis. Food Policy, 32(2): 205-228.

Dickovick, J. T. and T. Gebre-Egziabher. 2010. Comparative assessment of decentralization in Africa: Ethiopia desk study. Report prepared for the United States Agency for International Development.

Dryzek, J. S. 1994. Discursive democracy: politics, policy, and political science. Cambridge, NY: Cambridge University Press.

Duffield, J. 2007. What Are international institutions? International Studies Review, 9(1): 1-22.

Emerson, K., T. Nabatchi and S. Balogh. 2012. An integrative framework for collaborative governance. Journal of Public Administration Research and Theory 22 (1): 1-29. http://dx.doi.org/10.1093/jopart/mur011. 
Enserink, B., J.F.M. Koppenjian and I.S. Mayer. 2013. A policy sciences view on policy analysis. In: Thissen, W.A.H. and W.E. Walker (eds.) Public policy analysis: new developments: 11-40. Springer.

Entman, R. M. 2003. Cascading activation: contesting the White House's frame after 9/11. Political Communication, 20(4): 415-432.

Ethiopian People's Revolutionary Democratic Front (EPRDF). 2001. Yeitiyophiya hizboch abiyotawi dimokrasiyawi ginbar program. bearateyn dirijitawi gubae yetsedeke. [The Ethiopian People's Revolutionary Democratic Front (EPRDF) Program].

Evans, P. B. 1995. Embedded autonomy: states and industrial transformation. Princeton University Press.

Fantini, E. 2013. Developmental state, economic transformation and social diversification in Ethiopia. ISPI Analysis, 163(7).

FAO 2016. FAO in Ethiopia - El Niño Response Plan 2016. Available at http://www.fao.org/emergencies/resources/documents/resourcesdetail/en/c/380012/, accessed 1 July 2017.

Federal Democratic Republic of Ethiopia (FDRE). 2002. Sustainable Development and Poverty Reduction Program. Addis Ababa. 2005. A plan for accelerated and sustained development to end poverty. Addis Ababa.

. 2015. Growth and transformation plan II (2016 - 2020).

Fineberg, H. V. and P. C. Stern. 1996. Understanding risk: informing decisions in a democratic society. National Academies Press.

Fischer, L. B. and J. Newig. 2016. Importance of actors and agency in sustainability transitions: a systematic exploration of the literature. Sustainability (Switzerland), 8(5).

Fletcher, A. L. 2009. Clearing the air: the contribution of frame analysis to understanding climate policy in the United States. Environmental Politics, 18(5): 800-816.

Fourie, E. 2013. New maps for Africa? Contextualising the 'Chinese model' within Ethiopian and Kenyan paradigms of development. University of Trento.

Fritz, V. and A. R. Menocal. 2007. Developmental states in the new millennium: concepts and challenges for a new aid agenda. Development Policy Review, 25(5): 531-552. Available at http://dx.doi.org/10.1111/j.14677679.2007.00384.x, accessed 1 July 2017.

Garud, R. and J. Gehman. 2012. Metatheoretical perspectives on sustainability journeys: Evolutionary, relational and durational. Research Policy 41 (6): 980995. http:/ /dx.doi.org/http:/ /dx.doi.org/10.1016/j.respol.2011.07.009. 
Gebre Egziabher, T. 1998. The influence of decentralization on some aspects of local and regional development planning in Ethiopia. Eastern Africa Social Science Research Review (EASSRR), 16(1): 33-59.

Gebremedhin, B., D. Hoekstra and A. Tegegne. 2006a. Improving the competitiveness of agricultural input markets in Ethiopia: experiences since 1991. In: IAAE. Proceedings of the $26^{\text {th }}$ Triennial Conference of the International Association of Agricultural Economics (IAAE), August 2006, Gold Coast, Brisbane, Australia. Milwaukee, WI (USA): IAAE.

. 2006b. Commercialization of Ethiopian agriculture: extension service from input supplier to knowledge broker and facilitator. IPMS Working Paper I, Nairobi: International Livestock Research Institute.

Gebresenbet, F. 2014. Securitisation of development in Ethiopia: the discourse and politics of developmentalism. Review of African Political Economy, 41(sup1): S64-S74.

Geels, F. W. 2002. Technological transitions as evolutionary reconfiguration processes: A multi-level perspective and a case-study. Research Policy, 31(8-9): 1257-1274.

2004. From sectoral systems of innovation to socio-technical systems: insights about dynamics and change from sociology and institutional theory. Research Policy, 33(6-7): 897-920.

2005. Processes and patterns in transitions and system innovations: refining the co-evolutionary multi-level perspective. Technological Forecasting and Social Change, 72(6 SPEC. ISS.): 681-696.

. 2011. The multi-level perspective on sustainability transitions: responses to seven criticisms. Environmental Innovation and Societal Transitions, 1(1): 24-40.

. 2012. A socio-technical analysis of low-carbon transitions: introducing the multi-level perspective into transport studies. Journal of Transport Geography 24: 471-482. http://dx.doi.org/10.1016/j.jtrangeo.2012.01.021.

Geels, F. W. and J. Schot. 2007. Typology of socio-technical transition pathways. Research Policy, 36(3): 399-417.

Geels, F. W. and J. Schot. 2010. The dynamics of transitions: a socio-technical perspective. Transitions to sustainable development. New directions in the study of long-term transformative change. In: Grin, J., J. Rotmans and J. Schot (eds.) Transitions to sustainable development: new directions in the study of long term transformative change: 11-104. Routledge.

Gelaw, M. 2012. Seed demand forecasting, supply and distribution system in Oromia. In: Teklewold, A., D. Alemu, S. Kiyoshi and A. Kirub (eds.) Seed demand assessment practices: challenges and options. FRG II Project: 
Empowering Farmers' Innovation. Series No. 5: 19-36. Addis Ababa: EIAR/FRGII.

Getahun, M., Z. Afework, H. Mohammed and M. Hassena. 2014. Direct seed marketing in SNNPR: performance and experience, 2011-2104. ISSD Ethiopia research report. (unpublished).

Ghosh, D. and M. R. Ray. 1997. Risk, ambiguity, and decision choice: some additional evidence. Decision Sciences, 28(1): 81-104.

Gorfu, D., A. Ayalew, F. Mekbib and Y. Sahlu. 2012. Seed health testing in seed systems in Ethiopia. In: Teklewold, A., A. Fikre, D. Alemu, L. Dessalegne and A. Kirub (eds.) The defining moments in Ethiopian seed system: 169-180. Addis Ababa: EIAR.

Green, E. 2011. Decentralization and political opposition in contemporary Africa: evidence from Sudan and Ethiopia. Democratization, 18(5): 1087-1105.

Habermas, J. 1987. The philosophical discourse of modernity. Twelve lectures, MIT. Frankfurt: MIT press.

Hagmann, T. and J. Abbink. 2011. Twenty years of revolutionary democratic Ethiopia, 1991 to 2011. Journal of Eastern African Studies, 5(4): 579-595.

Hailu Seife. 2014. Is the Ethiopian People's Revolutionary Democratic Front rule sustainable in Ethiopia? A critical reflection. Public Policy and Administration Research, 4(11).

Halderman, M. 2005. The political economy of pro-poor livestock policy-making in Ethiopia. Pro-Poor Livestock Policy Initiative (PPLPI)Working Paper, No. 19. Rome: FAO. Available at http:/ /ageconsearch.umn.edu/bitstream/23770/1/wp050019.pdf, accessed 1 July 2017.

Hall, P. A. 1993. Policy paradigms, social learning and the state: the case of economic policymaking in Britain. Comparative politics, 25(3): 275-296.

Hardy, C., T. B. Lawrence and D. Grant. 2005. Discourse and collaboration: the role of conversations and collective identity. The Academy of Management Review,30(1): 58-77.

Hassena, M. and J. van den Broek. 2012. Regional seed partnerships: innovations to evolving and enabling seed policies in Ethiopia. In: Teklewold, A., A. Fikre, D. Alemu, L. Dessalegne and A. Kirub (eds.) The defining moments in Ethiopian seed system: 327-339. Addis Ababa: EIAR.

Hassena, M. and L. Dessalegn. 2011. Assessment of the Ethiopian Seed Sector. Paper presented at the African Seed and Biotechnology Program Workshop, May 2011, Addis Ababa. 
Haxeltine, A., L. Whitmarsh, N. Bergman, J. Rotmans, M. Schilperoord and J. Kohler. 2008. A conceptual framework for transition modelling. International Journal of Innovation and Sustainable Development, 3(1-2): 93-114.

Head, B. W. and J. Alford. 2013. Wicked problems: implications for public policy and management. Administration and Society, 20(10): 1-29.

Hendriks, C. M. and J. Grin. 2007. Contextualizing reflexive governance: the politics of Dutch transitions to sustainability. Journal of Environmental Policy and Planning, 9(3-4): 333-350.

Hermans, L. M. and S. W. Cunningham. 2013. Actor models for policy analysis. In: Thissen, W.A.H. and W.E. Walker (eds.) Public Policy Analysis: New Development: 185-213. Springer.

House of Peoples' Representatives (HoPRs). 1995. The Constitution of the Federal Democratic Republic of Ethiopia. Proclamation No 1/1995. Federal Negarit Gazette of the Democratic Republic of Ethiopia. Year 1, No. 1. Addis Ababa, Ethiopia. . 2000. Seed proclamation. Proclamation No. 206/2000. Federal Negarit Gazette of the Democratic Republic of Ethiopia. Year 6, No. 36. Addis Ababa.

2004. Reorganization of the Executive Organs of the Federal Democratic Republic of Ethiopia / Amendment/Proclamation No. 380/2004.

. 2006. The Regulation of Working Procedures and the Members Code of Conduct of House of Peoples' Representatives. Regulation No.3/2006. Federal Negarit Gazette of the Democratic Republic of Ethiopia. Addis Ababa.

. 2013. A proclamation on seed. Proclamation No. 783/2013. Federal Negarit Gazette of the Democratic Republic of Ethiopia. Year 1, No. 27. Addis Ababa.

Howlett, M. 2007. Analyzing multi-actor, multi-round public policy decisionmaking processes in government: findings from five Canadian cases. Canadian Journal of Political Science, 40(3): 659-684.

Ingram, H., A. L. Schneider and P. Deleon. 2007. Social construction and policy design. In: Sabatier, P.A. (ed.)Theories of the Policy Process: 93-126.Colorado: West Press.

International Development Law Organization (IDLO). 2010. Strengthening Ethiopia's agriculture sector: draft seed legislation. IDLO mission report submitted to The Ethiopian Ministry of Agriculture and Rural Development.

Jørgensen, U. 2012. Mapping and navigating transitions - the multi-level perspective compared with arenas of development. Research Policy, 41(6): 996-1010.

Karpouzoglou, T., A. Dewulf and J. Clark. 2016. Advancing adaptive governance of social-ecological systems through theoretical multiplicity. Environmental Science and Policy, 57: 1-9. 
Kassa, H. 2008. Agricultural extension in Ethiopia: historical evolution, relevant policies and challenges. In: Assefa, T. (ed.) Digest of Ethiopia's national policies, strategies and programs: 153-177. Addis Ababa: Forum for Social Studies.

Kassaw, A. and S. Weldselassie. 2015. Research-policy linkage in Ethiopia: a focus on selected ministries/government agencies and research institutions. Public Policy and Administration Research, 5(9).

Keeley, J. and I. Scoones. 2000. Knowledge, power and politics: the environmental policy-making process in Ethiopia. The Journal of Modern African Studies, 38(1): 89-120.

Kemp, R., D. Loorbach and J. Rotmans. 2007. Transition management as a model for managing processes of co-evolution towards sustainable development. International Journal of Sustainable Development and World Ecology, 14(1): 78-91.

Khan, K. 2013. Book review: North, D.C., J.J. Wallis and B.R. Weingast. 2009. Violence and social orders: a conceptual framework for interpreting recorded human history. Economic Systems, 37(1): 138-140.

Kivimaa, P. and F. Kern. 2016. Creative destruction or mere niche support? Innovation policy mixes for sustainability transitions. Research Policy 45 (1): 205-217. http://dx.doi.org/10.1016/j.respol.2015.09.008.

Kjær, A. M. and J. Joughin. 2012. The reversal of agricultural reform in Uganda: Ownership and values. Policy and Society, 31(4): 319-330.

Klein, P. G. 1998. New institutional economics. Available at SSRN: https:/ / ssrn.com/abstract=115811, accessed 1 July 2017.

Klitkou, A., S. Bolwig, T. Hansen and N. Wessberg. 2015. The role of lock-in mechanisms in transition processes: the case of energy for road transport. Environmental Innovation and Societal Transitions, 16: 22-37.

Lakew, T. and D. Alemu. 2012. Approaches and procedures of seed demand assessment in the formal seed sector. In: Teklewold, A., D. Alemu, S. Kiyoshi and A. Kirub (eds.) Seed demand assessment: practice, challenges, and options. FRG II Project. Empowering Farmers' Innovation. Series No. 5. Addis Ababa: EIAR.

Laws, D.and M. Rein. 2003. Reframing practice. In: Haijer, M.A. and H. Wagenaar (eds.) Deliberative policy analysis: understanding governance in the network society: 172-206. Cambridge, NY: Cambridge University Press.

Lee, R. P. and S. Gloaguen. 2015. Path-dependence, lock-in, and student perceptions of nuclear energy in France: implications from a pilot study. Energy Research and Social Science, 8: 86-99.

Lefort, R. 2012. Free market economy, 'developmental state' and party-state hegemony in Ethiopia: the case of the 'model farmers'. The Journal of Modern African Studies, 50(4): 681-706. 
Lefort, R. 2013. The theory and practice of Meles Zenawi: A response to Alex de Waal. African Affairs, 112(448): 460-470.

Lipsky, M., 1980, Street-Level Bureaucracy: Dilemmas of the Individual in Public Services. New York, NY: Russell Sage Foundation.

May, P. J. and S. C. Winter. 2009. Politicians, managers, and street-level bureaucrats: influences on policy implementation. Journal of Public Administration Research and Theory, 19(3): 453-476.

Mayer, I. S., C.E. van Daalen, and P.W. Bots. 2013.Perspectives on policy analysis: a framework for understanding and design. In: Thissen, W.A.H. and W.E. Walker (eds) Public Policy Analysis: New Developments: 41-64. Springer.

McGuire, S. 2005. Getting genes: rethinking seed system analysis and reform for sorghum in Ethiopia. PhD thesis. Wageningen: Wageningen University.

Mead, L. M. 2013. Teaching public policy: linking policy and politics. Journal of Public Affairs Education: 389-403.

Melese, A. T. and A. H. J. Helmsing. 2010. Endogenisation or enclave formation? The development of the Ethiopian cut flower industry. The Journal of Modern African Studies, 48(1): 35-66. Available at https://repub.eur.nl/pub/18132/JMAS481201035-66.pdf, accessed 1 July 2017.

Mintrom, M. 2011. Contemporary policy analysis. Oxford University Press.

Mkandawire, T. 1998. Shifting commitments and national cohesion in African countries. In: Wohlegemuth, L., S. Gibson, S. Klasen and E. Rothchild (eds.) Common security and civil society in Africa. Uppsala, Nordiska Afrikainstitutet.

Mkandawire, T. 2001. Thinking about developmental states in Africa. Cambridge Journal of Economics, 25(3): 289-314.

MoA/FAO. 2008. Technical report: study on the establishment of an independent crop variety release and registration body in Ethiopia. Ministry of Agriculture of Ethiopia/Food and Agriculture Organization of the United Nations(MoA/FAO). Addis Ababa: EIAR.

Mulé, R. 1999. New institutionalism: distilling some 'hard core' propositions in the works of Williamson and March and Olsen. Politics,19(3): 145-151.

Nefo, K., G. Kebede, B. Urgessa, M. Tola, S. Atnafu, M. Hassena, E. Takele and L. Bogale. 2015. Direct seed marketing in Oromia: performance and experience. ISSD Ethiopia research report. (unpublished).

Nordensvärd, J. and F. Urban. 2015. The stuttering energy transition in Germany: wind energy policy and feed-in tariff lock-in. Energy Policy, 82: 156-165.

North, D. 1990. Institutions, institutional change and economic performance. Cambridge: Cambridge University press.

Ohno, K. 2009. Ethiopia: Political regime and development policies. Tokyo, Japan. 
Ostrom, E. 2007. Institutional rational choice: an assessment of the institutional analysis and development framework. In: Sabatier, P.A. (ed.) Theories of the Policy Process: 21-64. Colorado: West Press.

Ostrom, E., R. Gardner and J. Walker. 1994. Rules, games, and common-pool resources: University of Michigan Press.

Park, V., A. J. Daly and A. W. Guerra. 2013. Strategic framing: how leaders craft the meaning of data use for equity and learning. Educational Policy, 27(4): 645-675.

Peters, G. B. 2005. The problem of Policy problems. Journal of Comparative Policy Analysis: Research and Practice, 7(4): 349-370.

Rashid, S., N. Tefera, N. Minot and G. Ayele. 2013. Can modern input use be promoted without subsidies? An analysis of fertilizer in Ethiopia. Agricultural Economics, 44(6): 595-611.

Rauch, J. E. and P. B. Evans. 2000. Bureaucratic structure and bureaucratic performance in less developed countries. Journal of Public Economics, 75(1): 4971.

Rausser, G. C. and R. E. Goodhue. 2002. Public policy: its many analytical dimensions. Handbook of agricultural economics, 2: 2057-2102.

Resh, W., S. Siddiki and W. R. McConnell. 2014. Does the network centrality of government actors matter? examining the role of government organizations in aquaculture partnerships. Review of Policy Research, 31(6): 584-609.

Rittel, H. J. and M. Webber. 1973. Dilemmas in a general theory of planning. Policy Science, 4(2): 155-169.

Rotmans, J. and D. Loorbach. 2010. Towards a better understanding of transitions and their governance. A systemic and reflexive approach. In: Grin, J., J. Rotmans and J. Schot (eds.) Transitions to sustainable development. New directions in the study of long-term transformative change: 105-198.

Rotmans, J., R. Kemp and M. van Asselt. 2001. More evolution than revolution: transition management in public policy. Foresight, 3(1): 15-31. Available athttp:/ / dx.doi.org/doi:10.1108/14636680110803003, accessed 1 July 2017.

Saasa, O. S. 1985. Public policy-making in developing countries: the utility of contemporary decision-making models. Public Administration and Development (pre-1986), 5(4), 309.

Sabatier, P. 1988. An advocacy coalition framework of policy change and the role of policy-oriented learning therein. Policy Sciences,21(2-3): 129-168.

Sahlu, Y. 2012. The Ethiopian seed quality control system. In: Alemu D., S. Kiyoshi, A. Kirub and K. Assefa (eds.) Ensuring seed quality in Ethiopian seed system: status and challenges. Empowering farmers' innovation. EIAR-FRG II project. Series

No.3.

Available

at 
https://www.jica.go.jp/project/ethiopia/001/materials/ku57pq00000kj6m e-att/seminar_03.pdf, accessed 1 July 2017.

Sahlu, Y., D. Alemu and A. Atlaw. 2012. Management and Delivery Challenges and Opportunities in the Ethiopian Seed System. In: Teklewold, A., A. Fikre, D. Alemu, L. Desalegn and A. Kirub (eds.) The defining moments in Ethiopian seed system. 197-208. Addis Ababa: EIAR.

Scharpf, F. W. 1997. Games real actors play: actor-centered institutionalism in policy research. Boulder, CO: Westview Press.

Schmidt, V. A. 2010. Taking ideas and discourse seriously: explaining change through discursive institutionalism as the fourth 'new institutionalism. European Political Science Review, 2(1): 1-25.

Schneider, A. and H. Ingram. 1993. Social construction of target populations: implications for politics and policy. American Political Science Review, 87(2): 334-347.

Schon, D.A. and M. Rein. 1994. Frame reflection: towards the resolution of intractable policy controversies. New York: Basic Books.

Sheahan, M. and C. B. Barrett. 2017. Ten striking facts about agricultural input use in sub-Saharan Africa. Food Policy, 67: 12-25.

Silverman, D. 2011. Interpreting qualitative data: a guide to the principles of qualitative research. Fourth edition. London: Sage publication.

Simane, B. 2008. Seed policies and regulations and informal seed supply in Ethiopia. In: Thijssen, M.H., Z. Bishaw, A. Beshir and W.S. de Boef (eds.) Farmers, seeds, and varieties: supporting informal seed supply in Ethiopia: 112-115. Wageningen: Wageningen University and Research

Simon, B. 2011. Ye-hulet merchawoch weg: nadan yegeta hagerawi rucha. [A Tale of Two Elections: A National Endeavour to put a Stop to an Avalanche]. Addis Ababa, Ethiopia.

Somorin, O. A. 2014. Governing Congo Basin forests in a changing climate: actors, discourses and institutions for adaptation and mitigation. PhD thesis. Wageningen: Wageningen University and Research.

Spielman, D. J., D. Byerlee, D. Alemu and D. Kelemework. 2010. Policies to promote cereal intensification in Ethiopia: The search for appropriate public and private roles. Food Policy, 35 (3): 185-194.

Spielman, D. J., D. K. Mekonnen and D. Alemu. 2013. Seed, fertilizer, and agricultural extension in Ethiopia. In: Dorosh, P. and S. Rashid (eds.) Food and Agriculture in Ethiopia: Progress and Policy Challenges: 84-122. IFPRI. University of Pennsylvania Press.

Strambach, S. 2010. Path dependency and path plasticity: the co-evolution of institutions and innovation. The German customized business software 
industry. In: Boschma, R.A. and R. Martin, (eds.) Handbook for evolutionary economic geography: 406-431. Edward Elgar, Cheltenham.

Sutton, R. 1999. The policy process: an overview. London: Overseas Development Institute.

Tefera, D. A., J. Bijman and M. A. Slingerland. 2016. Agricultural co-operatives in Ethiopia: evolution, functions and impact. Journal of International Development. doi: $10.1002 /$ jid.3240.

Teisman, G. R. 2000. Models for research into decision-making processes: on phases, streams and decision-making rounds. Public Administration, 78(4): 937-956. doi: 10.1111/1467-9299.00238.

Teklewold, A. and D. Mekonnen. 2012. Varietal development and release for enhancing the seed system in Ethiopia. In: Teklewold, A., A. Fikre, D. Alemu, L. Desalegn and A. Kirub (eds.) The defining moments in Ethiopian seed system:147-168. Addis Ababa: EIAR.

Termeer, C. J. A. M., A. Dewulf, G. Breeman and S. J. Stiller. 2013. Governance capabilities for dealing wisely with wicked problems. Administration and Society, 20(10): 1-31.

Teshome, A. 2006. Agriculture, growth and poverty reduction in Ethiopia: policy processes around the new PRSP (PASDEP). A paper presented on the Future Agricultures Consortium workshop, 20-22 March 2006.

Tewfik, H. 2010. Transition to federalism: the Ethiopian experience. Ottawa: Forum of Federation.

Thijssen, M., M. Hassena, G. Borman and W. de Boef. 2011. 2010 Annual report. Local seed business development and partnership. Wageningen: CDI, Wageningen University and Research. (unpublished).

Van Buuren, A.and L. Gerrits. 2008. Decisions as dynamic equilibriums in erratic policy processes. Public Management Review, 10(3): 381-399.

Van Buuren, A.andE.-H. Klijn. 2006. Trajectories of institutional design in policy networks: European interventions in the Dutch fishery network as an example. International Review of Administrative Sciences, 72(3): 395-415.

van der Zee, F. A. 1997. Political economy models and agricultural policy formation: empirical applicability and relevance for the CAP. Proefschrift Wageningen, Van der Zee, [S.1.].

Vaughan, S. 2011. Revolutionary democratic state building: party, state and people in the EPRDF's Ethiopia. Journal of Eastern African Studies, 5(4): 619-640.

Vaughan, S. and I. Rafanell. 2012. Interaction, consensus and unpredictability in development policy 'transfer' and practice. Critical Policy Studies, 6(1): 66-84.

Veen, Erwin van. 2015. Perpetuating power: Ethiopia's political settlement and the organization of security. Conflict Research Unit (CRU) report, Netherlands 
Institute of International Relations. Available at https:/ / www.clingendael.nl/publication/perpetuating-power-politics-andsecurity-ethiopia, accessed 1 July 2017.

Vink, M. 2015. Navigating frames: a study of the interplay between meaning and power in policy deliberations over adaptation to climate change. PhD thesis. Wageningen: Wageningen University and Research.

Walt, G. 1994. Health policy: an introduction to process and power. Johannesburg: Witwatersrand University Press.

Weick, K. E. 1995. Sensemaking in organizations. Thousand Oaks, CA: Sage.

Werbeloff, L., R. R. Brown and D. Loorbach. 2016. Pathways of system transformation: strategic agency to support regime change. Environmental Science and Policy, 66: 119-128.

White, D. D. 2013. Framing water sustainability in an environmental decision support system. Society and Natural Resources, 26(11): 1365-1373.

Wolde, M. A. 2005. A critical assessment of institutions, roles and leverage in public policy making: Ethiopia, 1974-2004. PhD thesis. University of Stellenbosch, Stellenbosch.

World Bank. 2014. The World Bank in Ethiopia: overview. Available atwww.worldbank.org/en/country/ethiopia/overview, accessed 1 July 2017.

World Bank. 2016. Ethiopia's great run: the growth acceleration and how to pace it. Available

http:/ / documents.worldbank.org/curated/en/693561467988949839/pdf/9 9399-REVISED-PUBLIC-thiopia-Economic-Update-2-11-16-web.pdf, accessed 1 July 2017.

Young, J. 1998. Regionalism and democracy in Ethiopia. Third World Quarterly, 19 (2): 191-204.

Young, J. 2005. Research, policy and practice: why developing countries are different. Journal of International Development, 17(6): 727-734.

Zimmermann-Steinhart P. and Y. Bekele. 2012. The implications of federalism and decentralization on socio-economic conditions in Ethiopia. Potchefstroom Electronic Law Journal, 15(2): 90-117. 

Appendixes 
Appendix-A. Date and place of interview of anonymous informants

\begin{tabular}{|c|c|c|}
\hline Informant number & Date interviewed & Place interviewed \\
\hline Informant 1 & $14-5-2013$ & Wageningen \\
\hline Informant 2 & $17-5-2013$ & Wageningen, skype \\
\hline Informant 3 & $25-5-2013$ & The Hague \\
\hline Informant 4 & $\begin{array}{l}\text { 12-6-2013, 29-10-2013, } 2- \\
7-2014\end{array}$ & Addis Ababa \\
\hline Informant 5 & $\begin{array}{l}\text { 13-6-2013, 28-6-2013, } \\
11,7-2014\end{array}$ & Addis Ababa \\
\hline Informant 6 & $24-6-2013$ & Addis Ababa \\
\hline Informant 7 & 25-6-2013, 4-8-2013 & Addis Ababa \\
\hline Informant 8 & $2-7-2013$ & Hawassa \\
\hline Informant 9 & $20-7-2013$ & Addis Ababa \\
\hline Informant 10 & $\begin{array}{l}24-7-2013,12-12-2013, \\
19-6-2015\end{array}$ & Addis Ababa \\
\hline Informant 11 & $27-7-2013$ & Addis Ababa \\
\hline Informant 12 & $30-7-2013,14-7-2015$ & Addis Ababa \\
\hline Informant 13 & 2-8-2013 & Addis Ababa \\
\hline Informant 14 & $\begin{array}{l}2-8-2013,4-8-2013,18-8- \\
2016\end{array}$ & Addis Ababa \\
\hline Informant 15 & $25-10-2013,10-7-2015$ & Addis Ababa \\
\hline Informant 16 & $25-10-2013$ & Addis Ababa \\
\hline Informant 17 & $12-12-2013$ & Addis Ababa \\
\hline Informant 18 & $21-12-2013,15-6-2015$ & Hawassa \\
\hline Informant 19 & $25-12-2013,26-6-2015$ & Bahir Dar \\
\hline Informant 20 & $3-1-2014$ & Addis Ababa \\
\hline Informant 21 & $6-1-2014$ & Addis Ababa \\
\hline Informant 22 & $6-1-2014$ & Addis Ababa \\
\hline Informant 23 & 8-1-2014 & Addis Ababa \\
\hline Informant 24 & $8-1-2014$ & Addis Ababa \\
\hline Informant 25 & $9-1-2014$ & Hawassa \\
\hline Informant 26 & $9-1-2013$ & Asella \\
\hline Informant 27 & $10-1-2014$ & Hawassa \\
\hline Informant 28 & $10-1-2014$ & Hawassa \\
\hline Informant 29 & $15-1-2014,17-6-2015$ & Addis Ababa \\
\hline Informant 30 & $23-1-2014$ & Bahir Dar \\
\hline Informant 31 & $10-5-2014$ & Addis Ababa \\
\hline Informant 32 & $3-7-2014$ & Addis Ababa \\
\hline
\end{tabular}




\begin{tabular}{|c|c|c|}
\hline Informant number & Date interviewed & Place interviewed \\
\hline Informant 33 & 7-7-2014 & Addis Ababa \\
\hline Informant 34 & $18-7-2014$ & Addis Ababa \\
\hline Informant 35 & $18-8-2014$ & Addis Ababa \\
\hline Informant 36 & 28-8-2014 & Addis Ababa \\
\hline Informant 37 & $30-9-2014$ & Addis Ababa \\
\hline Informant 38 & $30-4-2015$ & Addis Ababa \\
\hline Informant 39 & $15-5-2015$ & Addis Ababa \\
\hline Informant 40 & $6-5-2015$ & Addis Ababa \\
\hline Informant 41 & $4-6-2015$ & Addis Ababa \\
\hline Informant 42 & $5-6-2015$ & Bahir Dar \\
\hline Informant 43 & $5-6-2015$ & Addis Ababa \\
\hline Informant 44 & $5-6-2015$ & Addis Ababa \\
\hline Informant 45 & $6-6-2015$ & Addis Ababa \\
\hline Informant 46 & $6-6-2015$ & Addis Ababa \\
\hline Informant 47 & $7-6-2015$ & Addis Ababa \\
\hline Informant 48 & $7-6-2015$ & Addis Ababa \\
\hline Informant 49 & $14-6-2015$ & Hawassa \\
\hline Informant 50 & 14-6-2015 & Hawassa \\
\hline Informant 51 & $14-6-2015$ & Hawassa \\
\hline Informant 52 & $14-6-2015$ & Hawassa \\
\hline Informant 53 & $15-6-2015$ & Hawassa \\
\hline Informant 54 & $15-6-2015$ & Hawassa \\
\hline Informant 55 & $5-6-2015$ & Hawassa \\
\hline Informant 56 & $13-7-2015$ & Addis Ababa \\
\hline Informant 57 & $16-6-2015,6-3-2016$ & Hawassa \\
\hline Informant 58 & $16-6-2015$ & Hawassa \\
\hline Informant 59 & $16-6-2015$ & Hawassa \\
\hline Informant 60 & $16-6-2015$ & Hawassa \\
\hline Informant 61 & $13-7-2015$ & Addis Ababa \\
\hline Informant 62 & 18-6-2015 & Addis Ababa \\
\hline Informant 63 & $18-6-2015$ & Addis Ababa \\
\hline Informant 64 & $19-6-2015$ & Addis Ababa \\
\hline Informant 65 & $16-7-2015$ & Addis Ababa \\
\hline Informant 66 & 24-6-2015 & Bahir Dar \\
\hline Informant 67 & $24-6-2015$ & Bahir Dar \\
\hline Informant 68 & 24-6-2015 & Bahir Dar \\
\hline
\end{tabular}


Appendix-A. Continued

\begin{tabular}{lll}
\hline Informant number & Date interviewed & Place interviewed \\
\hline Informant 69 & $25-6-2015$ & Bahir Dar \\
Informant 70 & $25-6-2015$ & Bahir Dar \\
Informant 71 & $25-6-2015$ & Bahir Dar \\
Informant 72 & $25-6-2015$ & Bahir Dar \\
Informant 73 & $25-6-2015$ & Bahir Dar \\
Informant 74 & $25-6-2015$ & Bahir Dar \\
Informant 75 & $26-6-2015$ & Bahir Dar \\
Informant 76 & $26-6-2015$ & Bahir Dar \\
Informant 77 & $6-3-2016$ & Hawassa \\
Informant 78 & $26-6-2015$ & Bahir Dar \\
Informant 79 & $27-6-2015$ & Bahir Dar \\
Informant 80 & $10-7-2015$ & Addis Ababa
\end{tabular}


Summary 
Ethiopia is an agrarian country where agriculture dominates the economy, and thus agriculture is considered as an engine of growth by the government. Seed as one of the agricultural technologies, in fact, a carrier of many technologies, is critical to increasing production, but the use of quality seed from formal sources in Ethiopia is very limited. The current Ethiopian government has focused on agricultural development and has developed different policies both for agriculture in general and for the seed sector in particular. Following the developmental state approach, the government intensified its involvement in the seed sector to enhance agricultural development. Despite the policies and efforts of the government, a shortage of seed, a mismatch between demand and supply, the carryover of seed despite not satisfying the demand of farmers, and poor seed quality have been persistent challenges to the Ethiopian seed sector. Many studies have identified technical gaps that limit the development of the seed sector, and some of the studies have also discussed the extent to which policy responds to existing problems, and the extent to which what is in the policy documents is implemented. However, the causes of these 'gaps' are seldom discussed. The lack of such knowledge limits the understanding of the challenges, making it difficult to properly support the seed sector. For these reasons, this research has gone beyond the mere identification of 'gaps', aiming to analyse how actors and institutions influence seed policy making and implementation in Ethiopia.

The goal of this research is twofold: to narrow the knowledge gap about policy making and implementation in the Ethiopian seed sector, and to contribute to the debate concerning how to make the seed sector function better. The central research question is: how did actors and institutions influence the formulation and implementation of seed policies in Ethiopia from 2008 to 2016? The empirical research to answer this overall research question addresses two processes: policy making and policy implementation. These include the process of revising the 2000 Ethiopian seed law and the process of implementing direct seed marketing. By analysing these two processes, the thesis unravels how actors and associated institutions have influenced seed policy making and implementation in Ethiopia. The major sources of data were interviews of actors in the seed sector, and desk research of different reports. Guided by theoretical concepts, the research used qualitative methods to generate and analyse data.

Given the complexity of societal phenomenon, several analytical lenses have been used to examine the data in this research. In order to explain how actors negotiate the content of a policy document, including defining the problem and solution, the concept of discourse analysis is used, focusing on frame, the rounds model, and the 
policy arena. Similarly, to explain the process of implementing the existing policy and the outcome, the concepts of multi-level perspective on transition, transition management, non-decision making, and institutional lock-in are used. While using these analytical lenses to explain seed policy making and implementation, the concept of institutions has remained a central concept.

Chapter 2 analyses the negotiation process, looking into the topics of seed sector governance and variety registration. The analysis reveals that different policy arenas provide opportunities for different actors to place their preferred policy options on the table, and to get them incorporated into the draft working document. While this is a positive step towards a deliberative policy making, the final decision is made by the executive branch of the government. Such a process can be explained by two informal institutions. These are the loose connection between the drafting arenas and the decision-making arenas, and the blurred separation of power between the executive and the legislature. At the Council of Ministers (CoM), where the critical decisions are made, the ministry presents its perspective, particularly on issues where disagreement exists between the ministry and other actors. The council uses the content of the draft and the justification of the ministry for endorsing the draft policy document. Moreover, the parliament can change the content of the draft policy document only if the ministry agrees with the change, regardless of the arguments and justifications provided by other stakeholders. Thus, the inputs of stakeholders are considered as long as the ministry agrees with the suggestions, and the policy decision remains in the hands of the ministry.

Chapter 3 presents the different frames used by different actors to describe the problem of seed quality. While government officials attribute the problem of seed quality to the lack of alignment between the seed sector governance and the regional government structure, experts and bureaucrats attribute the problem to the lack of coordination at national level. As a result, they respectively suggest the decentralization and centralization of seed sector governance. These frames are embedded in the overall interest and strategy of the actors promoting the frames. The centralization frame reflects the interest of experts and bureaucrats to have a say with regards to the seed sector. They have lost this power because of the federal structure that was established formally in 1995. On the contrary, the decentralization frame is embedded in the government's aim to implement the constitution that established the federal structure in 1995. Despite the fact that the process of revising the seed law took about four years, these actors could not agree on either of the options or find an alternative. This shows a lack of deliberation and reflexivity during the process of revising the seed law, reflecting the fact that seed policy 
discussion has been part of a larger debate about (de)centralization in Ethiopia since 1991. Thus, in addition to the issue of seed quality, the frames of centralization and decentralization are shaped by the old (unitary) and the new (federal) institutions of the Ethiopian government system.

Chapter 4 focuses on the process of introducing and expanding direct seed marketing (DSM) in Ethiopia. Despite the fact that seed marketing is included in the policies on paper, the seed of major food crops is distributed through government channels resulting in inefficiency of seed distribution. The regional seed core groups introduced DSM in 2011, and by 2016 about one-third of the hybrid maize seed, the main seed marketed in Ethiopia, in Amhara, Oromia and the Southern Nations, Nationalities and Peoples' region (SNNPR), was sold through DSM. The presence of actors outside the seed distribution system was instrumental for introducing the concept of DSM. To start the piloting of this existing policy, the core group needed to get approval from the heads of the bureaus of agriculture (BoAs). However, such approval was not required for other new ideas, like establishing an independent regulatory body, showing how the informal institutions guide what has to be approved by bureau heads, regardless of the formal policy. In addition to the demonstrated potential of DSM to overcome the problem of seed distribution inefficiency, strategic management of the stakeholders' process was critical in expanding the area under the pilot. Many actors, including the executives, supported the expansion of DSM to many areas.

Despite the expansion of DSM, its demonstrated potential to overcome the problem of seed supply inefficiency, the support it received from the government officials, and the general policy of market-based approach, the government has not endorsed the use of DSM beyond the pilot. Chapter 5 points out that the government excluded the issue of seed marketing from the seed regulation enacted in 2016, showing that the government has no intention to make seed marketing one of the seed delivery channels in the near future. The major reasons for this are: bureaucrats do not want to contribute to the decision making of DSM because they assume that the government has a strong political interest to remain in seed distribution; bureaucrats need the seed distribution system to achieve the targets set by the government; there is a symbiotic relationship between actors, the extension service as well as seed producers, and the seed distribution system, and so actors want to maintain the distribution system Such institutionalized thinking and practices have created an institutional lock-in that prevents bureaucrats from presenting the recommendation to government officials, thereby leading to non-decision about the future of DSM. 
Chapter 6 summarizes the action of actors in affecting policy making and implementation as influenced by two conflicting sets of institutions. The first set relates to market-based thinking versus centralized planning as leading principles for economic development. Both are used as a discourse for promoting economic development and its operationalization, which are shaping how actors view and overcome the problems of the seed sector. This also explains why policies on paper are not implemented and why new initiatives are not formally endorsed. The tension between these divergent institutions has increased because of the dual use of seed by the government: the government has used the seed to both promote economic development and maintain strong political ties with farmers. The second set of conflicting institutions relates to authoritarian versus participatory decision making. On the one hand, is the government practice of authoritative decision-making, where only the input of stakeholders is considered when it fits in with the existing policy direction of the executives. On the other hand, it is common practice to organize stakeholders to contribute to policy making and implementation. The practice of considering the policy input of others only when it fits in with the policy direction of the decision-makers, creates a sense of being forced to accept, increasing the tension between how the government decides and the role of stakeholders.

Given the tension between the conflicting institutions, and circumstances in Ethiopia, this research suggested that choosing one approach over the other will not guarantee the development of the seed sector. There is no guarantee that the outcome of a deliberative policy making process will be a different policy option than the one opted for by one of the actors. However, the co-development of a solution for the shared seed sector problem will guarantee better ownership and thus better implementation than an imposed policy. It is also important to note that deliberative policy making and implementation is not an easy task given the current stakeholders' landscape and the culture of authoritative decision making. Thus, the change towards deliberative policy making and implementation is not something that emerges overnight: it is a process that matures over time. This calls for the strategic management of a process of change that leads to the transformation of the seed sector into a self-reliant and resilient sector. By identifying the underlying institutions behind the challenges of the seed sector and suggesting options for improvement, this thesis contributes to the debate on how to make the seed sector function better. At a higher level, it also contributes to the debate on policy making and implementation processes in Ethiopia 

Mohammed Hassena Beko

Wageningen School of Social Sciences (WASS)

Completed Training and Supervision Plan

Wageningen School of Social Sciences

\begin{tabular}{llll}
\hline Name of the learning activity & Department/Institute & Year & ECTS $^{*}$ \\
\hline
\end{tabular}

\section{A) Project related competences}

Governance, Trust and Policy Change, WUR

2013

6

PAP 30806

Intellectual Property Rights, LAW

WUR

2013

6

32306

Writing Proposal

WUR

2013

6

B) General research related competences

WASS introduction course

'Lessons from the Ethiopian seed policy making process (2008-2013)'

Seed marketing and uncertain future in Ethiopia.

Research Methodology: From Topic to

Proposal

Qualitative Data Analysis: Procedures and Strategies, YRM 60806

Interpretive methods and methodology

Scientific writing

Conceptual foundation of Public

Governance

C) Career related competences/personal development

Information literacy including EndNote WGS

2013

2013

2014

2016

1.8

WASS introduction

2013

1

ISSD, Addis Ababa,

2014

1

Ethiopia

CDI, Wageningen

2016

1

University

WASS

2013

4

Total

*One credit according to ECTS is on average equivalent to 28 hours of study load 


\section{Funding organization}

The research described in this thesis was implemented as part of the Integrated Seed Sector Development Ethiopia programme. The programme has been funded by the Directorate General for International Cooperation of The Netherlands, through the Embassy of the Kingdom of the Netherlands in Addis Ababa, Ethiopia.

Publisher: Digiforce/Proefschriftmaken.nl, Vianen 